\title{
Exposure to inorganic dust and occupational diseases : epidemiological methods and investigations
}

Citation for published version (APA):

Meijers, J. M. M. (1991). Exposure to inorganic dust and occupational diseases : epidemiological methods and investigations. [Doctoral Thesis, Maastricht University]. Maastricht University. https://doi.org/10.26481/dis.19910503jm

Document status and date:

Published: 01/01/1991

DOI:

10.26481/dis.19910503jm

Document Version:

Publisher's PDF, also known as Version of record

\section{Please check the document version of this publication:}

- A submitted manuscript is the version of the article upon submission and before peer-review. There can be important differences between the submitted version and the official published version of record.

People interested in the research are advised to contact the author for the final version of the publication, or visit the DOI to the publisher's website.

- The final author version and the galley proof are versions of the publication after peer review.

- The final published version features the final layout of the paper including the volume, issue and page numbers.

Link to publication

\footnotetext{
General rights rights.

- You may freely distribute the URL identifying the publication in the public portal. please follow below link for the End User Agreement:

www.umlib.nl/taverne-license

Take down policy

If you believe that this document breaches copyright please contact us at:

repository@maastrichtuniversity.nl

providing details and we will investigate your claim.
}

Copyright and moral rights for the publications made accessible in the public portal are retained by the authors and/or other copyright owners and it is a condition of accessing publications that users recognise and abide by the legal requirements associated with these

- Users may download and print one copy of any publication from the public portal for the purpose of private study or research.

- You may not further distribute the material or use it for any profit-making activity or commercial gain

If the publication is distributed under the terms of Article $25 \mathrm{fa}$ of the Dutch Copyright Act, indicated by the "Taverne" license above, 


\section{Exposure to inorganic dust and occupational diseases}

Epidemiological methods and investigations 



\section{Exposure to inorganic dust and occupational diseases}

Epidemiological methods and investigations

\section{PROEFSCHRIFT}

Ter verkrijging van de graad van doctor aan de Rijksuniversiteit Limburg te Maastricht, op gezag van Rector Magnificus Prof. Mr. M.J. Cohen, volgens het besluit van het College van Dekanen, in het openbaar te verdedigen op vrijdag, 3 mei 1991 om 14.00 uur

$$
\text { door }
$$

Johannes Mathijs Marie Meijers

geboren te Stein op 26 juni 1957 
Promotores:

Prof. Dr. F. Sturmans

Prof. Dr. Tj. de Boorder

Co-promotor: $\quad$ Dr. G.M.H.Swaen

Beoordelingscommissie: Prof. Dr. H.A.J. Struyker Boudier (voorzitter)

Prof. Dr. F. Bosman

Prof. Dr. J.A. Knottnerus

Prof. Dr. J. Kolk (Kath. Universiteit Nijmegen)

Dr. E. Wouters

CIP GEGEVENS KONINKLIJKE BIBLIOTHEEK DEN HAAG

Meijers, Johannes Mathijs Marie

Exposure to inorganic dust and occupational diseases :

epidemiological methods and investigations / Johannes

Mathijs Marie Meijers, - Maasincht : Datawyse, - Ill.

Thesis Matstricht. - With ref. With summary in Dutch.

ISBN $90-5291-048-0$

NUGI 743

Subject headings; inorganic dust and fibres / occupational disenses / lung disorders.

Produktie en layout: Datawyse Maastricht, Ruud Leliveld Druk: Krips Repro Meppel

Tekstverwerking: Vakgroep AMT, Marliese van Wissen 
"Niettegenstaande dit alles, mijne Heren, bleven ook tegenslagen mij niet bespaard".

(Vrij vertaald uit"Baron Münchhausen's narrative of his marvellous travels and campaigns in Russia". Rudolf Erich Raspe, 1785)

Voor mijn ouders Aan Ronneke 
Promotores: $\quad$ Prof. Dr. F. Sturmans

Prof. Dr. Tj. de Boorder

Co-promotor: Dr. G.M.H. Swaen

Beoordelingscommissie: Prof. Dr. H.A.J. Struyker Boudier (voorzitter)

Prof. Dr. F. Bosman

Prof. Dr. JaA. Knottnerus

Prof. Dr. J. Kolk (Kath. Universiteit Nijmegen)

Dr. E. Wouters

CIP GEGEVENS KONINKLIJKE BIBLIOTHEEK DEN HAAG

Meijers, Johannes Mathijs Marie

Exposure to inorganic dust and occupational diseases :

ephidemiological methods and investigations / Johamnes

Mathijs Marie Meijers. - Matricht: Datawyse. - Illl.

Thesis Manstriclst. - With ref. - With summary in Dutch.

ISBN 90-5291-048-0

NUGI 743

Subject headings: inorganic dust and fibres / occupational diseases / lung disorders.

Produktie en layout: Datawyse Maastricht, Ruud Leliveld Druk: Krips Repro Meppel

Tekstverwerking: Vakgroep AMT, Marliese van Wissen 
"Niettegenstaande dit alles, mijne Heren, bleven ook tegenslagen mij niet bespaard".

(Vrij vertaald uit"Baron Münchhausen's narrative of his marvellous travels and campaigns in Russia". Rudolf Erich Raspe, 1785)

Voor mijn ouders Aan Ronneke 


\section{Contents}

General introduction

Methodological aspects concerning the use of epidemiological techniques in occupational health studies

CHAPTER 1

Occupational epidemiological studies in the evaluation of carcinogenic properties of substances and their relation to animal experimental data

CHAPTER 2

Influence of design characteristics on the outcome of retrospective cohort studies

CHAPTER 3

Occupational cohort studies: The influence of design characteristics on the healthy worker effect

Epidemiological investigations concerning inorganic dust exposure and occupational diseases

CHAPTER 4

Lung cancer among Dutch coal miners:

A case-control study

CHAPTER 5

Long term mortality in miners with Coal Workers*

Pneumoconiosis in the Netherlands: A pilot study 
CHAPTER 6

Silica exposure and lung cancer in ceramic workers:

A case-control study

CHAPTER 7

Cancer morbidity in coal miners in the Netherlands:

A feasibility study

CHAPTER 8

Epidemiological studies of inorganic dust related lung diseases in the Netherlands

CHAPTER 9

Trends and geographical patterns of pleural mesotheliomas in the Netherlands, 1970-1987

CHAPTER 10

Chronical exposure to man-made vitreous fibres and respiratory diseases

Final discussion

Summary

Samenvatting

Dankwoord

Curriculum vitae 


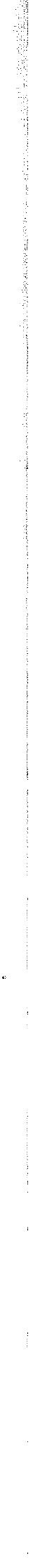




\section{Jeneral introduction}

Occupational medicine is an applied science in which many related disciplines are involved. The most important goal in occupational medicine is to improve the health of working populations by preventing occupational risks that cause injuries and diseases. Risk prevention can only be undertaken effectively if detailed knowledge exists about the causal relation between harmful exposures in the occupational environment and their health effects. Epidemiologic studies are particularly suited to identify existing health risks related to occupational exposures. Workers are exposed to many potential risks. Their health can be affected by noise, radiation, heat and cold stress, fysical overload, microbiological factors and toxic substances. This thesis deals primarily with risk assessment and effect studies of chemicals which regularly occur in occupational settings.

Many research techniques have been applied to study the adverse effects of chemical agents in living organisms. In toxicology numerous tests in animals and cell systems are used for this purpose. When properly conducted and evaluated, these toxicity tests to a certain extent can predict health risks in humans. However, the measurement of health effects from chemical exposure directly in humans either through epidemiological or controlled clinical studies provides the best evidence of toxicity in humans.

Because of medical ethical reasons it is not feasible to establish experimental clinical studies in humans if a substance is thought to have a carcinogenic potential. Thus the only direct method to study the possible carcinogenic effects of substances in exposed workers is through occupational epidemiology.

Occupational epidemiology is a science of growing importance and its outcomes are increasingly used by regulatory agencies. This makes an evaluation of its actual possibilities warranted. The first three chapters in this thesis focuss on the contribution of occupational epidemiology in risk assessment, and methods in occupational epidemiology which can influence its results. For obvious reasons it is important to know whether or not widely available chemical substances impose a carcinogenic risk on humans and what is the dose-effect relation. Short term in vitro tests alone cannot answer this question, and the contribution of data based on animal-experiments and epidemiological inves- 
tigations in exposed populations is indispensable. These studies can serve as complementary tools in cancer risk assessment. If epidemiological outcomes are not available, which is often the case, experimental results in animals are extrapolated to humans and used as a base for risk assessment. It is not clear how animal experimental and human data are related to each other in cancer risk assessment and what is their specific contribution in the process. The first chapter is dedicated to this question. The role of epidemiology in cancer risk assessment is evaluated in this chapter.

Retrospective cohort studies, in which groups of persons who have experienced an occupational exposure are followed-up to determine the occurrence of disease and mortality, are particularly carried out to investigate long term health effects of occupational exposures to chemical substances. In several studies reported in this thesis the retrospective cohort method is used. Partly because of its empirical, non-experimental character this study type has been subject to elaborate criticism. It is well known that design characteristics such as the selection of reference groups, the exposure definition and the period of follow-up influence the outcome of a study. Furthermore, a deficit in mortality, known as the healthy worker effect (HWE), usually occurs in retrospective cohort studies. The interpretation of these studies can be complicated because of the confounding influences by design characteristics and the healthy worker effect. In the second and third chapter meta-analyses of occupational cohort studies are reported in order to study the complex relation between the outcomes of these studies and the initial design.

In the second part of this thesis several studies are reported using occupational epidemiological techniques. The various chapters show how occupational risk assessment with epidemiological techniques, such as retrospective cohort studies, case-control studies and proportionate morbidity studies can be performed. They are focussed on the relation between exposure to inorganic dust and fibres and occupational diseases.

Occupational exposure to inorganic dust occurs in a broad range of industrial sectors. In many countries minerals, metal ores and fossil fuels are mined and those who work in these environments are exposed to dust arising from fragmented or comminuted rocks, minerals and ores. Minerals are used as raw materials for the production of a variety of consumer products such as ceramic ware, bricks, tiles, glass, cement and metal products.

In the sixteenth century Agricola already noticed that dust entering the lungs caused disease associated with dyspnoea in the Bohemian Joachimstal, the greatest mining area in Central Europe at that moment. The first systematic account of the pathological manifestations of dust related lung diseases was 
made in Holland by Ysbrand van Diemerbroeck (1609-1674), professor of medicine in Utrecht, in his Anatomia Corporis Humani. He described how several stone cutters died of asthma and he found at necropsy that to cut their lungs was like cutting a mass of sand. Two centuries later, in 1867, the German pathologist Zenker introduced the word 'pneumoconiosis", derived from the Greek words for 'lung' and 'dust', which covers the group of lung diseases due to dust inhalation in several occupations.

One of the typical pneumoconioses is silicosis, a fibrotic disease of the lungs produced by the inhalation and deposition of particulate matter containing free or uncombined silica, silicon dioxide, $\mathrm{SiO}_{2}$. The onset of silicosis is marked by dyspnoea on exertion, cough, and sometimes scanty sputum. In the second stage dyspnoea and productive cough become established, there is diminished expansion of the chest and always some degree of impairment of working capacity. In the third stage dyspnoea leads to total incapacity. Right heart hypertrophy and then failure may supervene. The clinical signs of coal workers' pneumoconiosis resemble those of silicosis, but the origin lies in the combined inhalation of a complex, mixed dust containing coal and a relatively small proportion of free silica.

Pneumoconioses caused by inhalation of inorganic dust have been described in the sandstone, granite and pottery industry, in gold, tin, haematite iron-ore, coal and graphite mining, the slate quarrying and dressing industry, grinding of metals, iron and steel foundries and sand blasting. They are a potential threat across a broad range of industrial sectors and constitute an important class of health effects arising from workplace exposures. However more recently other possible health effects generated by inorganic dust have been brought to notice. Based on experimental research in animals and several empirical studies in humans the assumption has been postulated that crystalline silica is a carcinogenic compound able to induce occupational lung cancer. Another puzzling issue in occupational health is the possible carcinogenicity of coal mine dust. Several researchers found an increased risk for stomach cancer or lung cancer in workers exposed to coal mine dust. Up to the present a definite conclusion about the carcinogenic properties of these dusts cannot be drawn. Nevertheless this question must be answered in order to establish rationally substantiated and realistic exposure limits for the occupational environment.

It is generally accepted that inorganic silicates from the asbestos group increase the cancer risk for workers exposed to these fibres. But it is highly controversial whether synthetic inorganic fibres partly used for asbestos replacement, such as man made mineral fibres, can induce cancer in humans. 
In the chapters 4 to 10 studies dealing with morbidity and mortality patterns in Dutch workers exposed to various types of airborne inorganic dust and fibres are reported. More specific, epidemiological studies have been carried out to investigate the cancer risk in fine ceramic workers and coal miners. Especially in the southern part of the Netherlands (South-Limburg), with 11 coal mines and two large fine ceramic factories in operation in the middle of this century, many workers experienced considerable dust exposures originally resulting in a high incidence of pneumoconiosis. Using several epidemiological techniques the occurrence of cancer in these populations was studied. Furthermore some consequences of the occupational exposure to asbestos in the Netherlands are reported, and a review of the health effects caused by inhalation of man made mineral fibres is presented. 


\section{Methodological aspects CONCERNING THE USE OF EPIDEMIOLOGICAL TECHNIQUES IN OCCUPATIONAL HEALTH STUDIES}





\section{CHAPTER 1}

\section{Occupational epidemiological studies in the evaluation of carcinogenic properties of substances and their relation to animal experimental data}

$J_{M M}$ Meijers $^{1}$, GH Schreiber ${ }^{1}$, GMH Swaen $^{1}, C$ van Vliet ${ }^{1}$, F Sturmans $^{2}$

${ }^{1}$ Department of Occupational and Environmental Health and Toxicology,

${ }^{2}$ Department of Epidemiology, University of Limburg, Maastricht, the Netherlands.

Submitted for publication

\section{ABSTRACT}

A review is presented of the epidemiological and animal experimental evidence in the evaluation of carcinogenicity of substances to humans. For the majority of animal carcinogens, as identified by the International Agency of Research on Cancer (IARC), no human data are available. The human and animal evaluations show a poor correlation: only 21 out of 203 agents with sufficient evidence of carcinogenicity in animals are classified as a human carcinogen. The causes of this discrepancy are discussed. Epidemiological studies should meet several basic design requirements, for example quantitative information about level and duration of exposure, in order to base dose-response calculations upon them. After analysis of occupational epidemiological studies concerning 14 human carcinogenic substances, human data for 6 substances were suited to carry out a quantitative risk assessment. Without exception these 6 studies concerned occupational exposures by inhalation, whereas in animal experimental investigations with these substances many different exposure routes were used. 
It can be concluded that epidemiologic studies are still not fully exploited in the process of quantitative risk assessment.

\section{INTRODUCTION}

In evaluating and controlling the risk of chemical compounds and substances in the occupational and general environment four steps are involved: hazard identification, risk assessment, exposure assessment and risk management [National Research Council, 1983]. For hazard identification we can partly rely on the outcomes of short term in vitro tests and animal experimental studies which can inform us in a rather general way about the mutagenicity and toxicity of chemicals. These tests have especially proved their usefulness in generating predictive information about the potential health risk for humans of products which are not already on the market [Illing, 1988]. However, some 10,000 important chemicals are used in modern industrial society, for many of which no systematical toxicological data exist [Smith, 1979]. Unfortunately we have learned about the detrimentous effect of some of these compounds because of human evidence. Vinyl Chloride (VC), benzene and asbestos are only some examples.

Nowadays, much attention is given to the question whether or not widely available substances impose a carcinogenic risk on humans. It is not possible to answer this question using the outcomes of short term in vitro tests alone. Many test systems have been developed for identifying the genotoxic properties of chemical agents. However, their sensitivity and specificity usually lie well below 90\% [Rudiger, 1990]. Positive findings in these short term tests can only justify a suspicion for a carcinogenic risk in humans, and the predictive value of the tests is much lower than that of animal studies [Henschler, 1987]. The contribution of experimental data based on long term animal experimental studies and epidemiological investigations in exposed populations is indispensable for the detection of a carcinogenic risk. In 1970 the International Agency for Research on Cancer (IARC) initiated a series of monographs in which relevant epidemiological and animal data on chemicals for which some evidence of carcinogenicity exists are collected and evaluated by international Working Groups of Experts [Vainio and Wilbourn, 1988]. These Working Groups judge every chemical to fall into one of four categories: (1) sufficient evidence, (2) limited evidence, (3) inadequate evidence or (4) no evidence of human carcinogenicity. Only if a causal relationship between the exposure and human cancer has been established, a chemical is considered to be a proven human carcinogen (Group 1) [IARC, 1987]. If human data are lacking or are 
insufficient, positive results from well conducted laboratory animal studies can only lead to categorization of the chemical in Group 2. It can be concluded that good human evidence is vital for recognizing a chemical as a carcinogenic compound and the onlly existing evidence for its carcinogenicity. However, because of their empirical, non-experimental nature epidemiological studies in humans are difficult to conduct. As a result information about the potential carcinogenic risk for many chemicals solely consists of animal experimental data.

The ultimate goal of toxicological research is not only to investigate whether or not chemicals are hazardous to humans, but also to define exposure limits for chemicals based on risk assessment, in order to create an acceptable risk for humans. The assumption that a no adverse effect level does not exist for genotoxic carcinogens is based on the hypothetical concept of the stochastic action of genotoxic substances. This implies that the possibility of a very low exposure without risk is rejected, although this cannot be proven in reality. Nevertheless governments and legislative authorities are in need of well defined exposure limits, below which the cancer risk is acceptable for carcinogenic substances which cannot be replaced or totally removed from the environment. For this reason risk assessment is important in cancer toxicology.

In principal, studies of laboratory animals and human epidemiologic studies can serve as complementary tools in cancer risk assessment. Both have their specific strengths and limitations which originate from the study designs [Savitz, 1988]. Principal advantages of the laboratory approach are the random exposure assignment and exact exposure assessment. The results are diminished in value by the need to extrapolate across species. The advantage of epidemiologic studies is that humans are studied under natural exposure conditions. Because of the empirical nature of epidemiologic investigations it is usually difficult to reconstruct exposure conditions and to correct for confounders. It is widely accepted that well conducted human studies without methodological and statistical flaws are a very useful tool in risk assessment. Although epidemiological studies have been used in cancer risk assessment in the past, animal experimental evidence has predominantly been applied in setting qualitative standards [Swaen, 1988].

In many situations occupational and environmental hygienic efforts have led to a dramatic decrease of exposure in modern industrialized countries in recent years. Besides, in modern plants with high technology relatively small groups of workers are in many cases only incidentally exposed to the toxic agents. This situation will seriously hamper the establishment of future epidemiologic research, which becomes less rewarding and of questionable practical applicability in cancer risk assessment. Consequently laboratory studies with animals 
remain essential and indispensable and will probably increase in importance. Many authors have already paid attention to the problems of extrapolation between animal species and men. It is not clear whether or not animal studies provide a sound base for risk assessment in humans. For this reason it is very important to know how results from human and animal experimental cancer studies correspond with each other. This is one of the issues that will be addressed in this paper. More specifically, the following questions are raised:

- To which extent are the outcomes of epidemiological studies in humans and laboratory studies in animals comparable regarding the detection of carcinogenic properties of chemicals (hazard identification)?

- Is the exposure assessment and the effect characterization found in epidemiological studies of carcinogenic chemicals suitable for reliable quantitative risk estimations?

- Is it possible to correlate epidemiological studies and animal experimental outcomes in the process of dose-response assessment of carcinogenic chemicals to humans?

To answer the first question, the latest update of the Monographs on the Evaluation of Carcinogenic Risks to Humans by the IARC will serve as a data base [IARC, 1987]. As far as the two other questions are concerned, analyses are restricted to the agents classified in Group 1 (Carcinogenic to humans, for which human and animal evidence is available. From this category only well characterized chemical compounds and minerals for which occupational data exist are taken into consideration. Industrial processes (for example, aluminium production), therapeutic combinations (for example, MOPP, oestrogens), food additives and cigarette smoke were left out of the evaluation. Also fibrous products such as asbestos and erionite were not considered because of the chemical and physical variations of these compounds. This resulted in the following 14 agents included in the analyses: Aflatoxins, Arsenic, 4-Aminobiphenyl, Benzene, Benzidine, Bis (chloromethyl), Ether and Chloromethyl Methyl Ether, Hexavalent Chromium Compounds, Coal Tars and Coal Tar Pitches, Untreated and Mildly Treated Mineral Oils, 2-Naphtylamine, Nickel and Nickel Compounds, Shale Oils, Soots and Vinyl Chloride. 


\section{THE ROLE OF EPIDEMIOLOGICAL AND ANIMAL EXPERIMENTAL DATA IN HAZARD IDENTIFICATION}

In Table I the classification of 597 agents under study in the latest overall evaluation of carcinggenicity is shown. As can be seen for 36 agents (6\%) sufficient evidence of carcinogenicity in humans exists and all these agents were classified as Group 1 agents. 15 Out of the 36 human carcinogens $(41,7 \%)$ did not show sufficient evidence of carcinogenicity in animals. For 1 of these agents no adequate animal data existed. In contrast, for 203 agents (34\%) sufficient evidence of carcinogenicity in experimental animals is available. Only 21 out of these 203 agents (10.3\%) also proved to be a human carcinogen. This is partly due to the fact that for 123 agents no adequate human data existed. Nevertheless for 59 of the 203 agents (29\%) the existing human evidence resulted in an evaluation which differed from the categorization based on animal evidence. Comparison of the animal and human results for agents with sufficient or limited evidence of carcinogenicity presented a comparable pattern: $61 \%$ of all evaluated agents provided at least limited evidence in animals. Out of these 364 agents only $42(11.6 \%)$ had limited or sufficient evidence in humans. The 247 agents for which no human data were available accounted in part for this bad correlation. However, for 75 agents with limited or sufficient evidence in animals, human data were inadequate. Concerning the 50 agents which showed at least limited evidence in humans, 42 of them (84\%) provided limited or sufficient evidence in animals.

It follows that the vast majority of agents which appeared to be carcinogenic in animals did not appear to produce clear and positive results in humans. For agents with sufficient evidence based on human epidemiologic studies the correspondence with animal experimental data is weak. Moreover, it is clear that for many of the agents under study no human data exist. Therefore the categorization of many agents depends largely on animal evidence.

The results of animal experimental studies are always hampered by the need to extrapolate across species. Although biological principles exist regarding the uptake, metabolization and elimination of carcinogens, there is substantial uncertainty whether or not the effects in animals are the same as in men [Savitz, 1988]. Animal studies were usually carried out in homogeneous, often inbred laboratory species. Normally the applied doses are much higher than actually experienced by human populations, usually restricted to a single agent and a thorough control of possible confounding factors exists. Laboratory animals have shorter lives than humans and the exposure conditions are more brief and intense than in most human cancer studies. Furthermore the allowed latency time between the exposure and tumor development is much shorter in animals 


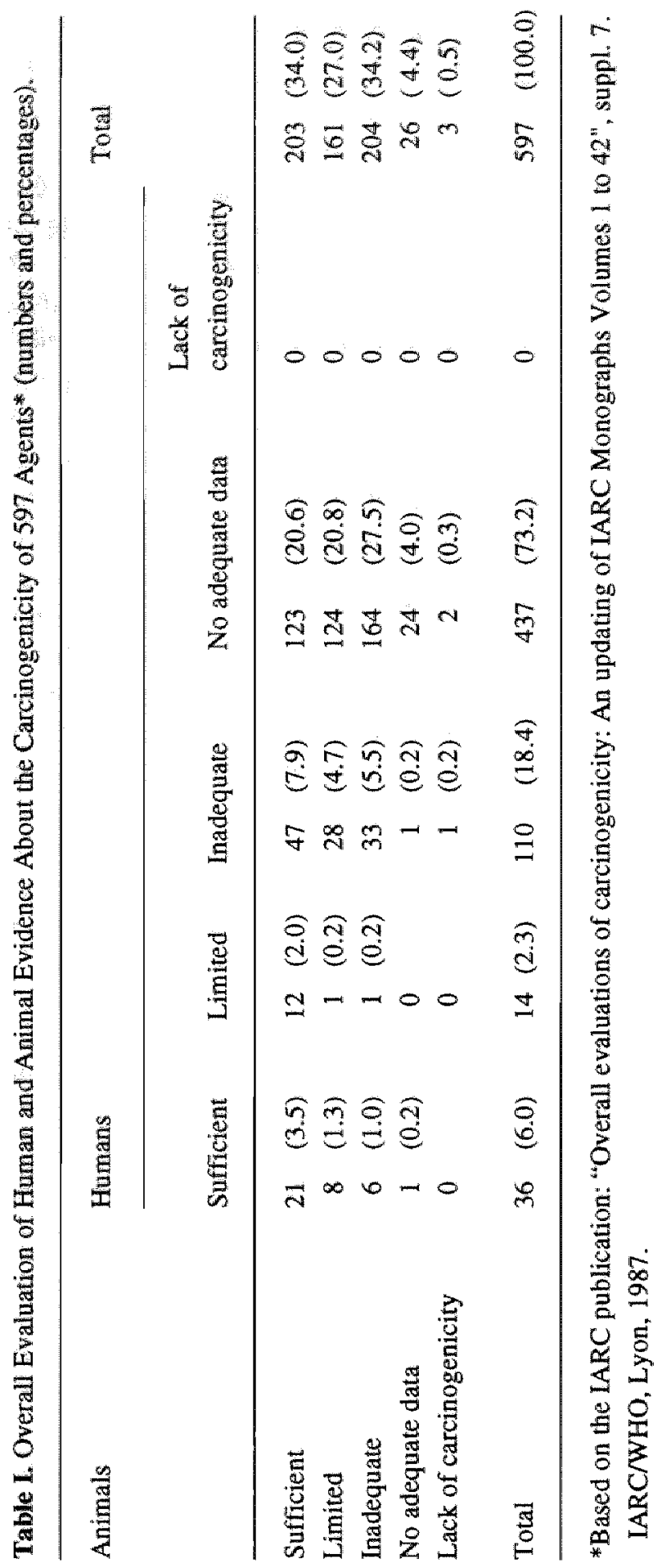


than in humans. The consequence of all these differences between controlled animal studies and empirical human studies for the observed variations in cancer potency is indistinct.

Furthermore, the way in which animal and human data are interpreted in the overall evaluation of carcinogenicity differs widely. The IARC Working Groups consider that sufficient evidence of carcinogenicity in experimental animals exists for an agent when this agent has led to an increased incidence of malignant (sometimes in combination with benign) neoplasms in two or more species of animals or in two or more independent studies in one species carried out at different times or in different laboratories or under different protocols [IARC, 1987]. The number of species that can be used for testing is sheer inexhaustible. Based on the assumption that there are differences in susceptibility between species, this means theoretically that the chance for an agent to cause tumors in one or another species increases with the amount of species that are tested. Thus it is imaginable that the classification of agents based on animal evidence can be modified by enlarging the number of species tested for.

For human data sufficient evidence of carcinogenicity exists when, following the IARC Working Groups, a positive relationship has been observed between exposure to the agent and cancer in studies in which chance, bias and confounding can be ruled out with reasonable confidence [IARC, 1987]. The interpretations are restricted to one species, namely humans. In practice the overall image of the studies provides the evidence of carcinogenicity because of the empirical character of the investigations. It is conceivable that the differences mentioned above in collecting, using and interpreting animal experimental and human data in the process of cancer risk assessment could result in a higher chance to find evidence for carcinogenicity in animals.

\section{THE QUALITY OF OCCUPATIONAL EPIDEMIOLOGICAL STUDIES IN THE LIGHT OF RISK ASSESSMENT}

In order to base risk assessment on empirical, human data, the design and the results of the epidemiological studies should give information about several essential aspects: first of all it is necessary to have a clear temporal relation between the exposure to the substance and the occurrence of a possible health effect. Good insight in the time interval between these two is vital to ascertain the cumulative exposure under interest which has preceeded and caused the disease and to use the cumulative exposure in the process of risk assessment. Although descriptive and transversal epidemiological studies, also called crosssectional prevalence studies, are certainly important in order to formulate 
hypotheses about possible hazardous substances, their role in cause-effect calculations as basis for standard setting is negligible. The reason for this is that exposure and effects are analyzed at the same point of time and dose-response curves and latency of diseases cannot be determined. To the contrary the design of case-control studies focusses on the relation between exposure conditions in the past and related effects in a fixed time interval. Starting point in case-control studies is always one specific disease. This makes their applicability in risk assessment difficult. Usually hazardous exposures do not lead to only one effect, but result in a complex mixture of diseases which have to be taken into account in the process of standard setting. Furthermore in case-control studies the investigations about the exposure factors usually take place after the occurrence of the diseases. This could lead to observer bias in attributing individual exposure levels or information bias if the patients or their relatives are examined about the exposure conditions. Sometimes it is not possible in case-control studies to get clarity about which of the variables is the causal factor and which is the effect because it is essentially a cross-sectionall study type. For these reasons these studies are in principal unable to evaluate doses or the related measure of latency, both of which are needed for risk assessment.

In cohort studies groups of exposed workers and non-exposed controls are clearly identified and followed-up over time. In the fundamental study design an accurate time dependent relation between exposure and effect is established, which makes the cohort study in principal the most appropriate epidemiological study type for occupational risk estimations.

In general the result of risk assessment should be the possibility to predict the nature and magnitude of the effect after a certain exposure experience. Therefore quantitative exposure data are absolutely required to base risk assessment upon and to compute mathematical dose-response curves. This usually means systematic and regullar measurement and recording of exposure for individual workers in order to collect information about the cumulative doses and the variations in time. In prospective cohort studies one can optimize the amount and frequency of exposure measurements in order to obtain detailed and accurate individual information per worker which can be used to construct doseresponse curves. However, for several reasons most cohort studies have a retrospective character, which means that the information about exposure preponderating depends on crude relative differences, incidental measurements in former workplaces or actual concentrations which have to be extrapolated to past production situations. If real exposure measurements are lacking and only qualitative variations of exposure (high, medium, low) are described, these cohort studies are not suited for risk assessment. However, if incidental or more frequent measurements are used to calculate the cumulative and total doses for 
different activities, work sites or job titles, it depends on the level of precision whether risk assessment can be undertaken.

Furthermore epidemiological studies should supply information about the duration of exposure. It is not possible to calculate cumulative doses as a function of duration and levels of exposure if data about exposure intervals are missing. In many cohort studies the duration of employment is used as a surrogate of the exposure duration. The multiplication of the employment periods and the exposure levels creates the cumulative doses in concentrationyears, on which dose-response curves depend. Based on these cumulative doses over a certain period, it is possible to extrapolate the theoretical exposure levels presuming that a continuous lifetime exposure takes place. The additional risk for the disease accompanying this lifetime exposure can be computed and used for risk assessment.

Finally it is necessary to be well informed about the specific effects of the exposure in terms of specific types of diseases or mortality. Risk assessment starts with the effect identification, which requires exact information about the additional diseases caused by the exposure.

Bearing in mind the basic design requirements as described above, it was investigated for the 14 selected carcinogenic substances whether epidemiologic publications were published in peer reviewed journals upon which risk assessment with empirical, human data could be based. The search for the scientific literature was executed in a standard way, looking for the most recent cohort study concerning occupational exposure with a quantitative exposure assessment as detailed as possible for every carcinogenic substance. If more than one study fulfilled these criteria, the largest study was selected. In Table II the results of these investigations are shown. All selected studies for the 14 carcinogens had a retrospective cohort design, consequently the quality of the exposure assessment largely depended on more or less routine industrial hygienic evalua tions or measurements in the past. No exposure information at all was provided in the reported studies of two substances. For 4 substances the exposure assessment was qualitative, in terms of high, medium and low exposure. In the remaining 8 studies $(57 \%$ ) measurements of individual or group exposures were available. This varied from early airborne measurements in many work areas [Lee-Feldstein, 1986; Rinsky et al, 1987] to estimates of respiratory exposures based on concentrations per kilogram dust [Hayes et al, 1984].

The next essential parameter for quantitative risk assessment is information about individual and cumulative duration of exposure. As can be seen from Table II, 12 studies ( $86 \%$ ) provided information about the duration of exposure. The quality of the data differed widely between the studies: Some studies 


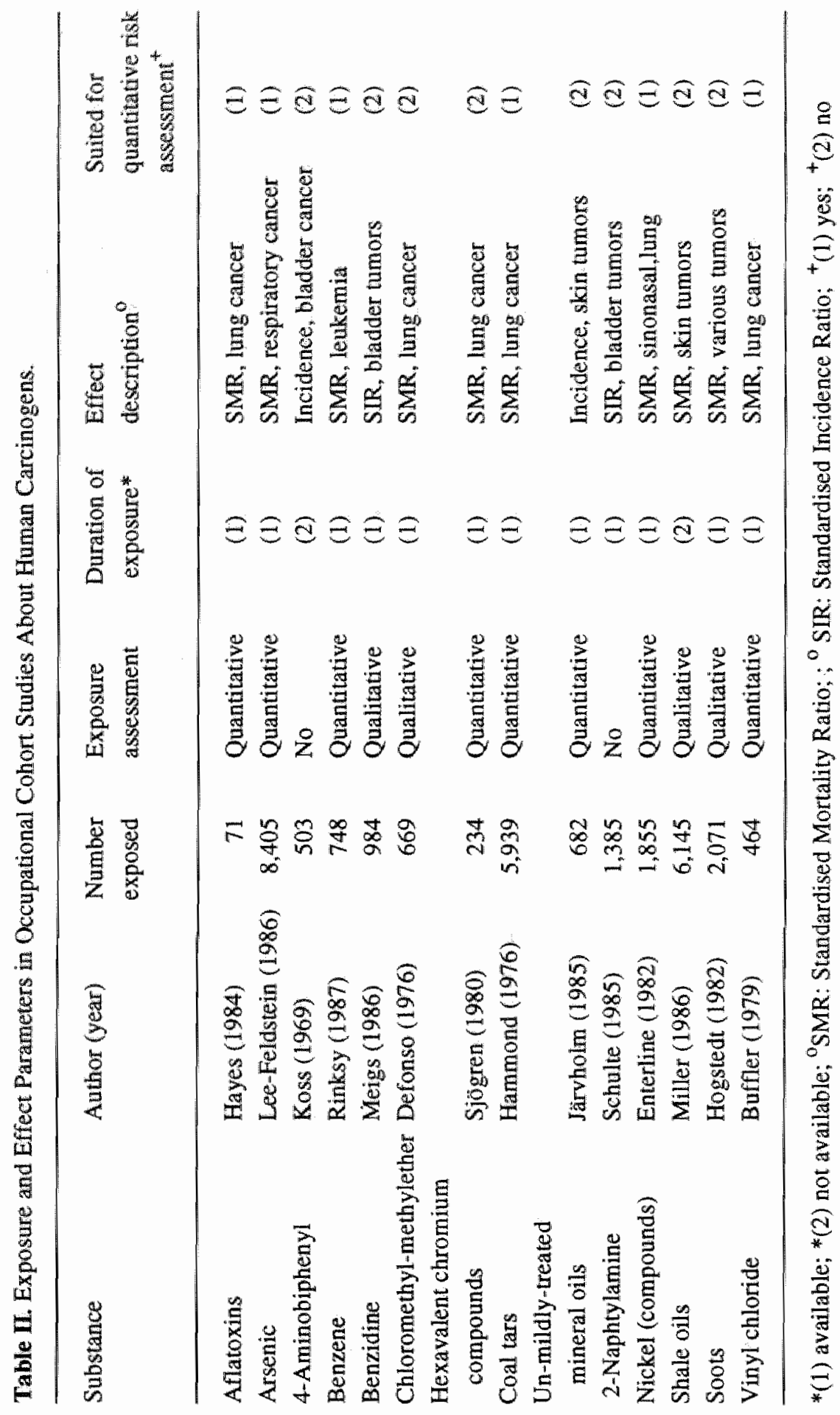


presented mean or individual exposure durations [Hammond et al, 1976; Hayes et al, 1984], whereas other studies supplied cumulative computations between concentrations and periods of time (in $\mathrm{mg} / \mathrm{m}^{3}-$ years, $\mathrm{ppm}$-months etc.).

As has been discussed earlier, knowledge about the specific effects of exposure in terms of diseases or mortality and their contribution to the overall morbidity or mortality is necessary in order to carry out risk assessment based on human data. Most occupational carcinogens exert an influence on specific tissues, organs and induce specific cancer types. This relation gets obscured if only general standardised morbidity or mortality ratios are given. Table II indicates that specific cancer incidences as well as mortality are reported in all selected studies, and that the studies provide accurate information about specific effects (overall cancer, cancer sites).

It depends on the quality of the combination of quantitative exposure information and exposure duration whether it is possible to base quantitative risk assessment on the empirical data. This is only possible for 6 out of the 14 studies (43\%). It can be concluded that for the majority of the known occupational carcinogens under investigation no quantitative dose-response estimations can be made, which emphasizes the necessity of more epidemiologic investigations in the process of risk assessment.

\section{THE COMPARISON OF HUMAN AND ANIMAL DATA}

One way to compare the quantitative dose-response relations between empirical study outcomes in humans and experimental results in animals is to calculate the life-time doses or concentrations of the carcinogenic substances which result in a fixed increase of the tumor incidence for both humans and animals. In order to perform such computations two prerequisites must be fulfilled. First of all the exposure routes must be analogous for men and animalls. If only inhalation studies are reported in humans in contrast to injection or implantation experiments in animals quantitative comparisons are not feasible. This is because it is illogical to suppose that the different applications resulting in other body and tissue concentrations do not influence the specific tumor rates.

Secondly the specific exposure effects must be comparable. An one percent increase in lung cancer in humans after a specific exposure has another impact than the same increase in liver cancer in animals.

For the selected 6 occupational carcinogens for which a quantitative risk estimation could be made, the exposure routes in the studies under investigation and the reported effects are shown in Table III. All occupational exposures concern inhalation situations whereas the effects are exclusively related to the 
Table III. Comparison of Exposure and Effect Characteristics Between Human and Animal Studies

\begin{tabular}{llllll}
\hline Substance & \multicolumn{2}{l}{ Human studies } & & \multicolumn{2}{c}{ Animal studies* } \\
\cline { 2 - 3 } & $\begin{array}{l}\text { Application } \\
\text { route }\end{array}$ & Effect & & $\begin{array}{l}\text { Application } \\
\text { route(s) }\end{array}$ & Effect \\
\hline Aflatoxins & Inhalation & Lung cancer & & Oral & Liver tumors \\
Arsenic & Inhalation & Respiratory cancer & & $\begin{array}{l}\text { Instillation/ } \\
\text { implantation }\end{array}$ & Lung cancer \\
Benzene & Inhalation & Leukemia. & & Inhalation & Various sites \\
Coal tars & Inhalation & Lung cancer & & Skin & Skin tumors \\
Nickel & Inhalation & Lung cancer & & Many & Various \\
Vinyl chloride & Inhalation & Lung cancer & & Inhalation/oral & Various \\
\hline
\end{tabular}

*Based on"Overall Evaluations of Carcinogenicity: An Updating of IARC Monographs
Volumes 1 to $42 "$, suppl. 7. IARC/WHO, Lyon, 1987.

respiratory tract or the lungs. On the other hand the picture emerging from the animal experimental studies in rats, mice and hamsters is completely contrary (see Table III). The application routes differ from implantation to oral administration, skin application and intratracheal instillation. Only for Benzene and Vinyl Chloride are well documented inhalation studies available, which makes a comparison between human and animal data possible. For Nickel 1 experimental inhalation study is reported, besides intramuscular injections, parenteral and implantation studies.

The low number of inhalation studies in animals is not surprising because these are difficult to carry out and as a consequence expensive to establish good inhalation experiments, whereas more direct implantations and applications to tissues are easier to perform. The differences in animal application led to a wide variety in tissue responses and (pre)carcinogenic effects, often not comparable to the human results. For instance in Vinyl Chloride studies in animalls increases in tumors of the mammary gland, lung, Zymbal gland, skin and angiosarcomas are reported in contrast to the experiences in man where solely lung cancer and angiosarcomas occur after airborne exposures. Because of the differences in application routes between human and animal study models, and the resulting effect variations it is not possible to compare dose-response relations on a quantitative level between these species. 


\section{EPILOGUE}

In this study we tried to analyze the overall contribution of epidemiological studies to the evaluation of the carcinogenic risk of substances to humans. Of course the interpretation of the data strongly depends on the literature that is reviewed. The latest update of the IARC Monographs on the Evaluation of Carcinogenic Risks to humans was used to collect the information necessary for the analyses [IARC, 1987]. The IARC Monographs Series provides a sound and detailled review of the scientific papers dealing with carcinogenic substances.

What can be concluded about the impact of epidemiological studies in cancer risk assessment and the relation to animal studies? Although empirical human results are required to prove that a substance is carcinogenic to humans, epidemiological studies only play a minor part in the evaluation of carcinogenicity of substances at the moment: for the majority of animal carcinogens no human data are available. For the substances with animal and human data the overall evaluations show little agreement. Differences in study design characteristics between experimental and observational studies and their expressiveness and application in hazard identification are in part responsible for the inconsistencies between the study types as has already been discussed in this paper. Besides, automation and occupational hygiene have reached a fairly high standard in modern industries, which has resulted in preponderating low and often incidental occupational exposures. It is possible that epidemiological methods are too inaccurate to find an increased cancer risk in workers experiencing such low exposure levels.

At the moment an increasing tendency exists to use epidemiological knowledge in the process of risk assessment. As has been discussed high quality exposure characteristics and detailled information about the duration of exposure are absolutely required to carry out dose-response computations with human data. An analysis for 14 occupational carcinogens learns that this information is usually not available, which makes risk assessment focussed on epidemiology a difficult and in some cases impossible task. The use of animal experimental results in risk extrapolations to humans leads perhaps to incorrect defined risk levels because it is unclear whether these levels are in good agreement with the levels based on human evidence.

In order to establish a prominent role for epidemiological research in the process of defining risks for occupational and general populations exposed to carcinogenic substances, it seems necessary to emphasize that the exposure conditions and durations of exposure are investigated and reported as detailed as possible. 


\section{REFERENCES}

Buffler PA, Wood S, Eifler C, Suarez L, Kilian DJ (1979): Mortality experience of workers in a vinyl chloride monomer production plant. J Occup Med 21: 195-203.

Detonso LR, Kelton SC (1976): Lung cancer following exposure to chloromethyl methyl ether. Arch Environ Health 31: 125-130.

Enterline PE, Marsh GM (1982): Mortality among workers in a nickel refinery and alloy manufacturing plant in West Virginia. J Natl Cancer Inst 68: 925-933.

Hammond EC, Selikoff UJ, Lawther PL, Seidman H (1976): Inhallation of benzpyrene and cancer in man. Ann New York Acad Sci 271: 116-124.

Hayes RB, Nieuwenhuize van JP, Raatgever JW, Kate ten FJW (1984): Aflatoxin exposures in the industrial setting: An epidemiological study of mortality. Fd Chem Toxic 22: 39-43.

Henschler D (1987): Risk assessment and evaluation of chemical carcinogens. Present and future strategies. Cancer Res Clin Oncol 113:1-7.

Hogstedt C. Andersson K, Frenning B, Gustavsson A (1982): A cohort study on mortality among long-time employed Swedish Chimney sweeps. Scand J Work Environ Health 8: $72-78$

IARC Working Group on the Evaluation of Carcinogenic Risk of Chemicals to Humans (1987): Overall evaluations of carcinogenicity: An updating of IARC Monographs. Vol. 1 to 42. In:"IARC Monographs on the Evaluation of Carcinogenic Risks to Humans. Lyon: suppI 7.

Illing HPA (1988): The European community chemicals notification scheme: Human health aspects. In Richardson M (ed): "Toxic hazard assessment of chemicals". Royal society of chemistry, Chapter 12. Whistable, Kent: pp 133-144.

Jărvholm B* Fast K, Lavenius B, Tomsic P (1985): Exposure to cutting oils and its relation to skin tumors and premalignant skin lesions on the hands and forearms. Scand J Work Environ Health 11: 365-369.

Koss LG, Melamer MR, Kelly RE (1969): Further cytologic and histologic studies of bladder lesions in workers exposed to para-aminodiphenyl: Progress report. J Nat Cancer Inst 43: 233-243.

Lee-Feldstein A. (1986): Cumulative exposure to arsenic and its relationship to respiratory cancer anong copper smelter employees. J Occup Med 28: 296-302.

Meigs JW, Marrett LD, Ulrich FU, Flannery JT (1986): Bladder tumor incidence among workers exposed to benzidine: A thirty-year follow-up. J Nat Cancer Inst 76: 1-8.

Miller BG, Cowie HA, Middleton WG, Seaton A (1986): Epidemiologic studies of Scottish oil shale workers: III Causes of death. An J Ind Med 9: 433-446.

National Research Council, Committee on the Institutional Means for Assessment of Risks to Public Health (1983): Risk assessment in the Federal Government: Managing the process. Washington DC: National Academy of Sciences.

Rinsky RA, Smith AB, Hornung R, Filloon TG, Young RJ, Okun AH, Landrigan PJ (1987): Benzene and leukemia. An epidemiologic risk assessment. New Engl J Med 316: 1044-1050.

Rtidiger HW (1990): Genotoxizitat: Wir brauchen ein Bewertungskonzept. Arbeitsmedizin, Socialmedizin, Prâuentivmedizin 2: 53 .

Savitz DA (1988): Human studies of human health hazards: Comparison of epidemiology and toxicology. Stat Sci 3: 306-313.

Schulte PA, Ringen K, Hemstreet GP, Altekruse EB, Gullen WH, Patton MG, Allsbrook WC (1985): Risk assessment of a cohort exposed to aromatic amines. J Occup Med 27: 115-121. 
Sjögren B (1980): A retrospective cohort study of mortality among stainless steel welders. Scand J Work Environ Health 6: 197-200.

Smith RJ (1979): NCI Bioassays yield a trail of blunders. Science 204: 1287-1292.

Swaen GMH (1988): The use of epidemiological data in risk assessment. Reg Tox Pharmacol 8: $422-430$.

Vainio H, Wilbourn J (1988): Identification of the carcinogenic risk of chemicals to humans. In Richardson M (ed): "Toxic hazard assessment of chemicals". Royal society of chemistry, Chapter 13. Whistable, Kent: pp 150-165. 



\section{Influence of design characteristics on the outcome of retrospective cohort studies: A review of the literature}

\section{G.M.H. Swaen, J.M.M. Meijers}

Department of Occupational and Environmental Health and Toxicology, University of Limburg, Maastricht, the Netherlands.

Published in the British Journal of Industrial Medicine 1988; 45: 624-629.

\section{ABSTRACT}

Retrospective cohort studies are increasingly being applied in occupational health. To describe and investigate further this type of study, 179 retrospective cohort studies published in six scientific journals between 1975 and 1985 inclusive were reviewed. A description of the 179 reviewed articles was made and relations between investigator oriented variables, design characteristics and the outcome of the study were investigated. Retrospective cohort studies focussing on exposures in the chemical industry appeared to yield most negative findings, which is partly explained by the relationship between the affiliation of the investigator and the outcome of the study. Studies requiring a minimal latency period, an occupational reference group, and a low percentage of lost to follow-up tended to have a higher chance of a positive finding. Study size, however, did not appear to be related to the outcome. 


\section{INTRODUCTION}

Epidemiologic studies have become one of the generally recognized tools to investigate long term health effects of the occupational environment. This is particularly true for retrospective cohort studies, or non-concurrent prospective studies. A retrospective cohort study can be defined as an epidemiological study in which a group of persons has been identified, who have all experienced a particular event (occupational exposure) in the past and are followed-up to determine the occurrence of disease or death. From a reference population an expected number of deaths for specific diagnoses may be calculated by means of indirect standardisation. The observed number of deaths, divided by the expected number, multiplied with 100 gives a standardised mortality ratio (SMR) that may be regarded as a measure of the relative risk for the exposed group to die of a particular disease compared with the reference population. Retrospective cohort studies are a powerful tool for detecting long term health effects of particular exposures, despite their observational character [Friedman, 1980]. They are expensive to carry out and usually take a long time to complete [Lilienfeld and Lilienfeld, 1980]. They are particularly effective in cases of a specific exposure that may play an aetiological part in various diseases if the problem to be dealt with is of the type: Does exposure to substance A lead to a higher risk of cancer and if so, what type of cancer?

Retrospective cohort studies are observational studies and have been subject to much criticism because they have not an experimental design [Enterline, 1976; Wang and Miettinen, 1982; Bell and Coleman, 1983; Gaffey, 1976]. Usually incorrect reference populations are applied, resulting in a healthy worker effect [Shindell et al, 1978]. The classical statistical procedure, the SMR analysis, has also been subject to elaborate criticism [Wong and Decouflé, 1982]. There is no alternative yet to retrospective cohort studies and therefore priority should be given to the improvement of existing methods and the policies by which these studies are conducted and the results published. It is essential to take sufficient care in collecting and interpreting the data to eliminate the possible effects of bias, confounding and chance that may lead to contradictory outcomes [Wong and Decouflé, 1982]. Furthermore, the design characteristics for example, number of people at risk and exposure definition may influence the results of cohort studies to a great extent.

Methodological issues in epidemiological studies may be investigated in several ways. One can take theoretical considerations as a basis and deduct the empirical effects of design characteristics [[Wang and Miettinen, 1982; Hernberg, 1981]. Wang and Miettinen, for instance, have argued on theoretical grounds that applying the mortality rates of the general population as the 
reference in retrospective cohort studies, is erroneous [Wang and Miettinen, 1982]. Another example of this approach is the statement that in retrospective cohort studies the healthy worker effect will fade out after a longer period of employment or a longer period of follow-up. After a longer period of employment the initially healthier population has had enough time to develop diseases that have not been picked up at the medical examination at first employment. This theoretical approach, however, misses the potential actually to quantify the effects of design characteristics on the outcome of a study or provide evidence that such effects occur in reality.

A second approach to investigate the effects of design characteristics on the outcome of a study is by simulation. An actual conducted study can be re-analyzed after artificial modification of a design characteristic. For instance, one can take a study with a long follow-up, in which no healthy worker effect was observed and artificially shorten the period of follow-up. If, after decreasing the duration of follow-up, a healthy worker effect is observed evidence is presented that a healthy worker effect occurs more frequently in retrospective cohort studies with a short period of follow-up. Such an approach, for instance, was taken by Koskela and co-authors [1984]. By analyzing the data of a large cohort study in various ways the investigators showed that in that particular study the cohort formation criteria had an effect on the outcome of the study. McMichael [1976] also used simulation to show how the healthy worker effect varied within different subgroups and with the use of different design characteristics in retrospective cohort studies.

A third possible approach is taken in this review in which 179 articles of retrospective cohort studies about occupational exposures in an 11 year period have been abstracted and analyzed. Each article has been regarded as an independent entity, comprising information about the effects of investigator oriented variables (country, authors' affiliation, and financers, for example) and design characteristics (including expected deaths, exposure definition, duration of follow-up) on the outcome of the retrospective cohort study. The investigator oriented variables and design characteristics were considered as the independent variables in this review. The dependent variable consisted of the outcome of the study: a negative study was defined as a study of which the investigators concluded that it did not give enough evidence for the existence of an increased risk of dying of a particular disease. "Non-conclusive studies"were also categorized as negative studies. We describe the research methods, the investigator oriented variables and design characteristics and report whether or not these independent variables are related to the outcome of the studies. 
Certainly the present review does not cover all occupational retrospective cohort studies reported during 1975 - 1985. To estimate the coverage we looked at the references given in the review article on occupation and cancer by Decoufle [1982] and noted that $66 \%$ of the retrospective cohort studies cited in that article, were published in journals covered by this survey.

\section{MATERLAL AND METHODS}

The following six scientific journals were searched from 1975 to 1985 inclusive:

- The American Journal of Epidemiology

- American Journal of Public Health

- British Journal of Industrial Medicine

- International Journal of Epidemiology

- Journal of Occupational Medicine

- Scandinavian Journal of Work, Environment and Health.

Every article reporting an occupational retrospective cohort study was abstracted. If the outcome was incidence of cancer registered in a cancer registry, the study was included on the condition that comparable follow-up and analytical procedures were used as in mortality studies. In these instances the standardised incidence ratio (SIR) of the total number of cancers was taken as SMR of the total number of deaths. If more than one article was written reporting a particular study only one article was included in the review. Updates, however, were regarded as separate studies.

In Appendix I all the variables collected in this review are displayed, with the categories that were used. All the articles were abstracted by one of us after specific agreements were made about how the items should be classified. The following guidelines were applied in the abstraction work: for the investigator oriented variables the first author of the publication was decisive. If no mention was made concerning the financial sources available to the retrospective cohort study it was assumed to be similar to the affiliation of the first author. For each study minimal and maximal latency were calculated using the cohort definition and the end date of the follow-up. For instance, if all the workers employed between 1945 and 1960 were followed-up until 1986 the minimal latency was 26 years and the maximal latency was 41 years. If all exposed workers employed after 1945 were followed until 1986 the minimal latency was 0 years 
(since a person who started working on 30 December 1985 was still eligible for follow-up) and the maximal latency was 41 years. Altogether, 179 retrospective cohort studies were abstracted.

The data collected in this review have been analyzed by statistical procedures generally applied in case-control studies. Odds ratios and two-sided $95 \%$ confidence limits were calculated, as described by Schlesselman [1982].

\section{RESULTS}

A total of 179 retrospective cohort studies was found from 1975 up to 1985 inclusive, 12 were"updates". The British Journal of Industrial Medicine and Journal of Occupational Medicine combined published $74 \%$ of the total number of occupational cohort studies in the given period, followed by the Scandinavian Journal of Work, Environment and Health (14\%). Typical epidemiological periodicals play no substantial part in the publication of occupational cohort studies. In the American Journal of Public Health not one study eligible for this review was published. From 1975 on to 1985 there was a consistent increase in the number of cohort studies published: In 1975 only 5 articles were found in the journals under investigation compared with 34 in 1985.

Of the studies, $45 \%$ were carried out in the United States. $21 \%$ In the United Kingdom, and $19 \%$ in Scandinavia; the remainder were conducted in a wide variety of countries in and outside Europe.

\section{Investigator oriented variables}

Several variables regarding the investigator were studied in relation to the outcome of the retrospective cohort studies.

The cohort studies performed by epidemiologists employed by governmental agencies had the highest percentage of positive results. Of the studies executed by them, $76 \%$ were positive compared with only $36 \%$ of the cohort studies performed by epidemiologists employed by industry (Table I). Similar differences were observed regarding the financial resources available to the cohort studies. About $77 \%$ of the studies funded by governmental agencies or universities were positive compared with $53 \%$ of the studies financed by industry (Table I). The outcome of the study also varied by the type of occupational exposure in industry that was under investigation (Table I). The only exposures in which more negative than positive outcomes were reported were those in the chemical industry. Therefore the relationship between the affiliation of the 
Table 1. Cross-tabulations of Investigator Oriented Variables, Design Characteristics and the Outcomes of 179 Retrospective Occupational Cohort Studies Published between 1975 and 1985

\begin{tabular}{|c|c|c|c|c|c|c|c|c|c|}
\hline & \multicolumn{2}{|c|}{ Positive } & \multicolumn{2}{|c|}{ Negative } & & \multicolumn{2}{|c|}{ Positive } & \multicolumn{2}{|c|}{ Negative } \\
\hline & $(\%)$ & No & $(\%)$ & No & & $(\%)$ & $\mathrm{No}$ & (\%) & No \\
\hline Afriliation & & & & & Number of wo & kers & & & \\
\hline University & $(68.4)$ & 52 & $(31.6)$ & 24 & $0-999$ & $(64.5)$ & 40 & $(35.5)$ & 22 \\
\hline Government & $(76.1)$ & 51 & (23.9) & 16 & $1,000-4,999$ & $(65.2)$ & 43 & $(34.8)$ & 23 \\
\hline Industry & $(35.5)$ & 11 & (64.5) & 20 & $5,000-9,999$ & (73.9) & 17 & $(26.1)$ & 6 \\
\hline Private & $(60.0)$ & 3 & $(40.0)$ & 2 & $>10,000$ & $53.3)$ & 16 & $(40.7)$ & 11 \\
\hline Total & $(65.4)$ & 117 & $(34.6)$ & 62 & Total & $(65.4)$ & 116 & $(34.6)$ & 62 \\
\hline \multicolumn{5}{|c|}{ Financial resources } & \multicolumn{5}{|c|}{ Minimal exposure period } \\
\hline Government: & $(76.7)$ & 56 & $(23.3)$ & 17 & None & $(66.3)$ & 67 & $(33.7)$ & 34 \\
\hline Industry & $(52.8)$ & 38 & $(47.2)$ & 34 & $<$ half year & (57.9) & 11 & $(42.1)$ & 8 \\
\hline University & $(77.8)$ & 21 & $(22.2)$ & 6 & Half year-year & $(55.2)$ & 16 & $(44.8)$ & 13 \\
\hline Private & $(28.6)$ & 2 & $(71.4)$ & 5 & $>$ year & (78.6) & 22 & (21.4) & 6 \\
\hline Total & $(65.4)$ & 117 & $(34.6)$ & 62 & Total & (65.5) & 116 & $(34.5)$ & $6 \pi$ \\
\hline \multicolumn{5}{|c|}{ Exposure under Investigation } & \multicolumn{5}{|c|}{ Number of expected deaths } \\
\hline Chemicals & $(48.6)$ & 36 & $(51.4)$ & 38 & $<100$ & $(59.6)$ & 28 & $(40.4)$ & 19 \\
\hline Metals & $(83.3)$ & 30 & (16.4) & 6 & $100-499$ & (65.6) & 42 & $(34.4)$ & 22 \\
\hline Asbestos & $(76.2)$ & 16 & $(23.8)$ & 5 & $500-999$ & $(64.0)$ & 16 & $(36.0)$ & 9 \\
\hline Dust & $(66.7)$ & 12 & (33.3) & 6 & $>1,000$ & (71.4) & 30 & $(28.6)$ & 12 \\
\hline Radioactivity & $(62.5)$ & 5 & $(37.5)$ & 3 & Total & (65.5) & 116 & $(34.5)$ & 61 \\
\hline Mining & $(85.7)$ & 6 & (14.3) & 1 & \multirow{2}{*}{\multicolumn{5}{|c|}{ Percentage lost to follow-up }} \\
\hline Others & $(80,0)$ & 12 & $(20.0)$ & 3 & & & & & \\
\hline Total & $(65.4)$ & 117 & $(34.6)$ & 62 & $<1 \%$ & (77.9) & 53 & $(22.1)$ & 15 \\
\hline \multirow{2}{*}{\multicolumn{5}{|c|}{ Country of investigation }} & $\%$ & $(56.7)$ & 34 & (43.3) & 26 \\
\hline & & & & & $9.9 \%$ & $(50.0)$ & 16 & $(50.0)$ & 16 \\
\hline The U.S.A. & $(51.9)$ & 42 & $(48.1)$ & 39 & $>10 \%$ & $(87,5)$ & 7 & $(12.5)$ & 1 \\
\hline The U.K. & $(65.8)$ & 25 & $(34.2)$ & 13 & Total & (65.5) & 110 & $(34.5)$ & 58 \\
\hline Scandinavia & $(82.4)$ & 28 & $(17.6)$ & 6 & \multirow{2}{*}{\multicolumn{5}{|c|}{ Duration of follow-up (years) }} \\
\hline Canada & $(90.9)$ & 10 & $(9.1)$ & 1 & & & 10 & $(16.7)$ & 2 \\
\hline Rest of Europe & $(80.0)$ & 8 & $(20.0)$ & 2 & $10-19$ & $(60.0)$ & 18 & $(40.0)$ & 12 \\
\hline $\begin{array}{l}\text { Others } \\
\text { Total }\end{array}$ & $\begin{array}{l}(80.0) \\
(65.4)\end{array}$ & $\begin{array}{r}4 \\
117\end{array}$ & $(20.0)$ & $\begin{array}{r}1 \\
62\end{array}$ & $20-29$ & $(59.6)$ & 34 & $(40.4)$ & 23 \\
\hline Total & $(65,4)$ & 117 & $(34.6)$ & & $30-39$ & $(66.0)$ & 35 & $(34.0)$ & 18 \\
\hline Journal & & & & & $40-49$ & $(78.9)$ & 15 & $(21.1)$ & 4 \\
\hline I Occup Med & $(53.7)$ & 36 & (46.3) & 31 & $>50$ & $(62.5)$ & 5 & $(37.5)$ & 3 \\
\hline $\begin{array}{l}\text { Br I Ind Med } \\
\text { Scand I Work }\end{array}$ & $(61.5)$ & 40 & $(38.5)$ & 25 & Total & $(65.5)$ & 117 & $(34.5)$ & 62 \\
\hline Env Health & $(96.0)$ & 24 & $(4.0)$ & 1 & & & & & \\
\hline Am J Epidemiol & $(64.3)$ & 9 & $(35.7)$ & 5 & & & & & \\
\hline Int J Epidemiol & $(100.0)$ & 8 & (0) & 0 & & & & & \\
\hline $\begin{array}{l}\text { Am J P } \\
\text { Health }\end{array}$ & $(0)$ & 0 & & 0 & & & & & \\
\hline Total & $(65.4)$ & 117 & $(34.6)$ & 62 & & & & & \\
\hline
\end{tabular}


principle investigator and the outcome of the cohort studies may be explained by the fact that epidemiologists employed by industry work mainly in the chemical industry, an area in which less positive results seem to be expected. The analysis was repeated after omission of all the studies conducted by epidemiologists affiliated with industry and private agencies. The tendency that proportionally most negative study outcomes were reported in the chemical industry was still noted. In fact there was no significant change in order of substances under investigation in respect of the proportion of positive studies after the omission of studies conducted by epidemiologists employed by industry or private agencies. Nevertheless, if the analysis was restricted to studies that focussed on occupational exposures in the chemical industry the difference in outcome between studies conducted by epidemiologists from industry itself and other epidemiologists was apparent. Only $32 \%$ of the studies in the chemical industry performed by epidemiologists employed by industry were positive, compared with $59 \%$ conducted by other epidemiologists. Although the number of studies is small, this difference is statistically significant $(p<0.05)$.

Another investigator oriented variable that appeared to be related to the outcome of the cohort studies, was the country in which the study was conducted (Table I) Restricting the analysis to the three geographical areas that contributed most retrospective cohort studies (the United States, the United Kingdom and Scandinavia), the highest proportion of positive studies was reported from the Scandinavian countries ( $82 \%)$, and the lowest being $52 \%$ from the United States. This difference was statistically significant $(\mathrm{p}<0.005)$. The proportion of positive outcomes of Scandinavian studies was also significantly higher than in all other studies combined $(\mathrm{p}<0.005)$. This difference remained after omitting cohort studies conducted in the chemical industry because of their unequal distribution over the countries and their subsequent potential confounding effect.

\section{Design characteristics}

There appeared to be no relation between the size of the exposed cohort and the study outcome (Table I). Of the studies with less than 5,000 workers $65 \%$ were positive compared with $66 \%$ of the studies with 5,000 or more workers. Only a weak relationship was found between the total number of expected deaths, the total person-years of follow-up, and the outcome of the study (Table I).

We investigated if the application of a minimal exposure period as eligibility criterion effected on the outcome of the retrospective cohort studies. No significant difference was observed in respect of the outcome between studies that 
had no minimal exposure period and studies that did (Table I). Among the studies in which the exposed cohort was restricted to workers who at least had experienced one year of exposure, however, there were more positive outcomes than among the studies in which no minimal latency was set. The odds ratio of a positive outcome in relation to the presence of a minimal latency period of one year was 1.9 (95\% confidence limits: $0.99-2.85$ ).

It has often been argued that comparing occupational cohorts with the mortality rates of the general population is inappropriate [Fox and Collier, 1976; Schlesselman, 1982], since occupational cohorts differ from the general population in such matters as education, socio economic status and health. Therefore we investigated the outcomes of retrospective cohort studies in which a specific, working comparison group was applied and cohort studies in which this was not done. In only 26 studies was a specific occupational comparison group used. These studies did appear to have more positive outcomes $(77 \%)$ than the studies with no specific comparison group (63\%). The odds ratio of a positive outcome was 1.9 in retrospective cohort studies in which a specific comparison group was used ( $95 \%$ confidence limits: $0.97-2.89$ ).

One of the concerns regarding the interpretation of results of retrospective cohort studies has always been if and in what way cohort members lost to follow-up influence the outcome of the study. To investigate this, we divided the studies reporting the percentage of lost to follow-up into studies with less than $1 \%$ of the cohort lost to follow-up and studies with $1 \%$ or more lost to follow-up. In studies with less than $1 \%$ lost to follow-up the odds ratio of a positive outcome was 2.66 (95\% confidence limits: $1.96-3.36)$.

Only a weak, non-significant association was found between duration of follow-up and the outcome of the study. Duration of follow-up was defined as the time between the first and last year of follow-up. In studies having 30 years or more of follow-up the odds ratio of a positive outcome was 1.3 in relation to retrospective cohort studies with less than 30 follow-up years ( $95 \%$ confidence limits: $0.69-1.93$ ).

\section{DISCUSSION}

Papers that consider the influence of methodological issues on the outcome of retrospective cohort studies usually consist of theoretical considerations or simulation examples. Here the relations between the investigator's background, design characteristics, and study outcome were analyzed for 179 occupational retrospective cohort studies on the basis of structured abstracts. The outcome was defined in terms of positive or negative outcome in the eyes of the 
investigators. There are pitfalls, however. When correlations are found between the distribution of independent and dependent variables, these may be influenced by other, confouding variables for example, the exposure under study. It must also be kept in mind that the conclusions are drawn from a non-experimental design and therefore we cannot study whether or not a relation is a causal one.

In the present review retrospective cohort studies conducted by epidemiologists employed by industry were found to have proportionally more negative results than those conducted by governmental agencies or universities (65\% versus respectively $24 \%$ and $32 \%$ ). Part of the difference could be explained by the fact that industrial research workers mainly investigated exposures in the chemical industry and this may a priori lead to more negative findings. When considering only exposures in the chemical industry, however, a tendency remained for industrially employed epidemiologists to conduct proportionally more studies with a negative outcome. One possible explanation for this finding may be that those industries that employ epidemiologists are also more aware of the potential risks involved and have put great effort into the improvement of the occupational environment. Another hypothesis may be that the background of the investigators influences their interpretation of the results. Epidemiologists employed and financed by industries have a more dependent relation to their study objects than epidemiologists working at universities or governments. Perhaps this could be reflected by a different interpretation of health risks.

Scandinavian studies reported significantly more positive findings $(82 \%)$ than studies from other countries; studies from the United States significantly less $(52 \%)$, even after omitting exposures to chemicals in the chemical industry, because of their confounding potentials. It follows that next to the affiliation and financial sources of the authors, the country also seems to be related to the study results. Different exposure levels at the workplace due to various preventive measures and other production methods may perhaps explain the geographical variation. It is also possible that political and economical differences shape outcomes.

No obvious relationship was found between design characteristics concerning the size of cohort studies and a positive or negative outcome. The total number of exposed workers, expected deaths, and total person-years of followup did not seem to influence the results. This was a somewhat surprising result and it may indicate that power calculations should not be the sole basis for deciding whether it is worthwhile to pursue a particular study. Some other design characteristics appeared to be related to the outcome of the study. 
Studies in which a high completeness of follow-up was achieved were more likely to be positive. This was also true for studies in which an industrial reference group was used.

In occupational cohort studies it is desirable to determine the vital status at the end of follow-up for as many persons under investigation as possible. Usually, this is not entirely feasible. Therefore in almost every study the lost to follow-up problem has to be dealt with. Interpretation of the 179 articles showed that lost to follow-up percentages were related to outcome. Studies with a percentage lost to follow-up lower than one had an odds ratio of a positive outcome 2.7 times as high as studies with $1 \%$ or more lost to follow-up. It is not obvious that these differences are caused by the vital status of those lost to follow-up; it is more plausible that the quality of a study is expressed by the percentage lost to follow-up. But then again it is not clear how the relation between this variable and the outcomes must be understood.

With this survey we hope we have contributed to a better understanding of the methodological issues regarding retrospective cohort studies in occupational epidemiology and a more objective assessment of the relevance of their results.

\section{REFERENCES}

Bell CMJ, Coleman DA (1983): Predicted mortality patterns in cohort study populations exposed to different types of hazard: can SMR's show a dose-resonse? Statistics in Medicine 2: 363-371.

Decoufle P (1982): Occupation. In Schottenfeld and Fraumeni (ed): "Cancer epidemiology and prevention". London: Saunders Company, pp 318-335.

Doll R (1984); Occupational Cancer: Problem in interpreting Human Evidence. Ann Occup Hyg 28: $291-305$.

Enterline PE (1976): Pitfalls in epidemiological research, and examination of the asbestos literature. J Occup Med 18: 150-156.

Fox AJ, Collier PF (1976): Low mortality rates in industrial cohort studies due to selection for work and survival in the industry. Brit J Prev Soc Med 30: 225-230.

Friedman GD (1980): "Primer of Epidemiology". New York: McGraw-Hill, pp 122.

Gaffey WR (1976): A Critique of the standardised mortality ratio. J Occup Med 18: 157-160.

Hernberg $S$ (1981): Negative results in cohort studies - how to recognize fallacies. Scand I Work Environ Health 7, suppl 4: 121-126.

Koskela R, Järvinen E, Kolari P (1984): Effect of cohort definition and follow-up length on occupational mortality rates. Scand J Work Environ Health 10:311-316.

Lilienfeld AM, Lilienfeld DE (1980): "Foundations of Epidemiology". New York: Oxford University Press, pp 247.

McMichael AJ (1976): Standardised mortality ratios and the healthy worker effect: Scratching beneath the surface. J Occup Med 18: 165-168. 
Schlesselman JJ (1982): "Case-control studies, design conduct analysis". New York: Oxford: University Press.

Shindell S, Weisberg RF, Giefer EE (1978): The healthy worker effect-fact or artifact. I Occup Med 20: 807-811.

Wang J, Miettinen O (1982): Occupational mortality studies. Scand J Work Enwiron Health 8 : $153-158$.

Wong O, Decoufle $\mathrm{P}$ (1982): Methodological issues involving the standardised mortality ratio and proportionate mortality ratio in occupational studies. J Occup Med 24: 299-304. 
Appendix I: Presentation of the Variables of which Information was Collected for the 179 Retrospective Cohort Studies Included in the Survey.

\section{Dependent variable:}

Positive or negative study.

Independent variables, investigator oriented:

Year of publication (from 1975 to 1985 inclusive).

Affiliation (government, university, industry, other).

Resources (government, university, industry, other).

Country (United States, Canada, the United Kingdom, Scandinavia, rest of Europe, rest of world).

\section{Independent variables, methodologically oriented:}

Number of exposed workers (numerical).

Definition of exposure (total industry, particular workplace, particular job, both).

Minimal exposure period (none, $<$ half year, $<$ one year, longer).

Reference group (yes, no), size if applicable.

Number of person-years of follow-up (numerical).

Minimal and maximal observed latency.

Adjustment (smoking, other variables).

First and last year of follow-up.

Number of deaths expected in the exposed group.

Percentage lost to follow-up.

Number of years between end date of follow-up and year in which the article was published. 


\section{CHAPTER 3}

\section{Occupational cohort studies: \\ The influence of design characteristics on the healthy worker effect}

J.M.M. Meijers ${ }^{1}$, G.M.H.Swaen ${ }^{1}$, A. Volovics ${ }^{2}$, L.J. Lucas $^{3}$, K. van Vliet ${ }^{1}$.

${ }^{1}$ Department of Occupational and Environmental Health and Toxicology,

${ }^{2}$ Department of Biostatistics, University of Limburg, Maastricht, the Netherlands;

${ }^{3}$ American Cyanamid Company, Wayne, New Jersey, USA.

Published in the International Journal of Epidemiology 1989; 18: 970-975.

\section{ABSTRACT}

A cross-sectional analysis of the relation between the estimated healthy worker effect (HWE), as measured by a total standardised mortality ratio (SMR) less than 100 , and relevant design characteristics in 270 published retrospective occupational cohort studies is presented. The majority of the reviewed studies showed a HWE, varying in SMR from 50 to 99 (mean: 84). The estimated HWE seemed to influence the final outcomes of the studies to a great extent. A tendency for a positive relation between the study size in terms of the number of exposed workers, total number of person-years of follow-up, and the HWE emerged. Studies with a comparatively short follow-up period had an increased chance to result in a HWE. Cohorts selected at one specific moment did not show a stronger HWE than open cohorts. Studies of chemical exposures revealed a fivefold excess of having a HWE compared with other studies. 


\section{INTRODUCTION}

Retrospective cohort studies with mortality as the study endpoint are increasingly applied in occupational epidemiology and have turned out to be very useful in detecting long-term health risks [Friedman, 1980]. They also can serve as tools in risk assessments of occupational exposures. The standardised mortality ratio (SMR) can be regarded as a measure of the relative risk of the exposed group dying from a particular disease as compared to the risk in the reference population. However, the SMR suffers from several methodological deficiencies. Gaffey argued that the SMR is a biased estimate of the relative risk, because the relative risk is defined in terms of probabilities of death, whereas the SMR is defined in terms of mortality rates [Gaffey, 1976]. The SMR overestimates the relative risk and the extent of overestimation increases as the probability of death increases [Gaffey, 1976]. If, in fact, an excess mortality risk exists in a given population, the cumulative SMR will tend to drop to 100 as the period of follow-up increases.

There are many pitfalls in the design and conduct of an appropriate cohort mortality study: the sample size may be too small; the exposure categorization of workers can be incorrect; the follow-up period may be too short in order to detect diseases with long latency (e.g. cancer); the follow-up may be incomplete and the statistical methods that are used may be insensitive or even wrong [Hernberg, 1980]. One issue that has received considerable attention is the healthy worker effect (HWE). The HWE is defined as the manifestation of a deficit in mortality, when the employed population is compared with a general population [McMichael et al, 1974; Goldsmith, 1975; Fox and Collier, 1976; Hernberg, 1981; Wang and Miettinen, 1982; Koskela, 1982; Wen et al, 1983; Monson, 1986]. The HWE originates from the fact that an employed group is usually healthier than the general population. Although this phenomenon was already known to several founders of occupational epidemiology [Weed, 1986], the HWE was first denominated as a discrete entity in 1974 and since then many epidemiologists have attempted to explain this phenomenon [McMichael et al, 1.974].

It is presumed that selection processes lie at the core of the HWE [Weed et al, 1987]. Primary selection refers to processes at time of hire. Persons who apply for a job usually undergo a medical examination and are refused if their health is not sufficient to meet the job requirement. Secondary selection refers to processes during employment. Harmful factors in the work environment can lead to health complaints and diseases which may force workers to leave their occupation which indirectly results in the survival of healthier persons employed in industry [Weed, 1986]. The HWE is not a static element. Its magni- 
tude varies and is thought to be affected by many variables, such as: race, sex, socio economic status, follow-up period, physical workload, cross-sectional or open study design, occupational exposures, and may vary among specific diseases [Fox and Collier, 1976; Koskela, 1982; Weed et al, 1987; McMichael et al, 1975; McMichael, 1976; Koskela et al, 1984]. In fact the general popullation is heterogeneous, not completely free from the exposure under investigation and it rarely represents the same social stratum as the study cohort. Therefore, the general population does not fulfill the elementary requirements of comparison validity [Hernberg, 1981; Wang and Miettinen, 1982]. The only way to overcome the HWE is to avoid comparisons with the general population. However, this solution is not feasible in many instances. Usually, it is extremely difficult to find and compile a large ad hoc working reference cohort with similar characteristics as the study group, which differs only in the fact that there is no exposure to the factor under study.

Because of practical, financial and methodological reasons, the use of general reference populations have continued in occupational cohort studies. The interpretation of SMRs in these studies is seriously complicated, because of the existing HWE: A SMR less than 100 does not necessarily indicate that no excess mortality risk exists in the studied population. In order to clear the way for future standardisation for the HWE, it is important to describe the variables that determine the magnitude of the HWE. Many investigators have examined this problem through the use of simulation models, and have re-analyzed conducted studies by artificial modification of design characteristics, including age distribution, follow-up and latency period, the proportion of active workers and different exposure subgroups [Gaffey, 1976; Wen et al, 1983; Monson, 1986; Weed et al, 1987; Pearce et al, 1986; Sterling and Weinkam, 1986]. They measured the HWE by means of the relative risk (SMR).

A different approach is taken in this review, which presents a cross-sectional analysis of the relation between the total SMR of 270 published retrospective cohort studies of occupational exposures and relevant design characteristics. The articles, published in a thirteen year period in seven scientific journals, were regarded as separate entities, comprising information about the design characteristics as independent variables and the outcomes in terms of SMRs as dependent variables. It was presumed that a total SMR lower than 100 represented an estimation of the occurrence of a HWE. Based on the classical definition of the HWE as a deficit in mortality in the employed population which expresses itself through the SMR, the authors considered the HWE to be a methodological phenomenon originating from the study design. Is was assumed that a SMR higher than 100 did not reflect a deficit in mortality, and 
therefore a HWE was regarded not to exist. However it is possible that the exposed population was initially healthier than the general population. the total SMR was regarded as a reasonable estimate for the HWE.

With a cross-sectional study design it is not possible to analyze exact causeeffect relationships between study characteristics and the estimated HWE. However, the method can be useful in order to obtain an overall impression of the distribution of the HWE in a sample of occupational cohort studies. The main objective of this paper is to determine, whether there are consistent correlations between design characteristics on the one hand, and the estimation of the HWE and its magnitude on the other. More specifically, the following questions are raised:

- What is the average magnitude of the estimated HWE?

- Does the occurrence and magnitude of a HWE change with the size of the study in terms of the number of exposed people, the person-years of follow-up and the number of expected deaths?

- Does a correlation between the HWE and the length of follow-up exist?

- Is there a relationship between the exposure definition and the HWE?

- Is there a relationship between the completeness of the study, in terms of the per cent"lost to follow-up" and the estimated HWE?

\section{MATERIAL AND METHODS}

Seven scientific journals were systematically searched from 1975 or from the first year of publication through 1987. Each article reporting an occupational retrospective cohort study in which the total SMR for the total exposed population regardless of cause of death was given, was abstracted. If more than one article was written reporting the same study, only one article was included in this review. However, cohort updates were regarded as separate studies. The number of selected articles per journal reviewed were as follows:

- The American Journal of Epidemiology ( $n=17)$;

- American Journal of Industrial Medicine $(n=28)$;

- British Journal of Industrial Medicine $(n=91)$;

- International Archives of Occupational and Environmental Health $(n=1)$;

- International Journal of Epidemiology $(n=9)$;

- Journal of Occupational Medicine $(n=77)$;

- Scandinavian Journal of Work, Environment and Health $(n=47)$. 
Appendix I lists the relevant variables collected for this review together with the categories that were used. Each article was abstracted after detailed, specific guidelines were developed for the classification of the items. As"country"was chosen the nation or combination of nations, where the exposed workers were selected. The nature of exposure was determined by the specific compounds. For each study, the minimal and maximal latency periods were calculated using the cohort definition and the end-date of the follow-up. For instance, if all the workers employed between 1950 and 1960 were followed-up until 1988, the minimal latency was 28 years and the maximal latency was 38 years. On the other hand, if all exposed workers employed after 1950 were followed until 1988 , the minimal latency was 0 years since a person who started working on 30 December 1987 was still eligible for follow-up.

The length of the follow-up period of a study was given by the difference between the last and first year of follow-up. A cohort which was composed of the total workforce at one specific point of time was considered to be a cross-sectional cohort, whereas an open cohort was selected from all people who worked or started to work in the industry during a period of time.

The final outcome of each study was determined by the conclusion of the author(s). A negative study was defined as a study in which the investigators explicitly concluded that it did not provide evidence for the existence of an increased relative risk due to an occupational exposure. "Non-conclusive"studies were also categorized as negative studies. The total SMR for the exposed group was regarded as an estimate of the HWE: the relative strength of the HWE was indicated by the calculation: (100 total SMR). If the total SMR amounted to 100 or more, a HWE was considered not to exist.

After dichotomizing the design characteristics, cross-tables between these variables and the estimated $\mathrm{HWE}$ were computed and the data were analyzed using a univariate model generally applied in case-control studies. Odds ratios and two-sided $95 \%$ confidence limits were calculated, as described by Schlesselman [1982]. In order to account for the combined effect of design characteristics on the SMR logistic regression analyses were carried out, using Generalized Linear Interactive Modelling (GLIM) [Payne, 1986].

\section{RESULTS}

The unweighted mean SMR for the 270 studies was 96.4 . Of these 172 studies $(63.7 \%$ ) showed a HWE, with an average SMR of 83.7.

The distribution of studies with a HWE over the selected design characteristics is displayed in Table I. Although awareness of the flow in the HWE in 
Table I Distribution of Studies With Healthy Worker Effect per Design Characteristic in 270 Retrospective Occupational Cohort Studies.

HWE present

Percentage of all studies

$\mathbf{N}$

\section{Publication year}

Before 1981

58.7

1981 and later

65.2

Country

USA

73.0

The United Kingdom

64.0

32

Scandinavia

54.9

28

Canada

50.0

Other

44.8

13

Exposure under investigation

Chemicalls

82.8

101

Metals

57.1

24

Minerals

43.3

29

Radiation

45.5

Others

46.4

Number of exposed workers

$$
\begin{array}{rr}
0- & 999 \\
1,000- & 4,999 \\
5,000- & 9,999 \\
\geq & 10,000
\end{array}
$$

61.4

62

76.2

52

80.0

Person-years of follow-up

$$
\begin{array}{r}
<10,000 \\
10,000-49,999 \\
50,000-99,999 \\
\geq 100,000
\end{array}
$$

63.0

83.8

Number of expected deaths

$$
\begin{array}{r}
<100 \\
100-199 \\
200-499 \\
500-999 \\
\geq 1,000
\end{array}
$$


HWE present

Mean years of follow-up per exposed worker

$$
\begin{array}{r}
<10 \\
10-15 \\
15-19 \\
20-24 \\
\geq 25
\end{array}
$$

45.0

66.7

24

61.8

21

58.1

18

63.2

24

Length of follow-up (years)

$$
\begin{array}{r}
0-19 \\
20-29 \\
30-39 \\
\geq 40
\end{array}
$$

69.5 57

59.1

Minimal observed latency (years)

$$
\begin{gathered}
0-9 \\
10-19 \\
\geq 20
\end{gathered}
$$

\section{Cohort definition}

Cross-section

Period

Minimal exposure period+

$$
\begin{aligned}
& \text { None } \\
&<\text { Half year } \\
& \text { Half year }-1 \text { year } \\
&> \mathbb{1} \text { Year }
\end{aligned}
$$

\section{Percentage lost to follow-up}

$$
<1
$$

$1-1.9$

$2-4.9$

$\geq 5$

Study outcome

Positive 
cohort studies is growing, it can be seen that the proportion of studies with a HWE has increased in recent years. The uncorrected odds ratio of the proportion of studies with a HWE published after 1981 in relation to earlier studies is 1.32, which is not statistically significant (Table II). Studies carried out in Scandinavian countries differed from those conducted in North America and the United Kingdom in in the low percentage of HWE. The uncorrected odds ratio of the HWE in studies in other regions was 1.6, but did not reach statisticall significance (Table II). A comparatively strong HWE occurred in studies of chemical substances. Almost $83 \%$ of all studies of chemical exposures showed a total SMR of less than 100 , with an uncorrected odds ratio of 5.2 (statistically significant). Studies of exposures to minerals had a significantly lower chance to reveal HWE (Table II).

Table I shows that as the number of exposed workers in occupational cohort studies increases, the chance of encountering a HWE also increases. In $80 \%$ of studies of 10,000 or more workers a total SMR less than 100 is reported, compared to $54 \%$ of the studies with less than 1,000 exposed workers. The uncorrected odds ratio of finding a HWE in a study with more than 5,000 exposed persons was 2.6 in relation to a study with less than 5,000 (statistically significant) (Tablle II). A similar relationship was found in respect of the number of person-years of follow-up accumulated in the study. Studies with 50,000 person-years or more had an uncorrected odds ratio of 2.94 of observing a HWE compared to studies with less than 50,000 person-years (Table II). However, no correlation was noted when the expected number of deaths in the entire cohorts was examined. The uncorrected odds ratio of 1.45 for an SMR smaller than 100 in studies with 200 expected deaths or more was not statistically significant (Table II).

If the average number of years of follow-up per exposed worker, defined as the quotient of the total number of person-years of follow-up and the number of exposed workers, were taken into account, no consistent relation between follow-up duration and the HWE emerged (Table II). In fact, as the length of the follow-up period of a study increased, the chance that a HWE occurred seemed to diminish: the uncorrected odds ratio of a HWE in studies with a follow-up period of less than 30 years was 1.48 in relation to studies with a longer follow-up. Nevertheless this difference was not statistically significant (Table II). The minimal observed latency period presented the same picture (Table I). As the minimal latency period increased, the proportion of studies with HWE diminished. The chance of finding a HWE in studies with a minimal latency of less than ten years is 2.52 in relation to that in studies with a longer latency, which is statistically significant (Table II). 


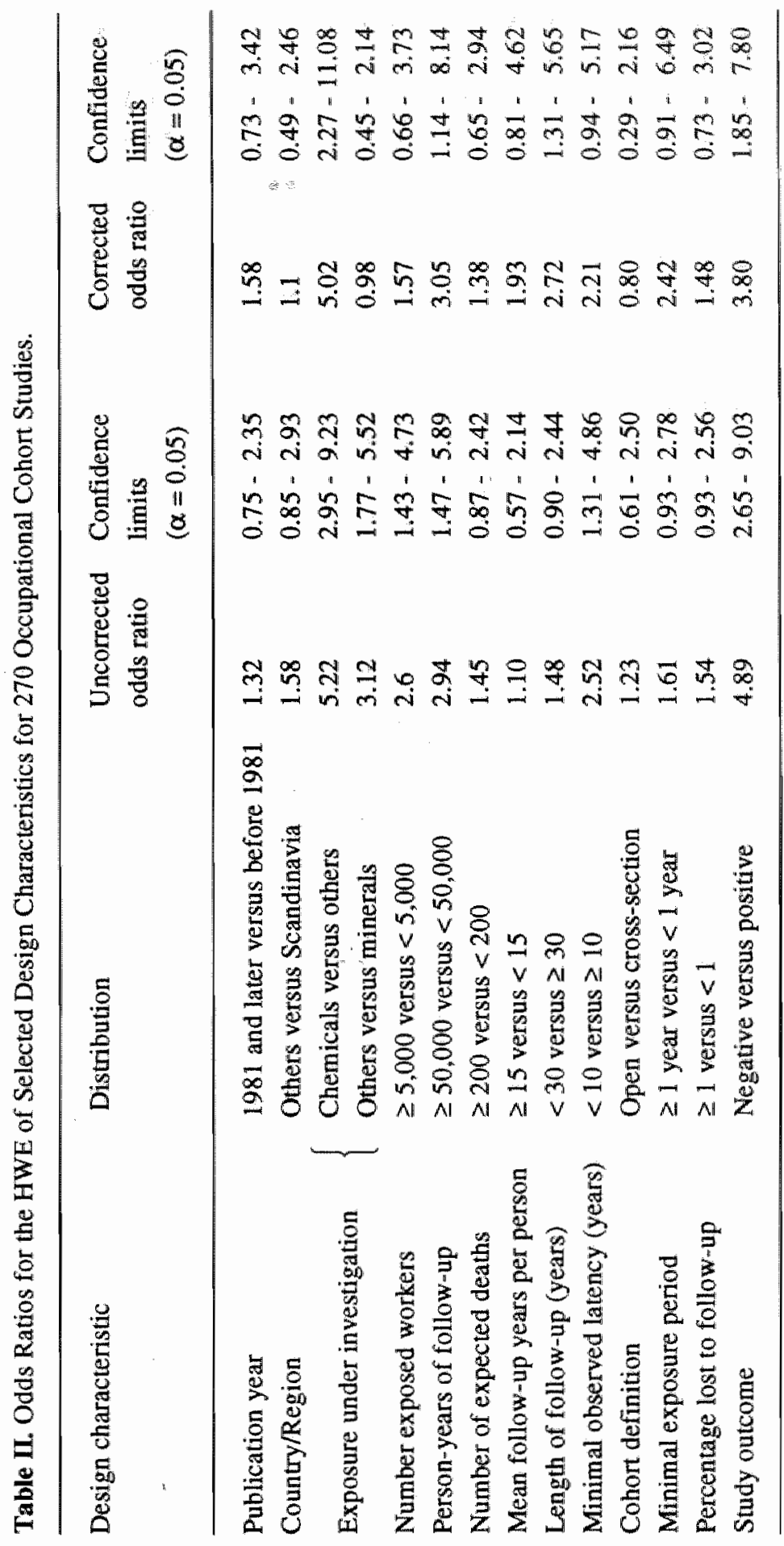


Perhaps some selection criteria used to define a cohort play a role in the occurrence of a HWE [Koskela, 1984]. In this descriptive study the uncorrected odds ratio of a HWE for an open cohort, constructed during a longer period, amounted to 1.23 in relation to a cross-sectional fixed cohort (not significant) (Table II). When a minimal exposure period of more than one year was used before a worker was sellected for the cohort, the uncorrected odds ratio for a HWE was 1.61 (not significant) (Table II).

The highest proportion of studies with a HWE was found in those with a percentage lost to follow-up of one percent or more (uncorrected OR: 1.54) (Tables I, II). There appears to be a strong relationship between the study outcome and the occurrence of a HWE. The odds ratio for a HWE in negative studies was 4.89 in relation to positive ones (Table II).

In order to correct for the confounding effect of all other design characteristics on the specific relation between a dichotomized characteristic and the HWE, a logistic regression analysis was carried out. The corrected odds ratios are shown in Table II. The model consisted of all the dichotomized variables mentionned in Table II.

The relation between studies about chemical exposures and a HWE remained strong and statistically significant (corrected odds ratio: 5.02 ). When taking into account the influence of other design variables, the relation between studies concerning minerals and $\mathrm{a} S M R \geq 100$ disappeared (Table II). The chance of finding a HWE in comparatively large studies (more than 5,000 exposed workers) also dropped to a statistically insignificant level. In fact, the only variable related to study size that showed a statistically significant correlation with the HWE after correcting for other design characteristics was the total number of person-years of follow-up. The odds ratio was 3.05 for studies with more than 50,000 years of follow-up (Table II). Generally a non-significant tendency for a positive relation between larger studies and the chance of revealing a HWE remained.

In contrast to the uncorrected calculations, the relation between the length of the follow-up period of a study and the HWE was statistically significant: studies with a shorter period of follow-up $(<30$ years) had an odds ratio of 2.7 for a HWE. When applying the logistic regression model, the odds ratio for a HWE in open cohort studies dropped below 1.0 (Table II). The positive relation between a negative study outcome and the occurrence of a HWE remained in the adjusted analyses.

After dichotomized, univariate modelling no other design characteristics studied in this review were capable of elucidating the increasing chance of finding a HWE in studies about chemicals, studies incorporating many personyears of follow-up and studies with a relatively short follow-up period. 


\section{DISCUSSION}

Because simulation models of the influence of methodological issues on the HWE are restricted to a particular study, they cannot give a comprehensive insight to the overall effect of methodological variables to the HWE in occupational cohort studies. In this review we report the results of a different approach. The cross-sectional investigation of selected design variables and total SMRs of 270 cohort studies was used for a descriptive analysis of the general impact of methodological entities upon the estimated HWE.

Nevertheless there are some pitfalls. In the first place, total SMRs were used as estimates for the HWE. The HWE originates from a complex body of selection processes, which accounts for a deficit in mortality in the study population. It was this mortality decrease the investigators where interested in, because it hampers the interpretation of study outcomes. In agreement with previous studies, they considered the SMR as a proper approximation of the HWE. Secondly, if by cross-tabulation of the overall distribution of design characteristics and the HWE correlations are found, these may as well be influenced by other factors. Conclusions are drawn from a cross-section and non-experimental design, and therefore it is impossible to investigate whether or not a relationship is a causal one. Nevertheless this method can be of use in developing new hypotheses regarding the origin and existence of the HWE.

In this review it was found that the majority of occupational cohort studies are subject to a HWE varying in SMR from 50 to 99 with a mean of 84 . It has been suggested that a reasonable approach to rule out the HWE is to apply a general correction factor of approximately $90 \%$ of total male mortality across al ages and causes [Goldsmith, 1975]. However, the results of this study show that the HWE is not a stable entity and varies widely between cohort studies. Thus, in agreement with Hernberg [1980], it would be an oversimplification to introduce a uniform adjustment factor. As the data show, more recent retrospective studies are not better equipted to deal with confounding because of the HWE than former studies.

A relation between the size of the studies and the occurrence of a HWE emerged. As the number of exposed workers and the total person-years of follow-up increased, the chance of finding a HWE increased as well. Several authors have demonstrated that the HWE diminishes as the follow-up period for an occupational cohort increases [Gaffey, 1976; Monson, 1986; McMichael, 1976; Koskela, 1984]. This review seems to confirm these observations. An inverse relationship between the follow-up period of a study and the HWE was noted. The positive correlation between the study size and a HWE could not be readily explained as larger studies did not have a shorter follow-up period. 
Studies concerning chemical substances experienced a HWE five times greater than other studies. As far as the authors know, this has not been mentioned in other reports, it is not at all clear which underlying factors may explain this important difference. It may be that workers in the chemical industry have to pass a more rigorous health selection process before they are accepted for the job; the health selection during employment is tighter or they may have a higher socio-economic status than the general population, which may result in a higher total SMR.

Koskela and co-authors [1984] al concluded from a simulation study that cross-sectional cohorts had a lower SMR than open cohorts, due to the health selection during employment. This effect increases as the health selection for certain professional groups (e.g. workers undertaking heavy physical efforts) becomes more important. This review demonstrated no tendency in the direction of an increased HWE in cross-sectional cohorts.

Studies of workers with an exposure of greater than one year had a twofold increased chance of revealing a HWE than studies with a less stringent exposure criterion did. Although this outcome was not significant, it contains an interesting hypothesis that needs further investigation. Epidemiologists often debate the necessity of introducing a minimal exposure definition. If a higher exposure definition leads to a healthier study population in relation to the reference group (for instance through greater health selection in that period) it would be advisable not to introduce such an exposure criterion.

We investigated the relation between the per cent lost to follow-up, as a surrogate of the quality of the studies and the total SMRs. As the lost to follow-up percentage increased, the chance detecting a HWE also increased. Although we do not know what exactly causes this relationship, the need for an accurate and complete gathering of vital information is again emphasized. The importance of the HWE in interpreting occupational cohort studies appears because a study subject to a HWE is less likely to be considered a positive study, regardless of the exposure under investigation. Thus the conclusions based on historical cohort studies appear to be directly related to the selection of an inaccurate reference population.

The HWE is an intriguing and complex methodological issue that affects almost every occupational cohort study. As long as no feasible alternative for the general population as a referent group exists, it is important to identify the variables that determine the HWE. With this cross-sectional review, we hope to have shed more light on the overall distribution of the HWE is occupational cohort studies and the methodological issues influencing the HWE. 


\section{REFERENCES}

Fox AJ, Collier PF [1976]: Low mortality rates in industrial cohort studies due to selection for work and survival in the industry. Br J Prev Soc Med 3: 225-230.

Friedman GD [1980]: "Primer of Epidemiology". New York: McGraw.Hill, pp 288.

Gaffey WR (1976):" A critique of the standardised mortality ratio. J Occup Med 18: 157-160.

Goldsmith J [1975]: What do we expect from an occupational cohort? J Occup Med 17: 126-127.

Hernberg S [1980]: Evaluation of epidemiologic studies in assessing the long term effects of occupational noxious agents. Scand J Work Environ Health 6: 163-169.

Hernberg S [1981]: "Negative"results in cohort studies How to recognize fallacies. Scand J Work Environ Health 7: 121-126.

Koskela RS [1982]: Occupational mortality and mortality in relation to selective turnover. Scand J Work Environ Health 8; suppl 1: 34-39.

Koskela RS, Järvinen E, Kolari PJ [1984]: Effect of cohort definition and follow-up length on occupational mortality rates. Scand J Work Environ Health 10: 311-316.

McMichael AJ, Spritas R, Kupper LL [1974]: An epidemiologic study of mortality within a cohort of rubber workers, 1964-1972. J Occup Med 16: 458-464.

McMichael AJ, Haynes SG, Tyroler HA [1975]: Observations on the evaluation of occupational mortality data. J Occup Med 17: 128-131.

McMichael AJ [1976]: Standardised mortality ratios and the" healthy worker effect": Scratching beneath the surface. J Occup Med 18: 165-168.

Monson RR [1986]: Observations on the healthy worker effect. J Occup Med 28: 425-437.

Payne CD (ed) [1986]: "The GLIM system, release 3.77, Manual"Revision A. Royal Statistical Society, United Kingdom.

Pearce N, Checkoway H, Shy C [1986]: Time-related factors as potential confounders and effect modifiers in studies based on an occupational cohort. Scand $J$ Work Environ Health 12 : 97-107.

Schlesselman JJ [1982]: "Case control studies, design conduct analysis". Oxford: Oxford University Press.

Sterling TD, Weinkam JJ [1986]: Extent, persistence and constancy of the healthy worker or healthy person effect by all and selected causes of death. J Occup Med 28: 348-353.

Wang JD, Miettinen OS [1982]: Occupational mortality studies. Principles of validity. Scand J Work Environ Health 8: 153-158.

Weed DL [1986]: Historical roots of the healthy worker effect. J Occup Med 28: 343-347.

Weed DL. Tyroler HA, Shy C [1987]: The healthy worker effect in actively working communications workers. J Occup Med 29: 335-339.

Wen CP, Tsai SP, Gibson RL [1983]: Anatomy of the healthy worker effect: a critical review. J Occup Med 25: 283-289. 
Appendix I: Presentation of the Variables for Which Information was Collected for the Retrospective Cohort Studies.

- Year of publication (from 1975 to 1987 inclusive).

- Country (USA, Canada, the United Kingdom, Scandinavia, rest of Europe, rest of world).

- Type of the occupational exposure (chemical, metal, mineral (including mining), radiation, other).

- Number of exposed workers.

- Minimal exposure period (none, < half year, < one year, $\geq$ one year).

- Cohort definition (cross-section or open).

- Number of person-years of follow-up.

- Minimal and maximal observed latency.

- First and last year of follow-up.

- Number of deaths expected in the exposed group.

- Percentage lost to follow-up.

- Positive or negative study.

- Total SMR of the exposed group. 


\section{Epidemiological investigations CONCERNING INORGANIC DUST EXPOSURE AND OCCUPATIONAL DISEASES}





\title{
CHAPTER 4
}

\section{Lung cancer among Dutch coal miners: A case-control study}

\author{
J.M.M. Meijers, G.M.H. Swaen, J.J.M. Slangen, C. van Vliet
}

Department of Occupational and Environmental Health and Toxicology, University of Limburg, Maastricht, the Netherlands.

Published in the American Journal of Industrial Medicine 1988; 14: 597-604.

\section{ABSTRACT}

A case-control study was conducted in the Southern part of the Netherlands to investigate the risk of lung cancer in coal miners. 381 Age-matched pairs of primary lung cancer cases and controls, diagnosed between 1972 and 1988 , were selected from the pathology department of the University hospital in the region. Information about past employment in coal mines was obtained through the registers of the collaborative pension fund for Dutch miners. $20 \%$ Of the cases were (at some time) employed in coal mining, compared with $21 \%$ of the controls (odds ratio 0.95 ; $95 \%$ confidence interval: $0.65-1.38$ ). $9 \%$ Of both cases and controls had an underground work history (odds ratio 0.96; 95\% confidence interval: $0.56-1.65$ ). The duration of underground coal mining did not differ substantially between cases and referents (average duration: respectively 117 and 108 months). No relation between specific histologic tumor cell types and coal mining could be demonstrated. The study gives no indication that workers in Dutch coal mines have an increased risk of developing lung malignancies. 
Silica $\left(\mathrm{SiO}_{2}\right)$ is a common contaminant of the occupational environment. The majority of silica exists in the natural crystalline form as quartz. The relation between silica exposure and silicosis is widely accepted and extensively documented. However, it is still a matter of debate whether silica exposure in the workplace plays a role in the etiology of lung cancer. Dible [1934] suggested a relation based on necropsy studies among silicotics. Since then many pathological, animal experimental and epidemiological studies have tackled this question.

Goldsmith et al [1982] state in a review article that there is growing evidence for an existing relation between occupational exposure to silica and lung cancer. They propose three possible hypotheses: silica directly induces lung cancer; silicosis is an intermediate state leading to lung cancer; or silica impairs lung clearance and interacts with other exposures ( $\mathrm{PAH}$, radiation, asbestos etc.) causing lung cancer. In contrast, Heppleston [1985] concludes that the mass of evidence does not support a causal connection between primary cancer of the lung and silica dust.

Experimental and observational studies have thrown a new light on the relation among silica, silicosis and lung cancer. Intrapleural, intraperitoneal and intravenous injection of silica induced excesses of malignant histiocytic lymphomas in several rat strains [Wagner et al, 1980]. In inhalation studies with Min-U-Sil5, (a highly purified quartz) in Fisher-344 rats, primary malignant peripheral lung tumors, predominantly of alveolar type II cells, were induced [Johnson et al, 1987]. The latter effect did not occur in hamsters [Holland et al, 1983]. However, the administration of silica with benzo(a)pyrene in hamster laboratory tests yielded more tumors than benzo(a)pyrene alone [Niemeier $e t a l$, 1986]. These experimental results suggest that silica, at least in certain rodents, acts as a carcinogen or co-carcinogen. The IARC working group on the evaluation of carcinogenic risk of chemicals to humans concluded after an extensive literature review, that there is "Sufficient evidence for the carcinogenity of cristalline silica to experimental animals"[IARC, 1987, pg. 111].

Epidemiological studies concerning the role of silica in the development of lung cancer in humans are less convincing. An excess lung cancer was observed in a number of occupational groups with exposure to silica, for example in ore miners [Edling, 1982; Boyd et al, 1970], foundry workers [Fletcher, 1986; Lynge et al, 1986], stone cutters [Lynge et al, 1986], granite workers [Koskela et al, 1987] and pottery workers [Forastiere et al, 1986; Thomas and Stewart, 1987]. This relation appeared to be much stronger when mortality studies were based on silicosis registers, as reported by Kurppa et al [1986], Finkelstein et al 
[1987], Westerholm et al [1986] and Forastiere et al [1986]. However, in some reports no possitive association between silica exposure or silicosis and lung cancer occurred [Davis et al, 1983; Hessel and Sluis-Cremer, 1986]. The inconsistent results in human studies can possibly be explained by the fact that the contribution of concomittant occupational exposures, such as cigarette smoke, radon, arsenicum and diesel exhaust fumes, to the prevalence of lung cancer was not sufficiently investigated in many studies.

Persons employed in coal mining are exposed to coal mine dust, which contains both silica and coal in different concentrations. Because of the possible carcinogenic properties of silica and the occurrence of carcinogenic agents in coal, especially certain derivatives of benzene [Mooney, 1979]; investigators have since long searched for an increased lung cancer risk in coal miners as a result of the occupational exposure to respirable coal mine dust. The outcomes of mortality studies in coal miners are contradictory: Classical reports by Kennaway and Kennaway [1953], James [1955] and Goldman [1965] showed that lung cancer is less common in British coal workers than in the general male population. In general, necropsy studies drew attention to a lower mortality from lung cancer among coal miners, especially those with Coal Workers Pneumoconiosis (CWP) [Ashley, 1968; Rooke et al, 1979], but Mooney [1975] detected a higher than expected lung cancer risk for British (ex)coal miners with pneumoconiosis. In longitudinal studies among coal miners in the United Kingdom [Liddell, 1973; Jacobsen, 1976; Atuhaire et al, 1986], Western Australia [Armstrong et al, 1979] and the United States [Costello et al, 1974; Ames et al, 1983] no evidence of an increased risk of lung cancer in coal miners was found. Several North American studies are in contrast with these findings: the outcomes of cohort studies by Enterline [1972], Scarano et al [1972] and Rockette [1977] confirmed the existence of a positive relation. It is not clear whether these differences in results can be attributed to the various study designs or regional differences in coal dust and other exposures.

In the first 70 years of this century in the southern part of the Netherlands, a coal mining industry existed which on its largest scale included eleven different mines with an annual production of 12 million tons of coal and employing over 30,000 underground miners. In a cross-sectional study in the $1950 \mathrm{~s} 27 \%$ of all underground workers showed anthracosilicotic lesions on X-ray examinations, mainly due to the high concentration of silica in coal dust [Hendriks, 1961]. After occupational hygiene measures were instituted in the successive years the CWP prevalence dropped rapidly. The mines were closed at the end of the 1960 s since they could not be operated profitably. Because of the availability of 
documentation about workers employed in coal mining, we regarded the region as suitable for conducting a case-control study to investigate the risk of lung cancer in coal miners.

In order to estimate the sample-size of the study required to detect a relative risk of 1.6 , a power calculation was made according to the method proposed by Schlesselman [1974]. Given a two-sided confidence level of $95 \%(\alpha=0.05)$ and an exposure proportion of $20 \%$ in the controls, a power of $80 \%$ would be achieved at a sample-size of 391 non-matched cases and controls.

\section{MATERIAL AND METHODS}

From the registers of the pathology department of the University Hospital in the coal mining region, all males with primary lung cancer were selected. Only histologically verified lung malignancies, detected in lung tissue obtained during a bronchoscopical examination between 1972 and 1988, were included in the study. A total of 381 cases was selected from the registers. Table I gives the distribution of the cases over the different histologic types of lung cancer.

For each case, one control person was selected from the same registers, matched on birth and diagnosis years plus or minus 1 year. Since the number of coal miners varied widely during time, the date of birth of cases and controls could influence the chance of having been a coal miner in the past. Table II lists the age distribution of the 381 matched pairs at the moment of diagnosis.

Controls were chosen regardless of their diagnosis except for having no primary lung malignancies. All controls possessed a histologically confirmed diagnosis. As can be seen from Table III, the number of controls with respiratory diseases was low. No diseases related to coal mining, such as pneumoconiosis, were observed in the control group, although they were not intentionally omitted. Therefore, it is unlikely that selection bias exists in this respect.

For all 762 patients enrolled in the study, information about past employment in the coal mines in the region was obtained through the files of the General Mining Fund, which is a collaborative pension and disability fund for all Dutch coal miners. The General Mining Fund keeps records with a complete occupational history on every person who ever worked in Dutch coal mines for 1 day or more. These records have a highly accurate, since retirement benefits of the coal miners depend on them. We gained access to the records and searched in a blind, standard manner for each person in the study to ascertain whether he was known to the General Mining Fund. The personal indentification data consisted of the family name, Christian names and birth date. If a person was labeled as having worked in the coal mines, information was gathered about the kind of 
Table I. Distribution of Lung Cancer Cases per Histological Category $(\mathrm{n}=381)$

Histological category

No. of cases

$\%$

Squamous cell carcinoma

255

66.9

Adenocarcinoma

43

11.3

Small cell carcinoma

52

13.6

Large cell carcinoma

9

2.4

Mixed patterns

22

5.8

Total

381

100.0

Table II. Age Distribution of the 381 Age-Matched Pairs

\begin{tabular}{lcr}
\hline Age category & No. of pairs & $\%$ \\
\hline$<40$ & 5 & 1.3 \\
$40-49$ & 26 & 6.8 \\
$50-59$ & 73 & 19.2 \\
$60-69$ & 164 & 43.0 \\
$70-79$ & 105 & 27.6 \\
$\geq 80$ & 8 & 2.1 \\
Total & 381 & 100.0 \\
\hline
\end{tabular}

Table III. Distribution of the Control Group Over Six Disease Categories $(n=381)$

Disease category

No. of controls

$\%$

Circulatory diseases 26

6.8

Respiratory diseases

10

2.6

Digestive diseases

135

35.4

Urogenital diseases

169

44.4

Diseases of skin and limbs

37

9.7

Diseases of endocrine and sensory organs 
work done (underground, overground) and the duration of employment. These data were used as parameters for occupational exposure to coal dust. This same procedure appeared to have a high validity in another epidemiological study [Swaen et al, 1985].

Because of the retrospective character of this study, no exact data concerning airborne coal mine dust exposures were available for individual coal miners. Dust measurements in 1965 showed that in $68 \%$ of all Dutch coal seams the total dust concentration was below $10 \mathrm{mg} / \mathrm{m}^{3}$, in $22 \%$ between 10 and $15 \mathrm{mg} / \mathrm{m}^{3}$ and in $9 \%$ over $15 \mathrm{mg} / \mathrm{m}^{3}$ [Hendriks and Mey, 1974]. In former decades, dust concentrations may have been considerably higher. The Dutch coal basin forms a geographic unity with the Belgian basin. The mean quartz content of respirable dust was found to be $4.2-14 \%$ in this coal region [Houbrechts, 1960].

\section{RESULTS}

Odds ratios and $95 \%$ confidence limits were calculated by the Mantel-Haenszel method for matched pairs [Schlesselman, 1982]. Lung diseases due to coal dust exposure are not restricted to miners at the coal face [Hunter, 1980]; for example, workers who ship and transport coal can also establish CWP, although the chance will be considerably lower. An odds ratio of 0.95 (95\% confidence limits: 0.65 -1.38) was calculated for the risk of lung cancer among workers employed in the Dutch coal mining industry, regardless of their specific occupations (Table IV). When the computations were restricted to the men with a history of underground mining and thus a higher coal dust exposure (data in Table V), the odds ratio was 0.96 (95\% confidence limits: $0.56-1.65$ ). To investigate the existence of a dose-response relationship, the duration of underground coal mining was taken into account (Table V1). The distribution of cases over the selected duration categories did not differ substantially from the controls: The average employment period for cases was 117 months, compared with 108 months for controls.

In former studies some attention has been given to the relation between the different histological types of lung cancer and silica or coal dust exposure [James, 1955; Vallyathan et al, 1985]. Vallyathan et al [1985] reported that lung carcinoma in coal miners differs little in its pathological features from that in men from the general population. Wegman and Peters [1978], however, have reported an increased occurrence of specific lung tumors in certain occupational exposure groups (e.g. oat cell tumors in asbestos and arsenic exposure). Odds 
Table IV. Distribution of Workers Employed in Coal Mining Within 381 Matched Pairs of Cases and Controls.

\begin{tabular}{lccc}
\hline Cases & $\begin{array}{l}\text { Controls } \\
\text { Ever employed in } \\
\text { coal mining }\end{array}$ & $\begin{array}{l}\text { Never employed in } \\
\text { coal mining }\end{array}$ & Total \\
\hline $\begin{array}{l}\text { Ever employed in } \\
\text { coal mining }\end{array}$ & 23 & 53 & 76 \\
$\begin{array}{l}\text { Never employed in } \\
\text { coal mining }\end{array}$ & 56 & 249 & 305 \\
Total & 79 & 302 & 381 \\
\hline
\end{tabular}

Table V. Distribution of Underground Coal Miners Within 381 Matched Pairs of Cases and Controls.

\begin{tabular}{|c|c|c|c|}
\hline \multirow[t]{2}{*}{ Cases } & \multicolumn{3}{|l|}{ Controls } \\
\hline & $\begin{array}{l}\text { With history of } \\
\text { underground coal mining }\end{array}$ & $\begin{array}{l}\text { Without history of } \\
\text { underground coal mining }\end{array}$ & Total \\
\hline $\begin{array}{l}\text { With history of } \\
\text { underground coal mining } \\
\text { Without history }\end{array}$ & 8 & 26 & 34 \\
\hline of underground coal mining & 27 & 320 & 347 \\
\hline Total & 35 & 346 & 381 \\
\hline
\end{tabular}

Table VI. Distribution (in Percentages) of the Duration of Underground Employment in the 11 Coal Mines for Cases and Controls.

\begin{tabular}{lcc} 
Duration of underground employment (years) & Cases (\%) & Controls (\%) \\
\hline$<1$ & 20.6 & 17.1 \\
$1-5$ & 35.3 & 42.9 \\
$6-10$ & 17.7 & 1.4 .3 \\
$11-20$ & 2.9 & 5.7 \\
$21-30$ & 8.8 & 17.1 \\
$>30$ & 14.7 & 2.9 \\
Total & 100.0 & 100.0 \\
\hline
\end{tabular}


Table VI. Odds Ratios Based on Matched Pairs per Lung Tumor Cell Type (Underground Coal Mining versus All Other Occupations).

Tumor cell type:

Odds ratio

Confidence limits

Sauamous cell carcinoma

1.06

$0.55-2.06$

Adenocarcinoma

1.66

$0.40-6.95$

Small cell carcinoma

0.67

$0.11-4.0$

ratios for the specific lung tumor cell types were calculated and the results are shown in Table VII. As can be seen, no convincing relation between a certain tumor cell type and coal mining could be demonstrated.

\section{DISCUSSION}

No lung cancer excess in Dutch coal miners was found in this study, and a relation between specific cancer cell types and coal dust exposure did not emerge. Yet, there are a few methodological shortcomings in the study. In the first place, no information was gathered concerning the smoking history of cases and controls. Cigarette smoking is by far the most important causal factor for lung cancer and small differences in smoking habits can stronlgy influence the outcomes. Only if coal miners in general smoke less than other persons would standardisation for smoking lead to positive results. Nevertheless, there is no evidence for a different smoking pattern in Dutch coal miners compared with the general population.

Second, no exact quantitative data on coal mine dust and silica exposure were available, but it is very likely that the qualitative classification based on working histories provides a proper estimation of coal dust exposure.

Finally, selection bias may have occurred as both cases and controls were collected from the registers of a pathological institute. However, it is not to be expected that different patterns in hospital attendance and clinical examinations of lung cancer exist between coal miners and the rest of the population.

An interesting matter is whether miners with CWP have a higher lung cancer risk. Although CWP patients were present in both the cases and controls, this question cannot be answered because the pathological data were based on tissue biopsies in living persons and pneumoconiotic lesions in the lung were not systematically examined. 
The negative results from this study are in agreement with the outcomes of the majority of epidemiologic surveys about lung cancer in coal workers [Rooke et al, 1979; Atuhaire et al, 1986; Armstrong et al, 1979; Ames et al, 1983], although occasional reports of an excess tumor rate exist [Enterline, 1972; Scarano et al, 1972; Rockette, 1977]. The Dutch data seem to indicate that silica containing respirable airborne coal dust plays no causal role in pulmonary carcinogenesis. These findings differ from animal experimental results and investigations in other dusty trades, where overall excess rates for lung cancer have been demonstrated.

According to Heppleston [1985], the increase of lung cancer in certain occupations is due to carcinogenic substances inhaled concomitantly with exposure to silica, such as arsenic, asbestos, polycyclic aromatic hydrocarbons and radioactivity from radon and its daughters. Most certainly, Dutch coal miners were not exposed to these atmospheric carcinogens in combination with coal dust. It is still questionable whether silica is an initiating or promoting agent that displays its tumor-inducing activities only in combination with other toxic substances. Future experimental and epidemiologic studies should try to answer this important question.

\section{ACKNOWLEDGMENTS}

The authors are indebted to the staff of the pathology department of the Academic Hospital in Maastricht and to the staff of the"AZL Heerlen", manager of the General Mining Fund for their collaboration during the study.

\section{REFERENCES}

Ames RG, Amandus H, Attfield M, Green FY, Vallyathan V (1983): Does Coal Mine Dust Present a Risk for Lung Cancer? A case-control Study of U.S. Coal Miners. Arch Environ Health 38:331-333.

Armstrong BK, McNulty JC, Levitt LJ, Williams KA, Hobbs MST (1979): Mortality in gold and coal miners in Western Australia with special reference to lung cancer. $\mathrm{Br} J$ Ind Med 36:199-205.

Ashley DJ (1968): Lung Cancer in Miners. Thorax 23:87-91.

Atuhaire LK, Campbell MJ, Cochrane AL, Jones M, Moore F (1986): Specific causes of death in miners and exminers of the Rhondda Fach 1950-1980. Br J Indl Med 43:497-499.

Boyd JT, Doll R, Faulds JS, Leiper J (1970): Cancer of the lung in iron ore (haematite) miners. $\mathrm{Br} J$ Ind Med 27:97-105. 
Costello J, Ortmeyer LE, Morgan WKC (1974): Mortality from Iung cancer in U.S. coal miners. Am I Public Health $64: 222224$.

Davis LK, Wegman DH, Monson RR, Froines J (1983): Mortality experience of Vermont granite workers. An J Ind Med 4:705-723.

Dible J (1934): Silicosis and malignant disease. Lancet 2:982.

Edling C (1982): Lung cancer and smoking in a group of iron ore miners. Am I Ind Med 3:191-199.

Enterline PE (1972): A review of mortality data for American coal miners. Ann NY Acad Sci $200: 260-272$.

Finkelstein M, Liss GM, Krammer F, Kusiak RA (1987): Mortality among workers receiving compensation awards for silicosis in Ontario 1940-1985. Br J Ind Med 44:588-594.

Fletcher AC (1986): The mortality of foundry workers in the United Kingdom. In Goldsmith DF, Winn DM, Shy CM (eds): "Silica, Silicosis and Cancer. Controversy in Occupational Medicine". Cancer Research Monographs, Vol 2. New York: Praeger, pp 385-401.

Forastiere F, Lagorio S, Michelozzi P, Cavariani F, Arca M, Borgia P, Perucci C, Axelson $O$ (1986): Silica, silicosis and lung cancer among ceramic workers: A case-referent study. Am Ind Med 10:363-370.

Goldman KP (1986): Mortality of coal-miners from carcinoma of the lung. Br J Ind Med 22:72-77.

Goldsmith DF, Guidotti TL, Johnston DR (1982): Does occupational exposure to silica cause lung cancer? Am J Ind Med 3:423-440.

Hendriks CAM (1961): Silicose en Iong-TBC bij de arbeiders in Nederlandse steenkolenmijnen. PhD thesis, University of Utrecht, the Netherlands.

Hendriks ChAM, Mey AVM (1974): Pneumoconiose bij werken in de kolenmijnen. In Burger GCE (ed): "Arbeids- en bedrijfsgeneeskunde". Leiden: Stenfert Kroese, pp 304-316.

Heppleston AG (1985): Silica, pneumoconiosis and carcinoma of the lung. Am J Ind Med 7:285-294.

Hessel PA, Sluis-Cremer GK (1986): Case-control study of lung cancer and silicosis. In Goldsmith DF, Winn DM, Shy CM (eds): "Silica, Silicosis and Cancer. Controversy in Occupational Medicine". Cancer Research Monographs, Vol. 2, New York: Praeger, pp $351-355$.

Holland LM, Gonzales M, Wilson JS, Tillery MI (1983): Pulmonary effects of shale dusts in experimental animals. In Wagner WL, Rom WN, Merchant JA (eds): "Health Issues Related to Metal and Nonmetallic Mining". Ann. Arbor, MI: Ann Arbor Science Publishers, pp $485-496$.

Houbrechts A (1960): The amount of free silica found in dust from Belgian coal mines. In Orenstein AJ (ed): "Proceedings of the Pneumoconiosis Conference, Johannesburg. February 1959". London: J and A Churchill, pp 299-300.

Hunter D (1980): "The Diseases of Occupations", London: Hodder and Stoughton.

IARC Working Group on the Evaluation of the Carcinogenic Risk of Chemicals to Humans (1987): Silica and some silicates. In: "IARC Monographs on the Evaluation of the Carcinogenic Risk of Chemicals to Humans", Vol. 42, pp 39-143.

Jacobsen $\mathrm{M}$ (1976): Dust exposure, lung diseases and coal miners mortality. PhD thesis, University of Edinburgh.

James WRL (1955): Primary lung cancer in South Wales coal-workers with pneumoconiosis.

Br J Ind Med 12:87-91. 
Johnson NF. Smith DM, Sebring R, Holland LM (1987): Silica-induced alveolat cell tumors in rats. Am J Ind Med 11:93-107.

Kennaway EL, Kennaway NM (1953): The incidence of cancer of the Jung in coal miners in England and Wales. Br J Cancer 7:10-18.

Koskela RS, Klockars M, Jărvinen E, Kolari PJ, Rossi A (1987): Cancer mortality of granite workers. Scand J Work Environ Health 13:26-31.

Kurppa K, Gudbergsson H, Hannunkari I, Koskinen H, Hernberg S, Koskela RS, AhIman K (1986): Lung cancer among silicotics in Finland. In Goldsmith DF, Winn DM, Shy CM (eds): "Silica, Silicosis and Cancer. Controversy in Occupational Medicine". Cancer Research Monographs, Vol. 2. New York: Praeger, pp 311-319.

Liddell FDK (1973): Mortality of British coal miners in 1961. Brit J Ind Med 30: 15-24.

Lynge E, Kurppa K, Kristofersen L, Malker H, Sauli H (1986). Silica dust and lung cancer: Results from the Nordic Occupational Mortality and Cancer Incidence Registers. JNCI 7 (4):883 889 .

Mooney FS (1975): Coalworker's pneumoconiosis and carcinoma of the lung (Letter). Lancet $1: 390$.

Mooney FS (1979): Carcinoma of the lung in Lancashire coal miners (Letter). Thorax 34:826827.

Niemeier RW, Mulligan LT, Rowland J (1986): Cocarcinogenicity of foundry silica sand in hamsters. In Goldsmith DF, Winn DM, Shy CM (eds): "Silica, Silicosis and Cancer. Controversy in Occupational Medicine". Cancer Research Monographs, Vol. 2. New York: Praeger, pp 215-227.

Rockette HE (1977): Cause specific mortality of coal miners. J Occup Med 19:795-801.

Rooke GB, Ward FG, Dempsey AN, Dowler JB, Whitaker CJ (1979): Carcinoma of the lung in Lancashire coal miners. Thorax 34:229-233.

Scarano D, Fadali AM, Lemole GM (1972): Carcinoma of the lung and anthracosillicosis. Chest $62: 251-254$.

Schlesselman JJ (1974): Sample size requirements in cohort and case-control studies of disease. Am J Epidemiol 99:381-384.

Schlesselman JJ (1982): “Case-control Studies. Design, Conduct, Analysis”. New York: Oxford Univerity Press.

Swaen GMH, Aerdts CWHM, Sturmans F, Slangen JJM, Knipschild P (1985): Gastric cancer in coal miners: A case-control study in a coal mining area. Br J Ind Med 42:627-630.

Thomas TL, Stewart PA (1987): Mortality from lung cancer and respiratory disease among pottery workers exposed to silica and talc. Am J Epidemiol 125:35-43.

Vallyathan V, Green FHY, Rodman NFi, Boyd CB, Althouse R (1985): Lung carcinoma by histologic type in coal miners. Arch Pathol 109:419-423.

Wagner MMF, Wagner JC, Cavies R, Griffiths DM (1980): Silica-induced malignant histiocytic lymphoma: Incidence linked with strain of rat and type of silica. Br J Cancer 41:908-917.

Wegman DH. Peters JM (1978): Oat cell lung cancer in selected occupations. J Occup Med 20:793-796.

Westerholm P, Ahlmark A, Maasing R, Segelberg I (1986): Silicosis and risk of lung cancer or lung tuberculosis: A cohort study. Environ Res 41:339-350. 


\section{CHAPTER 5}

\section{Long-term mortality in miners with Coal Workers' Pneumoconiosis in the Netherlands A pilot study}

J.M.M. Meijers', G.M.H. Swaen ${ }^{1}$, J.J.M. Slangen ${ }^{1}$, C. van Vliet ${ }^{1}$, F. Sturmans ${ }^{2}$

${ }^{1}$ Department of Occupational and Environmental Health and Toxicology,

${ }^{2}$ Department of Epidemiology, University of Limburg,

Maastricht, the Netherlands.

Published in the American Journal of Industrial Medicine 1991; 19: 43-50.

\section{ABSTRACT}

In order to investigate whether the prolonged exposure to coal mine dust increases the cancer risk for coal miners, a pilot study in a selected cohort of 334 Dutch miners with coal workers' pneumoconiosis (CWP), followed from 1956 until 1983, was conducted. In total, 165 miners had died (49.4\%); for 162 (98.2\%) the cause of death was traced. In comparison to the general Dutch male population, total mortality in the cohort was statistically significantly increased (SMR: 153). This was in general due to the significantly higher than expected cancer mortality (SMR: 163), cancer of stomach and small intestine (SMR: 401) and non-malignant respiratory disease (SMR: 426). The lung cancer mortality was within the expected range. 
Long-term mortality of coal miners has been the subject of considerable scientific interest. Due to various selection influences, the overall mortality in coal miners can be lower than expected, compared to national or regional mortality rates [Jacobsen, 1976; Miller and Jacobsen, 1985]. However, it is clear that coal mining does not prolong life. Although fatal accidents have gradually declined, a coal miner still has a two-fold higher risk of being killed at work than the average man [Editorial, 1979]. Numerous epidemiological studies have pointed out that nonmalignant respiratory diseases, such as progressive massive fibrosis, chronic bronchitis and emphysema impose a serious risk for premature death among coal miners [Enterline, 1964; Cochrane, 1973; Ortmeyer et al, 1973; Rockette, 1977; Miller and Jacobsen, 1985].

A question that has caused much more controversy and with which this study deals, is whether coal miners are at an increased risk of developing cancer due to the exposure to coal mine dust. This issue is quite relevant from a toxicological point of view, because coal contains various potentially carcinogenic organic compounds, such as benzo(a)pyrene, chrysene and benzo(a)anthracene derivates and some inorganic carcinogens, mostly trace metals like cadmium, chromium and nickel in various concentrations [Falk and Jurgelski, 1979]. Furthermore, the International Agency for Research on Cancer has classified crystalline silica, present in coal mine dust in varying amounts, as a probable carcinogenic compound [IARC, 1987]. With regard to lung cancer, the majority of epidemiological investigations has reported appreciably lower than expected rates in coal miners [James, 1955; Goldman, 1965; Lidell, 1973, Costello et al, 1974; Ames and Gamble, 1983; Atuhaire et al, 1985]. Furthermore, in a 22 year follow-up study concerning approximately 25,000 British coal miners, with detailled information about the smoking history and estimated cumulative dust exposure, no association between exposure to coal mine dust and lung cancer was found [Miller and Jacobsen, 1985].

Several epidemiological studies imply that coal miners experience an elevated risk for gastric cancer [Stocks, 1962; Matolo et al, 1972; Rockette, 1977; Miller and Jacobsen, 1985]. Altogether, the elevated gastric cancer risk is the third most consistent mortality finding for coal miners, after accidents and nonmalignant pulmonary diseases.

From 1902 until 1974 a coal mining industry existed in the southern part of the Netherlands, which in the late 1950s employed almost 20,000 underground miners in 11 mines [Messing, 1988]. All the mines were closed after 1965 since they could not be operated profitably and because deposits of natural gas were found in the north of the country. 
In a cross-sectional study in the $1950 \mathrm{~s} 27 \%$ of all underground workers showed pneumoconiotic lesions on X-ray examinations [Hendriks, 1961]. Because of the availability of medical records and occupational histories and in order to evaluate the cancer risk in these coal miners compared with the general male population, a pilot retrospective cohort study was undertaken to investigate the mortality experience of a group Dutch miners affected with coal workers' pneumoconiosis (CWP). Special emphasis was given to the gastricand lung cancer risks.

\section{MATERIAL AND METHODS}

\section{Study population}

The initial study population consisted of approximately 5,400 males who worked in the 11 Dutch coal mines without a CWP disability benefit, but in whom a grade of pneumoconiosis was diagnosed in a cross-sectional routine X-ray examination between 1956 and 1960 [Hendriks, 1961]. The CWP was not classified according to the corresponding 1950 ILO-classification, but was categorized as light, moderate or severe pneumoconiosis as a result of the presence on the lung roentgenogram of (micro)nodulations, confluent opacities, or massive tumors respectively.

Medical information about the 5,400 coal miners diagnosed with CWP in the cross-sectional study between 1956 and 1960 was compiled in the files of the General Mining Fund. This is a collaborative pension and disability fund for all Dutch coal miners. The General Mining Fund keeps records with a complete occupational history on each person who worked in the Dutch coal mines for 1 day or more. The above mentioned cohort of 5,400 coal miners was not separately administered, but was distributed among the total population of the pension fund. The files of the fund are arranged in alphabetical order based on family names. The investigators searched these files in a random manner in order to select radiologically confirmed CWP cases, based on the screening between 1956 and 1960. From the files of the General Mining Fund 334 coal miners with pneumoconiosis, having a Dutch residence and nationality, were selected for this pilot study.

Table I shows some characteristics of the study group. The majority of the 334 coal miners were 40 years or older at the time of diagnosis and had worked 
Table I. Characteristics of 334 Dutch Coal Miners With Coal Workers" Pneumoconiosis.

\begin{tabular}{lcrc}
\hline & & $\mathrm{N}$ & $\%$ \\
\hline Age at diagnosis & $<40$ & 32 & 9.6 \\
& $40-49$ & 167 & 50 \\
& $50-59$ & 123 & 36.8 \\
& $\geq 60$ & 12 & 3.6 \\
Total underground & $<10$ & 5 & 1.5 \\
years of employment & $10-19$ & 37 & 11.1 \\
& $20-29$ & 118 & 35.3 \\
& $30-39$ & 159 & 47.6 \\
& $\geq 40$ & 15 & 4.5 \\
Grade of CWP & & 202 & 60.5 \\
(Not ILO) & (Micro)nodulations & 109 & 32.6 \\
& Confluent opacities & 23 & 6.9 \\
Smoking history & Massive tumors & 63 & 18.9 \\
& & 114 & 34.1 \\
& Non smokers & 49 & 14.7 \\
& Yes < 10/day & 108 & 32.3 \\
\hline & Yes $\geq 10 /$ day & &
\end{tabular}

more than 20 years underground. A light grade of coal workers" pneumoconiosis (micronodulation) predominated in the study group. There were 163 known smokers: no smoking status information was available for 108 .

\section{Exposure assessment}

It was not possible to estimate the individual cumulative exposure to mine dust based on reliable, quantitative measurements for the coal miners in this retrospective study. The Dutch Technical Research Institute [TNO] carried out limited dust measurements in 1963 in an aselect sample of 159 workplaces that represented the general exposure situation in the different coal pits. The mean total, gravimetric dust concentrations amounted to $27.3 \mathrm{mg} / \mathrm{m}^{3}$; the mean percentage of quartz was 5.33. Although relative differences in the dust concentra- 
tions between the pits and seams existed, the underground exposure to mine dust has been generally high and usually above $20 \mathrm{mg} / \mathrm{m}^{3}$. The working career of coal miners in the Netherlands was very similar: starting as a coal selector and moving to hawler, hewer and, possibly, supervisor, respectively.

Due to the lack of information about the exact workplaces, e.g., histories and the use of dust masks as well as the limited number of dust measurements which showed an overall picture of high dust exposure in Dutch mines, the total duration of underground employment and the CWP diagnosis were used as surrogate measures of exposures.

On the basis that all workers had CWP, that $87.4 \%$ had worked more than 20 years underground, and that the cohort size was rather small, it was decided not to introduce more stringent exposure differences in this pilot study.

\section{Determination of vital status}

The 334 selected CWP patients were followed through December 31,1983 using the municipal population registries in the Netherlands. Every inhabitant of the Netherlands must be registered at the population registry of the municipality in which he/she is living. In case of death, a certificate must be filed at the municipality in which death occurred. The death certificate is always filed by a certified physician, in many cases the medical attendant. The death certificate is sent to the Central Bureau of Statistics [CBS]. At the CBS a trained nosologist codes the causes of death according to the latest International Classification of Diseases (ICD).

The Dutch annual vital statistics are generated from this database. In collaboration with the CBS, the causes of death were ascertained for the deceased persons in the cohort. Taking into consideration the changes in ICD-classifications that occurred during the period of follow-up, the ICD-codes were converted to the 9th Revision of the ICD [WHO, 1977] and classified into broader categories. In Table II the results of the follow-up for the cohort are shown.

As can be seen, a 100\% completeness of follow-up was achieved in the study. For 162 out of the 165 persons identified as dead at the end-date of follow-up, the exact cause of death was available. In case of the remaining 3 , the death certificate was not found at the CBS. To correct for differences in age distribution, period of follow-up, and fluctuations of background mortality, a persontime analysis was conducted by the computer program designed by Peto [1980]. The cause, age, and calendar time specific death rates of the total male Dutch population were applied to the generated person-years of the CWP cohort in order to calculate expected numbers of death. According to the indirect stand- 
Table II. Vital Status Among 334 Dutch Miners With CWP Followed to December 31 , 1983.

\begin{tabular}{lrr}
\hline & $\mathrm{N}$ & $\%$ \\
\hline Total study population & 334 & 100 \\
Alive & 169 & 50.6 \\
Dead & 165 & 49.4 \\
Total person-years of follow-up & 6,628 & \\
& & 98.2 \\
Cause of death & & 1.8 \\
$\quad$ Known & 162 & \\
$\quad$ Not known & 3 & \\
\hline
\end{tabular}

ardisation method, the quotient of the observed number of cause-specific deaths for each specific disease category and the expected number, multiplied by 100 , results in the standardised mortality ratio (SMR). This is a measure of the relative risk of a specific cause of death in the study population of coal miners, in comparison to the mortality in the total male Dutch population, $95 \%$ twosided confidence limits were calculated as proposed by Breslow and Day [1987].

\section{RESUITS}

The cause-specific observed numbers of death and standardised mortality ratios are shown in Table III. Total mortality in this select cohort of 334 miners is significantly higher than expected (SMR: $153 ;$ C.1.: 1.3-1.8). This is partly due to the increased cancer mortality (SMR: 163; C.1: 1.2-2.1). Cancers which originate from the digestive organs and peritoneum are significantly increased (SMR: 261 ; C.1: 1.7-3.9), but the only specific type of cancer of the gastrointestinal tract that is significantly higher than expected is cancer of the stomach and small intestine (SMR: 401; C.1.: 2.3-6.5). The overall lung cancer mortality is increased, but does not reach a significant level (SMR: 131; C.1.: 0.8-2.0). Several other specific cancer types show an increased, but not significantly higher, SMR. However, the observed numbers of these cancers are usually very small. 
Table III. Cause-Specific Observed Deaths and SMR in 334 Dutch Coal Miners With CWP.

Cause of death (ICD 9th Revision Codes)

Observed number

SMR

All causes of death

165

$153^{*}$

All malignant neoplasms (140-209)

$163^{*}$

Buccal cavity, pharynx (140-149)

56

0

Digestive organs, peritoneum (150-159)

Esophagus (150)

25

$261^{*}$

Stomach, small intestine (151-152)

396

Large intestine (153)

$401^{*}$

Rectum (154)

Biliary passage, liver (155-156)

Pancreas (157)

Respiratory system (160-165)

Nose, sinuses (160)

Larynx (161)

Bone (170)

19

Connective tissue (171)

Skin (172-173)

0

Breast (175)

0

Prostate (185)

$\infty$

Testis, male genitals (186-187)

Bladder, urinary organs (188-189)

Central nervous system (191)

Thyroïd gland (193)

Lymphatic, hematopoietic tissue (200-208)

Residual malignant neoplasms

Benign neoplasms (210-239)

Infections diseases (1-139)

Circulatory diseases (390-459)

Nonmalignant respiratory diseases (460-519)

61

Nonmalignant diseases of digestive organs (520-579)

Residual nonmalignant diseases

All external causes of death (E800-E999)

$* \mathrm{P}<0.05$ two-sided 
For nonmalignant respiratory diseases, a strong and statistically significant increase of the SMR can be seen. This group of miners with coal workers' pneumoconiosis has a fourfold increased risk of death due to nonmalignant respiratory disease, including lung fibrosis (SMR: 426; C.1.: 2.9-6.0).

Mortality due to infections, circulatory diseases, and violence or accidents is not significantly increased.

\section{DISCUSSION}

This retrospective cohort study shows that Dutch miners with CWP have an increased mortality risk due to cancer, especially stomach cancer, and nonmalignant lung diseases. Nevertheless, there are limitations to this study. The conclusions are based on a relatively small select group of CWP miners and chance can seriously distort the results. Yet, the long follow-up period and high mortality rate in the cohort under investigation compensate in part for this effect. However, the suggested positive relation between cancer mortality and CWP miners can be influenced by confounders that are not directly related to the mining occupations, such as smoking and alcohol consumption. As far as smoking is concerned, almost $90 \%$ of all Dutch men smoked in the late 1950 s, the period in which this cohort was selected [Stichting V en R, 1987]. In regard to the smoking characteristics of the miners (Table I), it is unlikely that variations in the smoking behavior can account for the observed differences in mortality between the miners and the general population. It must also be kept in mind that the conclusions are based on a preselected cohort of miners with CWP and a long history of underground work and predominantly simple pneumoconiotic manifestations.

Because of privacy rules and the directives of the Central Bureau of Statistics, the causes of death were given in such a way that these could not be traced to individual persons by the investigators. Thus, the frequency distribution of causes of death in the total cohort was supplied by the CBS, but each cause of death could not be linked to any individual coal miner. For this reason it was also not possible to address the influence of the pneumoconiosis grade on the mortality differences or to make dose-effect computations.

In this CWP cohort, the overall cancer risk is clearly higher than expected. As far as lung cancer is concerned, many investigators have observed a lower than expected risk in coal miners [James, 1955; Goldman, 1965; Lidell, 1973; Costello et al, 1974; Ames and Gamble, 1983; Atuhaire et al, 1985; Miller and Jacobsen, 1985]. A few studies failed to corroborate these findings and pointed to a slightly increased risk for lung cancer [Enterline, 1972; Scarano et al, 1972; 
Rockette, 1977]. A more recent autopsy study among 111 coal miners with primary lung cancer and controls, matched on age, smoking, and years of underground mining, showed a significantly higher proportion of CWP in the lung cancer cases [Vallyathan et al, 1984]. The authors suggested that pneumoconiosis is in some way related to the histogenesis of lung cancer in coal workers. In this pilot study, the increased lung cancer risk also suggests a relation with CWP, although it does not reach statistical significance. This result is contradictory to the overall evidence from larger cohort studies in the United Kingdom and the United States, and could be due to statistical chance.

Considering gastric cancer, many investigations have reported an increased risk for coal miners [Stocks, 1962; Matolo et al, 1972; Rockette, 1977; Miller and Jacobsen, 1985], although some studies did not confirm this correlation [Atuhaire et al, 1986; Swaen et al, 1987].

The growing body of evidence for an increased rate of gastric cancer in coal miners has led to the postulation of various hypotheses, according to its origin. Some researchers have argued that the elevated risk of gastric cancer is mainly due to differences in susceptibility, life style, and socio-economic status of coal miners compared to reference populations [Ames, 1982]. Other investigators pointed to a more direct relation between occupational exposure to coal dust and stomach cancer [Whong et al, 1983]. Some $98 \%$ of inhaled coal dust is swallowed and introduced in the acidic environment of the stomach, where it can interact with nitrosating agents, such as nitrite. Experimental results in the Salmonella /microsome assay system have confirmed that this leads to the formation of compounds which have mutagenic activity [Whong et al, 1983]. Jacobsen [1976] reported a positive relationship between gastric cancer mortality and pneumoconiosis progression in colliers in England and Wales, implying that the increase in stomach cancer is likely to be associated with coal dust exposure and that pneumoconiotic miners are at a higher risk for stomach cancer. Meyer and colleagues, on the contrary, postulated that miners with a normal pulmonary clearance system may be subject to a higher incidence of gastric cancer, because they receive more coal dust particles in the stomach, whereas CWP miners with an impaired clearance system do not experience an increased risk of stomach cancer [Meyer et al, 1980]. Later studies have failed to confirm this hypothesis [Ames, 1983].

The findings of this study favor a relationship between CWP and the risk of gastric cancer. It is still unclear whether this is the result of lung fibrosis, swallowing of inhaled coal dust, or a combination of these two. These results are in contrast with the hypothesis of Meyer et al [1980] and in line with the 
previous observations by Jacobsen [1976]. It is not likely that this increased risk of gastric cancer can be explained by differences in life-style factors other than smoking behavior between coal miners and the general population.

The question of whether coal dust is a carcinogenic compound is important for setting occupational hygiene standards. Future investigations with well-defined cohorts and information about exposure should address the cancer risk for coal miners with and without pneumoconiosis, taking into account dose-effect relationships.

\section{ACKNOWLEDGMENTS}

The authors wish to thank the Staff of the "AZL Heerlen" manager of the General Mining Fund for participating in the study and the Central Bureau of Statistics [CBS] for providing the causes of death.

\section{REFERENCES}

Ames RG (1982): Gastric cancer among coal miners: Some hypotheses for investigation. Presented at the Eastern Sociological Society Annual Meetings, Philadelphia PA, March 1982. J Soc Occup Med 32: 73-81.

Ames RG, Gamble JF (1983): Lung cancer, stomach cancer and smoking status among coal miners. A preliminary test of a hypothesis. Scand J Work Environ Health 9: 443-448.

Atuhaire LK, Campbeil MJ, Cochrane AL, Jones M, Moore F (1985): Mortality of men in the Rhondda fach 1950-1980. Br J Ind Med 42: 741-745.

Atuhaire LK, Campbell MJ, Cochrane AL, Jones M, Moore F (1986): Specific causes of death in miners and ex-miners of the Rondda fach 1950-1980. Br J Ind Med 43: 497-499.

Breslow NE, Day NE (1987): "Statistical Methods in Cancer Research". Vol. II. The Design and Analysis of Cohort Studies. Lyon: IARC, Sci Publ no 82.

Cochrane AL (1973): Relation between radiographic categories of coal workers' pneumoconiosis and expectation of life. Br Med J ii: 532-534.

Costello J, OrtmeyerCE, Morgan WKC (1974): Mortality from lung cancer in U.S. coal miners. Am J Public Health 64: 222-224.

Editorial (1979): Coal mining and mortality. Br Med Jii: 1168-1169.

Enterline PE (1964): Mortality rates among coal miners. Am J Public Health 54 (5): 758-768.

Enterline PE (1972): A review of mortality data for Americal coal miners. Ann NY Acad Sci 200: $260-272$.

Falk HL, Jurgelski W (1979): Health effects of coal mining and combustion: Carcinogens and cofactors. Environ Health Persp 33: 203-226.

Goldman KP (1965): Mortality of coal-miners from carcinoma of the lung. Br J Ind Med 22: $72-77$. 
Hendriks CAM (1961): Sillicose en long-TBC bij de arbeiders in Nederlandse sicenkolennijnen.

Ph.D. Thesis, Utrecht.

Intemational Agency for Research on Cancer (IARC) (1987): LARC monographs on the evaluation of carcinogenic risks to humans. Supplement no. 7: Overall evaluations of carcinogenicity: An updating of IARC monographs, Vol. 1 to 42. Lyon: IARC, pp 341-343.

Jacobsen M (1976): Dust exposures, lung diseases and coal miners" mortality. Ph. D. Thesis, Scotland: University of Edinburgh.

James WR (1955): Primary lung cancer in South Wales coal workers with pneumoconiosis. Br J Ind Med 12: 87-91.

Lidell FDK (1973): Mortality of British Coal Miners in 1961. $\mathrm{Br}$ J Ind Med 30: 15-24.

Matolo NM, Klauter MR, Gorisher WM, Dixon JM (1972): High incidence of gastric carcinoma in a coal mining region. Cancer 29: 733-737.

Messing FAM (1988): "Geschiedenis van de mijnsluiting in Limburg". Leiden: Martinus Nijhoff.

Meyer MB, Luk GD, Sotelo JM, Cohen BH, Menkes HA (1980): Hypothesis: The role of the lung in stomach carcinogenesis. Am Rev Resp Dis 121: 887-892.

Miller BG, Jacobsen M (1985): Dust exposure, pneumoconiosis and mortality of coalminers. $\mathrm{Br} \mathrm{J}$ Ind Med 42: 723-733.

Ortmeyer CE, Baier EJ, Crawford GM (1973): Life expectancy of Pennsylvania coal miners compensated for disability. Arch Environ Health 27: 227-230.

Peto J (1980): Manyears: A program for computing observed and expected deaths or incidence rates. International Publication. ICRF Cancer Unit, Oxford.

Rockette HE (1977): Cause specific mortality of coal miners. J Occup Med 19 (12): 795-801.

Scarano D, Fidali AMA, Lemole GM (1972): Carcinoma of the lung and anthrasilicosis. Chest 62: $251-254$.

Stichting Volksgezondheid en Roken (1987): Jaarverslag, p 23.

Stocks P (1962): On the death rates from cancer of the stomach and respiratory diseases in 1949-1953 among coal miners and other malle residents in counties of England and Walles. $\mathrm{Br} J$ Cancer 16: 592-598.

Swaen GMH, Aerdts CWHM, Slangen JJM (1987): Gastric cancer in coal miners. Final report. $\mathrm{Br}$ J Ind Med 44: 777-779.

Vallyathan V, Althouse R, Green FHY, Boyd C, Rodman N (1984): Relation between coal workers. pneumoconiosis and lung cancer. Am Rev Resp Dis 129: A 147.

Whong WZ, Long R, Ames RG, Ong TM (1983): Role of nitrosation of the mutagenic activity of coal dust: A postulation for gastric carcinogenesis in coal miners. Environ Res 32: 298-304.

World Health Organisation (1977). "International Classification of Diseases. Manual of the Intemational Statistical Classification of Diseases, Injuries and Causes of Death". WHO, Geneva, Vol 1. 


\section{CHAPTER 6}

\section{Silica exposure and lung cancer in ceramic workers:}

A case-control study

J.M.M. Meijers ${ }^{1}$, G.M.H. Swaen ${ }^{1}$, A. Volovics ${ }^{2}$, J.J.M. Slangen ${ }^{1}$, K. van Vliet ${ }^{1}$

${ }^{1}$ Department of Occupational and Environmental Health and Toxicology,

${ }^{2}$ Department of Biostatistics, University of Limburg, Maastricht, the Netherlands

Published in The International Journal of Epidemiology 1990; 19: 19-25.

\section{ABSTRACT}

The results are presented from a case-control study, concerning the possible relation between silica exposure in the Dutch fine ceramic industry and lung cancer. For this purpose 381 male, age-matched pairs of primary lung cancer cases and controls were selected from the pathology department of the University Hospital in the region, where two large ceramic companies are located. Information about employment in the ceramic industry was obtained from the personnel and financial administration departments of the two companies. On the basis of job titles a panel of occupational hygiene experts reached consensus about the qualitative exposures of each individual worker. $21 \%$ of the cases were employed in the ceramic industry, compared with $19 \%$ of the controls (odds ratio $1.11 ; 95 \%$ confidence limits: $0.77-1.61$ ). Although the average employment period of cases and their relative silica exposure surpassed those of controls, odds ratios for long duration of employment and considerable exposure to respirable silica dust did not reach statistical significance. After constructing a qualitative exposure index, based on the amount and duration of exposure, a tendency towards a positive correlation with lung cancer emerged. 
No relation between specific histological tumor cell types and working in the ceramic industry emerged. Although the study does not suggest a consistent cause-effect relation between silica exposure in the regional, Dutch fine ceramic industry and lung cancer, an increased risk for the high exposure group in the past cannot be totally excluded.

\section{INTRODUCTION}

The question whether or not crystalline silica $\left(\mathrm{SiO}_{2}\right)$ is able to induce lung cancer in exposed workers cannot be unequivocally answered at the moment. The growing body of experimental and observational research contains numerous contradictions and a fundamental understanding of the possible pathofysiological mechanism still does not exist.

Short-term pre-screening on carcinogenicity has generally led to negative results [IARC, 1987]. Silica was not mutagenic to Salmonella typhimurium and Escherichia Coli [Mortelmans and Griffin, 1981]. But it was possible to induce micronuclei in vitro in Syrian hamster embryo cells with $\alpha$-quartz [Hesterberg et $a l, 1986]$. However, in vivo exposure of mice to $\alpha$-quartz did not induce micronuclei in bone marrow cells [Vanchugova et al, 1985]. Sister-chromatid exchanges did not occur after adding various concentrations of purified $\alpha$ quartz (Min-U-Sil) to Chinese hamster cells [Price-Jones et al, 1980].

Intrapleural, intraperitoneal and intravenous injection of silica induced excesses of malignant histiocytic lymphomas in several rat strains [Wagner et al, 1980]. Various investigators also reported an increase of squamous cell carcinomas and adenocarcinomas in the lungs of Fisher-344 and Spraque Dawley rats, both after intratracheal instillation and inhalation of $\alpha$-quartz [Holland $e t$ al, 1983; Saffiotti, 1986; Johnson et al, 1987]. In Syrian golden hamsters no carcinogenic effects were detected under a comparable exposure regime [Holland ef al, 1986; Niemeier et al, 1986].

Crystalline silica deposits, usually consisting of quartz, are abudant in the earth's crust. Quartz constitutes about $12 \%$ of continental land masses and is used as a raw material in many industrial processes [Murphy and Henderson, 1983]. It has been estimated that millions of workers are exposed to quartz and many epidemiological studies have addressed the role of silica in the development of lung cancer in these populations. Increased rates of lung cancer have been observed in a wide range of occupational groups, for example in ore miners [Boyd et al, 1970; Edling, 1982], coal miners [Enterline, 1972; Rockette, 1977], foundry workers [Fletcher, 1986; Lynge et al, 1986], stone cutters [Lynge et al, 1986] and granite workers [Koskela et al, 1987]. This relation 
appeared to be much stronger if mortality studies were restricted to silicotics [Kurppa et al, 1986; Finkelstein ef al, 1987; Westerholm et al, 1986]. However, in some reports no possitive association between silica exposure or silicosis and lung cancer occurred [Davis et al, 1983; Ames et al, 1983; Atuhaire et al, 1986; Hessel and Sluis-Cremer, 1986; Meijers et al, 1988]. The obvious discrepancies between the observational study outcomes can perhaps be explained by existing differences in respirable dust exposures, the relative quartz content of the dusts and the fact that the contribution of concomittant occupational exposures such as cigarette smoke, radon, arsenic and diesel exhaust fumes was not sufficiently investigated in many studies.

Epidemiological reports from the ceramic and pottery industry are fairly uniform. This is the more striking because crystalline silica dust is usually considered to be the only serious chemical exposure component in this industry, where concomittant exposures to various known carcinogens are minimal or not existant [Forastiere et al, 1986]. In their classical descriptive study, Kennaway and Kennaway have reported that potters not only suffered from silicosis and tuberculosis, but also had an elevated risk for lung- and laryngeal cancer. [Kennaway and Kennaway, 1947]. A mortality study in three plants producing silica and alumosilicate fire-bricks in the USSR revealed a two- to threefold elevated relative risk for lung cancer in silica exposed males [Katsnelson and Mokronosova, 1979]. In a cohort study of silica-exposed workers in a refractory plant in Italy between 1960 and 1979 , the standardised mortality ratio (SMR) for cancer of the lung, bronchus and trachea amounted to 208 for non-silicotics and 167 for silicotics [Puntoni et al, 1985]. Thomas conducted a proportionate mortality analysis of workers in the US pottery industry and detected a slight but statistically significant elevated lung cancer risk of 1.21 in white males which occurred exclusively in persons who had worked in the sanitary ware manufacturing industry. Because silica exposure was said to be similar in other plants, Thomas postulated the hypothesis that the use of talc to dust moulds in the sanitary ware divisions was mainly responsible for the observed lung cancer excess [Thomas, 1982]. The report of a recent cohort mortality study in 2,055 workers in a ceramic plumbing fixtures company confirmed this supposition to a certain extend. Men exclusively exposed to high levels of sillica dust had a mortality ratio of 1.37 . However, those exposed to non-fibrous talc in addition to silica showed a significant 2.5-fold excess risk of lung cancer [Thomas and Stewart, 1987]. A regional Italian case-referent study involving 72 lung cancers and 314 matched controls revealed after controlling for smoking a statistically significant rate ratio of 2 for lung cancer in workers in the ceramic industry, mainly due to a rate ratio of 3.9 for silicotics [Forastiere et al, 1986]. The risk for non-silicotic ceramic workers was 1.4 (not significant). In another Italian 
study, the risk of lung cancer in silica exposed workers was only increased in the presence of silicosis [Mastrangelo et al, 1988]. Thus, the majority of observational studies in the ceramics and pottery industry showed an approximately twofold increase in the risk for lung cancer [IARC, 1987]. Silica exposure and silicosis seemed to play an important role in this excess. Nevertheless suspicions have been raised concerning the relation between talc exposure and lung cancer.

In Maastricht, a town in the southern part of the Netherlands a prosperous fine ceramic industry developped during the last 150 years, which in the $1950 \mathrm{~s}$ employed approximately $10 \%$ of the regional manpower. Currenty this industry is concentrated in two large companies which produce sanitary ware, tiles and earthenware.

Ball clay, kaolin and feldspar are used as major raw materials in the Dutch ceramic industry. They contain different amounts of chrystalline silica up to some 50\% [Valk de, 1981]. The use of talc was restricted to the production of sanitary ware. In the sanitary section workers dusted less than $15 \%$ of the moulds in a very localized way with talc, which they kept in a closed bag. Because of the very limited and concentrated application of talc, no significant exposure to talc dust was expected. Exposure to substances as diesel exhaust products and radon did not appear in the production processes. Traditionally the prevalence of silicosis among workers in the ceramic industry was substantial, due to the high amount of free silica in respirable dust. A study published in 1955 revealed that 49 out of 135 persons $(36.3 \%$ ) who had worked for more than ten years in divisions with high airborne concentrations of respirable silica dust showed silicosis after radiographical examination [Gerritsen, 1955].

After occupational hygiene measures and technical innovations introduced in the 1960s the silica exposure and number of new cases of silicosis dramatically decreased in the region [Swaen et al, 1988]. Because of the availability of reliable documentation about the work history of labourers employed in the fine ceramic industry and their predominant exposure to silica dust, we regarded the region as suitable for conducting a case-control study to investigate the risk of lung cancer in ceramic workers, with special emphasis on the relation between crystalline silica (quartz) exposure and lung cancer.

In order to estimate the sample size of the study required to detect a relative risk of 2.0 , a power calculation was made according to the method proposed by Schlesselman [Schlesselman, 1974]. Given a two-sided confidence level of $95 \%(\alpha=0.05)$ and an exposure proportion of $10 \%$, in the controls, a power of $90 \%$ would be achieved in a sample size of 378 non-matched cases and a similar number of controls. 


\section{MATERIALS AND METHODS}

From the registers of the pathology department of the local University Hospital, which is also the only general hospital in the town, people with primary lung cancer were chosen. All new lung cancer cases based on histologically verified malignancies, detected in lung tissue obtained during a bronchoscopical examination and diagnosed between 1972 and 1.988, were included in the study. No age or residence restrictions were made. Altogether 414 cases were selected from the registers ( 381 males and 33 women). Table I gives the distribution of the cases over the histological types of lung cancer. For each case, one control person was selected from the same registers, matched on sex, year of birth and diagnosis plus or minus one year. In the pathology registers patients are classi-

Table I. Distribution of Lung Cancer Cases per Histological Category $(n=414)$.

Histological category

Squamous cell carcinoma

Adenocarcinoma

Small cell carcinoma

Large cell carcinoma

Mixed patterns

Total
No. of cases

$\%$

64.9

12.6

52

58

14.0

9

2.2

26

6.3

414

Table II. Age Distribution of the 414 Age-Matched Pairs.

$\begin{array}{crr}<40 & 6 & 1.4 \\ 40-49 & 31 & 7.5 \\ 50-59 & 81 & 19.6 \\ 60-69 & 178 & 43.0 \\ 70-79 & 108 & 26.1 \\ \geq 80 & 10 & 2.4 \\ \text { Total } & 414 & 100.0\end{array}$


fied in order of their birth date. After selection of a case, the first suitable patient meeting the selection criteria was chosen as control out of the registers. Since the number of workers in the local fine ceramic industry varied widely over time, the date of birth of cases and controls could influence the chance of having been a ceramic worker in the past. Table II lists the age distribution of the 414 matched pairs at the time of diagnosis.

Controls were chosen from the registers of the same pathology department, regardless of their diagnosis except for having primary lung malignancies. All controls possessed a histologically confirmed diagnosis (Table III). The number of controls with respiratory diseases turned out to be low. No diseases related to work in the ceramic industry, such a silicosis, were observed in the control group, although they would not have been intentionally omitted, if they had occurred. Of the cases, $94 \%$ and $95 \%$ of the controls resided in the hospital area. In the control group the distribution of ceramic workers and those with no history in the ceramic industry over the specific disease categories did not differ significantly from each other. Therefore it is probable, that both cases and controls originate from the same population base. It is unlikely that selection bias has occurred in this respect.

Information about past employment in the fine ceramic industry was obtained through the files of the personnel and salary administration departments of the two companies for all 828 patients enrolled in the study. These companies keep accurate records with a complete occupational history on every person who has worked in their factories since 1900 . We were given access to these records and searched in a blind, standard manner for each person in the study to ascertain whether he or she had ever worked in the ceramic industry. The personal identification data consisted of the family name, forenames and date of birth. If a person was identified as having worked in the ceramic industry, detailed information was abstracted from the company records about the department, job titles and the dates of employment by the company.

Because of the retrospective character of the study, no quantitative data on the past exposure of the workers were available. In order to make a reliable estimate of the silica exposure for every detected worker, a panel of occupational hygienists was contacted in each of the two companies. Consensus was reached about the relative exposure to silica dust in the different stages of production and the corresponding job titles, prior to the technical innovations which lowered the dust concentrations considerably. The basic processes in the fine ceramic industry have remained essentially unchanged in the last century. The silica dust exposure seemed to be highly correlated to the stage of production. In Table IV the exposure estimates in each stage of production are shown, resulting in a high dust exposure in all phases prior to the biscuit firing until 
Table III. Distribution of the Control Group over Six Disease Categories $(n=414)$.

Disease category

No. of controls

$\%$

Circulatory diseases 27

Respiratory diseases

Digestive diseases

Urogenital diseases 187

Diseases of skin and limbs

Diseases of endocrine and sensory organs

Table IV. Basic Processes in the Pottery Production and Silica Exposures Until 1970.

Preparation of the body ingredients, crushing, grinding raw materials, blending in water

High

Forming and shaping, casting in moulds, pressing

Drying and finishing High

Biscuit firing

High

Application of glaze

Moderate

Glost firing

Moderate

Decoration

Moderate

Inspecting

Low

Packaging and labelling

Low

Maintenance, technical division

Low

Laboratory

Low

Administration

None

None

1970. After 1970, all silica exposures were presumed to be low except for the laboratory and administration sector were virtually no exposure to silica existed. The exposure classification for each case and control who appeared to have worked in the fine ceramic industry was undertaken in the following way: 
The hygienists blindly scored the exposure estimates appropriate to the job title and working period. Next, each person was given a total exposure index. For this index the products of the scored exposure levels (high $=3$; moderate $=2$; low $=1$ ) and full working years in that exposure category were computed. The individual exposure index consisted of the sum of al these products (for example exposure index ' $60^{\prime}$ means: 30 years exposed to level 2 or 20 years exposed to level 3 ).

In the analyses of the collected data odds ratios and $95 \%$, two-sided confidence limits were calculated according to the Mantel-Haenszel method for matched pairs [Schlesselman, 1982] The odds ratio approximates the risk ratio for a disease in the exposed population.

\section{RESULTS}

Only 3 out of the 66 selected women appeared to have worked in the local fine ceramic industry. Because it would not be sensible to base estimates of the relative risk for lung cancer on such a small number, we decided to restrict the further analyses of the data to the 762 matched males, of which $152(20 \%)$ had worked for some time in the ceramic industry. An odds ratio of 1.11 (95\% confidence limits: 0.77 - 1.61) was calculated for the risk of lung cancer among workers employed in the regional ceramic industry, regardless of the duration of employment or the relative silica exposure (Table V).

Table V. Distribution of Workers Employed in the Fine Ceramic Industry Within 381 Matched Pairs of Cases and Controls.

Cases

Controls

Ever employed in the Never employed in the Total
ceramic industry
ceramic industry

Ever employed in the

ceramic industry

Never employed in the

ceramic industry

Total

Odds ratio: 1.11 (confidence limits: $0.77-1.61$ ). 
Considering the duration of employment in the local ceramic industry for cases and controls, persons who only worked for a short period are over-represented in the control group. Of the controls $37.5 \%$ worked less than one year in the industry versus $22.1 \%$ of the cases. The opposite occurred for longer exposure durations. Of all cases $18.2 \%$ worked more than 20 years in the ceramic industry against $8.3 \%$ of the controls. The average employment period for lung cancer cases was 117 months, compared with 76 months for controls.

More cases than controls were at any time exposed to high airborne silica concentrations (respectively $46.9 \%$ and $34.3 \%$ ) and only a minority of both cases and controls, who ever worked in the fine ceramic industry, never experienced a significant quartz exposure ( 5 and 2 people respectively). Of the cases $46.8 \%$ (37) and $63 \%$ of the controls (46) with an occupational history in the industry were estimated to have a low or moderate exposure level. However, calculated odds ratios for long ( 3 years) versus short ( $<3$ years) duration of employment (odds ratio: 1.41 ; Confidence limits: $0.86-2.31$ ) and considerable (moderate, high) versus low (none, low) exposure levels (odds ratio: 1.1.1; Confidence limits: 0.74-1.67) did not reach statistical significance.

As described earlier a qualitative, individual exposure index was constructed for each of the 152 people who had an occupational history in the fine ceramic industries. In order to compare the risk of lung cancer in various exposure groups, odds ratios were calculated for the different exposure categories versus the lowest exposure levels using simple $2 \times 2$ tables as indicated by Pearce et al [1989] (exposure $<1$ : this means not having experienced a silica exposure during one full year or more). As can be seen in Table VI, the odds ratios tend to increase with increasing silica exposure. The odds ratio for the highest

Table VI. Odds Ratios of Different Exposure Levels Compared With the Lowest Exposure Level for Cases and Controls with a Work History in the Ceramic Industry.

\begin{tabular}{rcccc} 
Exposure index & $\begin{array}{l}\text { Number of } \\
\text { cases }\end{array}$ & $\begin{array}{l}\text { Number of } \\
\text { controls }\end{array}$ & $\begin{array}{l}\text { Odds ratio } \\
\text { (Exposure index versus } \\
\text { lowest exposure) }\end{array}$ & $\begin{array}{l}\text { Confidence } \\
\text { limits }\end{array}$ \\
\hline$<1$ & 17 & 28 & 1.00 & - \\
$1-9$ & 32 & 25 & 2.11 & $0.95-4.68$ \\
$10-39$ & 16 & 14 & 1.88 & $0.74-4.79$ \\
$40-79$ & 8 & 5 & 2.64 & $0.74-9.40$ \\
$\geq 80$ & 6 & 1 & 9.88 & $1.09-89.3$ \\
\hline
\end{tabular}


Table VII. Odds Ratios Based on Matched Pairs per Lung Tumor Cell Type (Ceramic Workers versws All Other Occupations).

Tunor cell type

Odds ratio

Confidence limits

Squamous cell carcinoma

1.13

$0.70-1.82$

Adenocarcinoma

1.13

$0.43-2.92$

Small cell carcinoma

1.25

$0.49-3.17$

exposure group differs statistically significant from 1 . Finally odds ratios for several tumor cell types were calculated to investigate whether people employed in the regional fine ceramic industry had a higher chance of developing specific lung cell tumors. As Tabel VII shows, no correlation could be detected.

\section{DISCUSSION}

From this case-control study, no overall raised risk of lung cancer emerged in workers occupationally exposed to respirable silica dust in two fine ceramic industry locations in the Netherlands. No consistent cause-effect relation or correlation between a specific histological tumor cell type and silica exposure could be demonstrated. The interpretation of the correlation between the exposure index and lung cancer is somewhat more complex. The lung cancer risk shows a positive relation with the increasing exposure index, reaching statistical significance in the highest exposure group. However, the prevalence of cases and controls in the highest exposure groups is small and chance cannot be excluded as an explanation for this relation. There are a few potential methodological flaws in the study. Firstly, the study was carried out in a region where many underground workers lived, who were exposed to silica-containing coal mine dust in the past. This could possibly interfere with the results from the ceramic industry. Detailed analyses of lung cancer in Dutch coal miners did not provide evidence for an increased risk [Meijers et al, 1988], and the odds ratio for lung cancer was not statistically significantly raised in the mining and ceramic industry. Besides, very few ceramic workers appeared to have worked in the coal mines. Selection bias may have occurred as both cases and controls were collected from the registers of a pathological institute. Nonetheless, due to the same residential areas of cases and controls and the equal distribution of ceramic and non-ceramic workers over disease categories in the control group, 
it is not feasible that different patterns of hospital attendance and clinical examinations of lung cancer exist between ceramic workers and the general population. Because of the retrospective character of the study, no exact measurements of respirable quartz concentrations were available. But it is likely that the exposures estimated by the occupational hygienists panels provide a sound qualitative base for the dust levels that existed in reality in the factories prior to the technical innovations.

No information was gathered concerning the smoking history of cases and controls. Based on a cross-sectional analysis of the smoking behaviour of the fineceramic workers in the $1970 \mathrm{~s}$, it was concluded that $61.7 \%$ was smoker and $38.3 \%$ non-smoker. This is comparable with the smoking behaviour of the general Dutch population [Swaen et al, 1988]. Besides, Siemiatycki et al [1988] concluded that it is unlikely that smoking as a confounder seriously distorts the findings in epidemiologic cancer studies. Only if workers in the fine ceramic industry in general smoke appreciable less than other people, would standardisation for smoking lead to positive results. At the moment there is no evidence for a different smoking pattern in ceramic workers in this study compared with the general population.

The outcome of this study differs from the results by Forastiere et al [1986], who found a raised rate ratio of 2.0 for lung cancer in ceramic workers, regardless of silicosis. Contrary to the method applied in our study, the employment data in the Italian study were based on questionnaires and may have been influenced by information bias. The results are also in disagreement with the outcomes of a cohort study in the United States, in which no increased lung cancer risk was detected among men exposed to high levels of silica dust [Thomas and Stewart, 1987]. However this study shows a suggestive tendency towards a positive relation between high and prolonged exposure and lung cancer. The International Agency for Research on Cancer defined crystalline silica as a compound with sufficient evidence of carcinogenicity to experimental animals and limited evidence of carcinogenicity to humans [IARC, 1987]. The present study gives no unambiquous indication that high silica exposure in the fine ceramic industry is directly related to an increased risk of developing lung malignancies. A question that cannot be easily answered yet with an epidemiological design, is whether sillica is an initiating or promoting agent that only exerts its malignant effect when combined with other toxic substances. Mastrangelo et al [1988] propose that silicosis is an essential step in the development of lung cancer. This hypothesis could not be tested in this casecontrol study. Future investigations in the Dutch fine ceramic industry will therefore pay attention to the possible relation between lung cancer and silicosis. 


\section{ACKNOWLEDGMENTS}

The authors thank the staff of the pathology department of the University Hospital in Maastricht for taking part in the study, and also the managers and salary administration staffs of the two ceramic industries in the same town for their cooperation during the study.

\section{REFERENCES}

Ames RG, Amandus H, Aufield M, Green FY, Vallyathan V (1983): Does coal mine dust present a risk for lung cancer? A case-control study of U.S. coal miners. Arch Environ Health 38: $331-333$.

Atuhaire LK, Campbell MJ, Cochrane AL, Jones M, Moore F (1986): Specific causes of death in miners and exminers of the Rhondda Fach 1950-1980. Br J Ind Med 43: 497-499.

Boyd JT, Doll R, Faulds IS, Leiper J (1970): Cancer of the lung in iron ore (haematite) miners. Br J Ind Med 27: 97-105.

Davis LK, Wegman DH, Monson RR, Froines J (1983): Mortality experience of Vermont granite workers. Am J Ind Med 4: 705-723.

Edling C (1982): Lung cancer and smoking in a group of iron ore miners. Am J Ind Med 3: 191. 199 .

Enterline PE (1972): A review of mortality data for American coal miners. Ann NY Acad Sci 200: $260-272$.

Finkelstein M, Liss GM, Krammer F, Kusiak RA (1987): Mortality among workers receiving compensation awards for silicosis in Ontario 1940-1985. Br J Ind Med 44: 588-594.

Fletcher AC (196): The mortality of foundry workers in the United Kingdom. In Goldsmith DF, Winn DM, Shy CM (eds): "Silica, Silicosis and Cancer. Controversy in Occupational Medicine". Cancer Research Monographs, vol. 2, New York: Praeger, pp 385-401.

Forastiere F, Lagorio S, Michelozzi P, Cavariani F, Arca M, Borgia P, Perucci C, Axelson O (1986): Silica, silicosis and lung cancer among ceramic workers: A case-reference study. Am J Ind Med 10: 363-370.

Gerritsen WB (1.955): Silicose in de aardewerk- en porceleinindustrie. De veiligheid 245-250. Hessel PA, Sluis-Cremer GK (1986): Case-control study of lung cancer and silicosis. In Goldsmith DF, Winn DM, Shy CM (eds): "Silica, Sillicosis and Cancer. Controversy in Occupational Medicine". Cancer Research Monographs, vol. 2, New York: Praeger, pp 351-355.

Hesterberg TW, Oshimura M, Brody AR, Barrett JC (1986): Asbestos and silica induce morphological transformation of mammalian cells in culture: A possible mechanism. In Goldsmith DF, Winn DM, Shy CM (eds): "Silica, Silicosis and Cancer. Controversy in Occupational Medicine". Cancer Research Monographs, vol. 2, New York: Praeger, pp 177-190.

Holland LM, Gonzales M, Wilson JS, Tillery MI (1983): Pulmonary effects of shale dusts in experimental animals. In Wagner WL, Rom WN, Merchant JA (eds): "Health issues related to metal and nonmetallic mining". Ann Arbor:" Ann Arbor Science Publishers, pp 485-496. 
Holland LM, Wilson JS, Tillery MI, Smith DM (1986): Lung cancer in rats exposed to frbrogenic dusts. In Goldsmith DF, Winn DM, Shy CM (eds): "Sillica, Silicosis and Cancer. Controversy in Occupationall Medicine". Cancer Research Monographs, vol. 2, New York: Praeger, pp 267-279.

LARC. Working Group on the Evaluation of Carcinogenic Risk of Chemicals to Humans (1987): Silica and some silicates. In: "IARC Monographs on the Evaluation of the Carcinogenic Risk of Chemicals to Humans". Vol. 42, pp 39-143.

Johnson NF, Smith DM, Sebring R, Holland LM (1987): Silica-induced alweolar cell tumors in rats. Am J Ind Med 11: 93-107.

Katsnelson BA, Mokronosova KA (1979): Non-fibrous mineral dusts and malignant tumors. An epidemiological study of mortality. J Occup Med 21: 15-20.

Kennaway EL, Kennaway NM (1947): A further study of the incidence of cancer of the lung and larynx. Br J Cancer 1: 260-298.

Koskela RS, Klockars M, Järvinen E, Kolari PJ, Rossi A (1987): Cancer mortality of granite workers. Scand J Work Enwiron Health 13:26-31.

Kurppa K, Gudbergsson H, Hannunkari I, Koskinen U, Hernberg S, Koskela RS, Ahlman K (1986): Lung cancer among silicotics in Finland. In Goldsmith DF, Winn DM, Shy CM (eds): "Silica, Silicosis and Cancer. Controversy in Occupational Medicine". Cancer Research Monographs, vol. 2, New York: Praeger, pp 311-319.

Lynge E, Kurppa $\mathrm{K}$, Kristofersen L, Malker $\mathrm{H}_{4}$ Sauli $\mathrm{H}$ (1986): Silica dust and lung cancer: Results from the Nordic Occupational Mortality and Cancer Incidence Registers. J Nat Cancer Inst 77: 883-889.

Mastrangelo G, Zambon $\mathrm{P}$, Simonato L, Rizzi P (1988): A case-referent study investigating the relationship between exposure to silica dust and lung cancer. Int Arch Occup Environ Health $60: 299-302$.

Meijers JMM, Swaen GMH, Slangen JTM, Vliet van C (1988): Lung cancer among Dutch coal miners: A case-control study. Am J Ind Med 14: 597-604.

Mortelmans KE, Griffin AF (1981): Microbial mutagenesis testing of substance: Compound report F76-037, silica-silicon G-910 SCM Glidden Pigments, lot \# 14-J-2, CAS \# 7631869. SRI international, Menlo Park.

Murphy TD, Henderson GV (1983): Sillica and Silicon. In Lefond SJ (edl): "Industrial Minerals and Rocks (non-metallics other than fuels)". New York: Society of Mining Engineers, pp 1167-1185.

Niemeier RW, Mulligan LT, Rowland J (1986): Cocarcinogenicity of foundry silica sand in hamsters. In Goldsmith DF, Winn DM, Shy CM (eds): "Silica, Silicosis and Cancer. Controversy in Occupational Medicine". Cancer Research Monographs, vol "2, New York: Praeger, pp 215-227.

Pearce $\mathrm{N}$, Checkoway $\mathrm{H}_{4}$ Dement J (1989): Design and Conduct of Occupational Epidemiology

Studies: IV. The Analysis of Case-Control Data. Am J Ind Med 15: 403-416.

Price-Jones MJ, Gubbings G, Chamberlain M (1980): The genetic effects of crocidolite asbestos; comparison of chromosome abnormalities and sister-chromatid exchanges. Mutat Res 79: 331-336.

Puntoni R, Vercelli M, Bonassi S, Valerio F, Di Giorgio F, Ceppi M, Stagnaro E, Filiberti R, Santi L (1985): Prospective study of the mortality in workers exposed to silica (Ital.). In Deutsch El, Marcato A (eds): "Silice, Silicosi e Cancro". Padua, University of Padua, pp 79-92. 
Rockette HE (1977): Cause specific mortality of coal miners. J Occup Med 19: 795-801.

Saffioti U (1986): The pathology induced in relation to fibrogenesis and carcinogenesis. In Goldsmith DF, Winn DM, Shy CM (eds)" Silica, Silicosis and Cancer. Controversy in Occupational Medicine" . Cancer Research Monographs, vol. 2, New York: Praeger, pp $287-307$.

Schllesselman JJ (1974): Sample size requirements in cohort and case-control studies of disease. Am Ji Epidemiol 99: $381-384$.

Schlesseliman JJ (1982): Case control studies. Design, conduct, analysis. New York, Oxford Universily Press.

Siemiatycki J, Wacholder $S$, Dewar R, Cardis E, Greenwood C, Richardson L (1988): Degree of confounding bias related to smoking, ethnic group and socioeconomic status in estimates of the associations between occupation and cancer. J Occup Med 30: 617-625.

Swaen GMH, Passier PECA, Attekum van AMNG (1988): Prevalence of silicosis in the Dutch fine-ceramic industry. Int Arch Occup Environ Health 60: 71-74.

Thomas $\mathrm{T}$ (1982): A preliminary investigation of mortality among workers in the pottery industry. Int J Epidemiol 11: 175-180.

Thomas TL, Stewart PA (1987): Mortality from lung cancer and respiratory disease among pottery workers exposed to silica and talc. Am J Epidemiol 125:" 35-43.

Valk de JHCM (1981): Het silicose-onderzoek in de fijnkeramische industrie. T Soc Geneesk 59: 790-794.

Vanchugova NN, Frash VN, Kogan FM (1985): The use of a micronuclear test as a short-term method in detecting potential blastomogenicity of asbestos-containing and other mineral fibers. Gig Tr Prof Zabol 6: 45-48.

Wagner MMF, Wagner JC, Davies R, Griffiths DM (1980): Silica-induced malignant histiocytic lymphoma: Incidence linked with strain of rat and type of silica. Br J Cancer 41 : 908-917.

Westerholm P, Ahlmark A, Maasing R, Segelberg 1 (1986): Silicosis and risk of lung cancer or lung tuberculosis: A cohort study. Environ Res 41: 339-350. 


\section{CHAPTER 7}

\section{Cancer morbidity in coal miners in the Netherlands:}

A feasibility study

J.M.M. Meijers ${ }^{1}$, G.M.H. Swaen ${ }^{1}$, L.J. Schouten ${ }^{3}$, J.J.M. Slangen ${ }^{1}$, E. F. Sturmans ${ }^{2}$

${ }^{1}$ Department of Occupational and Environmental Health and Toxicology,

${ }^{2}$ Department of Epidemiology, University of Limburg, Maastricht, the Netherlands.

${ }^{3}$ IKL-Cancer Registry, Comprehensive Cancer Centre Limburg, Maastricht, the Netherlands.

Submitted for publication.

\section{ABSTRACT}

In this paper cancer morbidity patterns in a group of Dutch coal miners are reported. 3,798 Dutch miners with and without coal workers' pneumoconiosis (CWP) were selected based on medical examinations between 1952 and 1962. A linkage was carried out between 1985 and 1990 with the newly existing regional cancer registry. The linkage resulted in 121 tumors in 110 persons. Proportional incidence ratios (PIRs) for the total cohort and selected sub-cohorts did not provide statistically significant outcomes. The overall stomach cancer PIR was not increased (PIR: 92), but amounted to 142 for miners with progressive massive fibrosis. Lung cancer incidences in the total group and sub-cohorts were lower than expected. The study outcomes are discussed in the light of the limitations of the study design. 
Several million people are at present employed throughout the world in the extraction of coal [WHO, 1986]. Consequently this number of workers is potentially exposed to the harmful effects of coal mine dusts. The most important health effect associated with the inhalation of these dusts is coal workers pneumoconiosis (CWP), pathologically characterized by many small discrete foci or aggregations of dust, known as coal macules.

Questions have been raised about the potential carcinogenic properties of coal mine dust. Miners with coal workers" pneumoconiosis in a previous study were not at an increased risk of developing bronchogenic carcinoma [Meijers et al, 1988]. Nevertheless, there is evidence suggesting that coal miners have an increased risk of developing gastric cancer. Epidemiological studies in the United States and the United Kingdom have repeatedly reported a relation between prolonged exposure to coal mine dust and gastric cancer [Ames and Gamble, 1983; Miller and Jacobsen, 1985]. But this finding has not been universal. A recent case-control study in a city with high death rates from gastric cancer found a weak, statistically not significant relation with coal mining [Coggon et al, 1990]. It has been suggested that other factors, such as socio-economic status and the diet, are in particular determinants of the gastric cancer risk.

A pilot retrospective cohort study in Dutch miners with CWP reported a statistically significant fourfold excess of gastric and small intestine cancer mortality [Meijers et al, 1990]. Jacobsen [1976] reported a positive correlation between the grade of CWP and gastric cancer. There is a toxicological rational for the carcinogenicity of coal mine dust. Coal mine dust is a mixture of many potential or suspected carcinogens [Falk and Jurgelski, 1979]. Swallowed coal dust generates compounds in the stomach which have mutagenic activity [Whong et al, 1983].

A vivid coal mining industry with 11 mines existed in the middle of this century in South-Limburg, the most southern part of the Netherlands. All the mines were closed before 1975 since they could no longer be operated profitably. The work histories and medical records of many coal miners are still available which creates the possibility to study their cancer morbidity patterns.

Since 1982 the IKL cancer registry is operating in the region in which the coal mines were located. The registry obtains information about tumor data from all hospitals in the area. There is a presumably complete coverage since 1986 [Van den Brandt et al, 1990]. A cohort of underground coal miners with a long working history was selected and linked to the IKL-registry, in order to 
investigate the feasibility of occupational cancer research using cancer regis tries in the Netherlands, and to analyze the cancer morbidity patterns in this group of workers.

\section{MATERIAL AND METHODS}

\section{Study population}

The initial study population consisted of all underground miners who worked in the 11 Dutch coal mines between 1952 and 1962. All the miners who were expected to retire within a few years, and the miners who complained of airway diseases were invited for a medical examination in this same period. One of the purposes of the examination was to evaluate whether a miner was eligible for a disability pension because of pneumoconiosis due to the inhalation of coal mine dust. In total 3,798 Dutch miners were systematically medical examined, with detailed information about their working history in the coal mines, previous diseases and health status. Also physical examinations, lung function tests and $\mathrm{X}$-ray examinations were performed and documented. The CWP was not classified according to the corresponding 1950 ILO-classification, but was categorized by skilled pulmonologists as non-existing, simple pneumoconiosis or progressive massive fibrosis (PMF) as a result of the presence on the lung roentgenogram of (micro)modulations or confluent opacities and massive tumors, respectively. For a part of the population the smoking status was available. The medical files of the selected group were kept by the occupational health service of the Dutch State Mines (NV Staatsmijnen) and available for scientific purposes. The researches computerized the family name and christian name, the underground years of employment, grade of CWP and smoking history for every Dutch miner. Table I shows some characteristics of the study group. The majority of the miners were 50 years or older at the time of diagnosis. More than $50 \%$ had 30 or more underground employment years. Simple pneumoconiosis predominated in the cohort. Information on smoking habits was available for 1,465 persons, only $7.2 \%$ was non-smoker. 
Table 1. Characteristics of the 3,798 Coal Miners.

N

Age al diagnosis

$$
\begin{array}{r}
<40 \\
40-49 \\
50-59 \\
60-69 \\
\geq 70
\end{array}
$$

Total underground years

$$
<10
$$

of employment

$$
\begin{array}{r}
10-19 \\
20-29 \\
30-39 \\
\geq 40
\end{array}
$$

CWP classification

None

Simple pneumoconiosis

Progressive massive fibrosis

Smoking history

Non-smokers

\section{Determination of cancer diagnosis}

From 1985 onwards the IKL cancer registry was investigated in order to determine the cancer cases in the miners cohort. The IKL abstracts tumor data from pathology reports and medical records of persons living in the region where the registry is operating, and codes them according to the ICD-oncology. The birthdate, sex and the first 4 characters of the family names of the miners were used for the computerized record linkage between the miners cohort and the cancer registry. Doubtful computer matches were analyzed further by visual inspection in order to accept only existing correct matches between the 2 data files (procedure described by Van den Brandt et al, 1990). Tumor classifications were given according to the 9 th revision of the ICD. 


\section{Statistical analyses}

Proportional cancer incidence ratios (PIRs) were computed based on observed and expected numbers per tumor category as described by Monson [1980]. Expected numbers per tumor site were computed based on the IKL cancer incidences in the period 1986-1988 for males 60 years and older. 95\% Twosided confidence limits were calculated as proposed by Breslow and Day [1987].

\section{RESULTS}

The initial linkage of the $3,798 \mathrm{coal}$ miners with the IKL files yielded in 128 identified persons with a cancer diagnosis. The IKL registered 140 tumors in total within these persons. 19 Tumors were not accepted because they occurred before 1985, the diagnosis was basal cell carcinoma of the skin or a non-malignant tumor. This resulted in 121 malignant tumors in 110 persons.

Proportional incidence ratios (PIRs) for the total cohort and per CWP-category are shown in Table II. For none of the cancer diagnoses a statistically significant PIR emerged. The overall stomach cancer incidence was not increased (PIR: 92), nor for the groups without lung fibrosis and with simple CWP. The stomach cancer PIR for miners with PMF amounted to 142 . In total 27 lung cancer cases occurred. The lung cancer incidence was lower than expected for the total cohort and the three subgroups, with a very low PIR of 34 in the miners with PMF. For skin cancer and cancer of the bladder and urinary organs, observed cases for the total coal miners cohort and the three subgroups were all higher than expected. For the other tumor categories no specific pattern occurred.

Further analyses based on duration of employment did not give evidence for a relation between the cumulative years of underground employment, as a surrogate for coal mine dust exposure, and increases in specific cancer types.

\section{DISCUSSION}

This is the first reported study in the Netherlands, in which occupationally exposed cohorts are linked to cancer registry files. The results show that it is now possible to carry out this type of cancer morbidity studies in the Netherlands. 


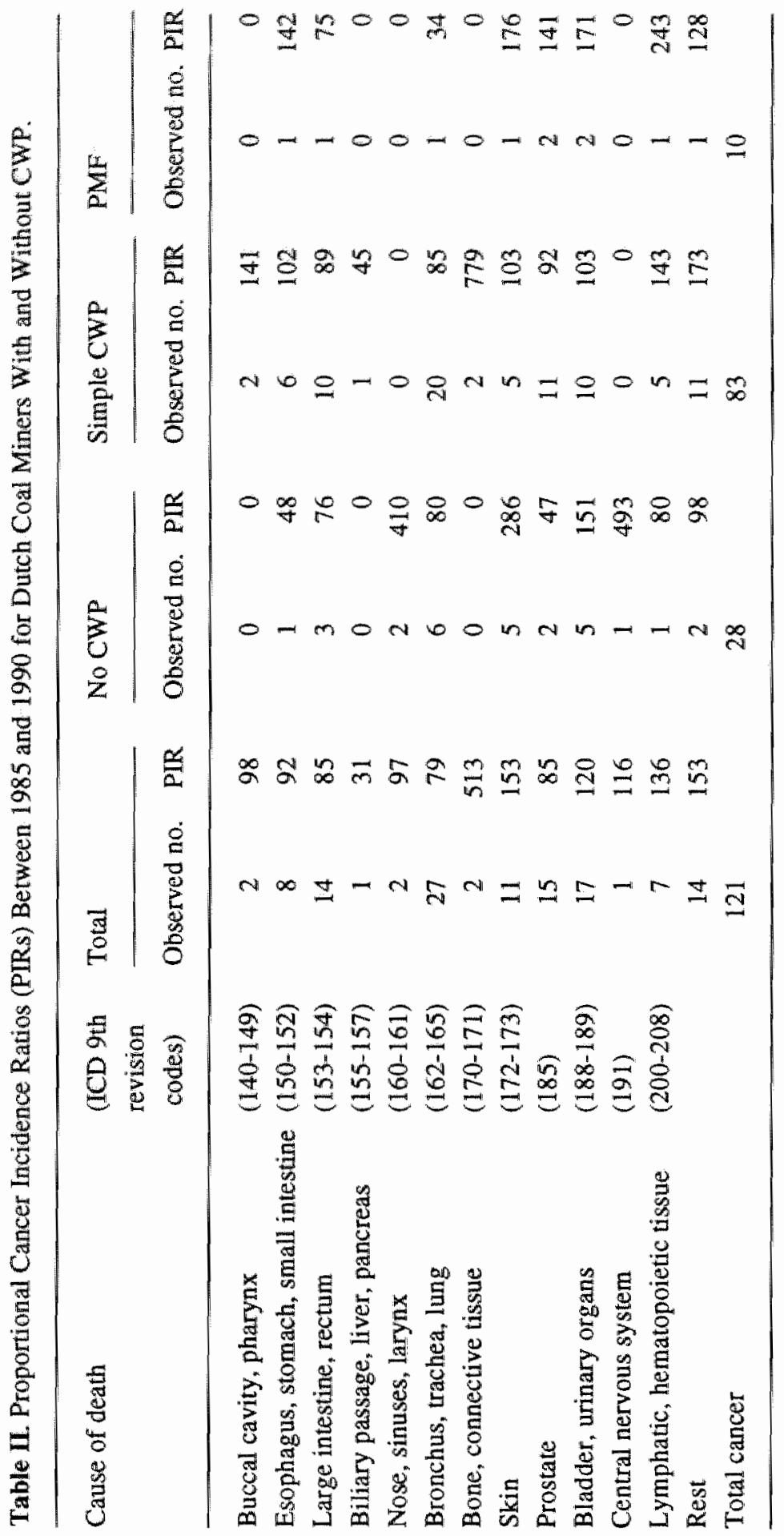


The outcomes, however, are somewhat in contrast with earlier findings in the United Kingdom and the United States. Opposive to the results of a cohort study in miners with CWP reported by Meijers et al [1990], no excess stomach and small intestine cancer risk revealed in miners with and without CWP. Several factors have to be taken into account in this respect. First of all the observed numbers for the different cancer types in the cohort are relatively small, which creates the possibility of a considerable influence of statistical chance. Secondly, the coal miners cohort is a specially selected group with a long occupational history, emphasis on the older ages and not an exact reflection of the total Dutch miners population. Nevertheless, it is not to be expected that selection has seriously distorted any existing cancer risk.

Furthermore, the linkage with the cancer registry was only established in the period between 1985 and 1990, whereas the miners were selected between 1952 and 1962. They had already experienced a considerable underground coal mine dust exposure at that time. It is possible that a significant increased stomach cancer morbidity has disappeared prior to 1985 in this group. Nonetheless, this hypothesis cannot be tested, because cancer registries were only recently established in the Netherlands. The results from a Dutch case-control study based on stomach cancers identified by pathology departments between 1973 and 1983 also did not confirm a relation between increased gastric cancer risks and coal mining [Swaen et al, 1987].

At the moment, a retrospective cohort study is carried out for the $3,798 \mathrm{coal}$ miners, taking into consideration the mortality between the moment of selection and 1989. This study will produce new and supplementary information about the stomach risk in coal miners and the moment of appearance.

The lung cancer risk is lower than expected in this cohort, which is in accordance with the outcomes of large cohort studies in the United Kingdom and the United States. In fact, the lung cancer risk decreases with an increasing grade of coal workers' pneumoconiosis. It could be possible that Dutch miners with a very serious lung fibrosis die before they may develop lung cancer.

Although it may be concluded that the cancer registries in the Netherlands are established too late to create considerable insight in cancer risks for occupational groups exposed long ago, it can be expected that their usefullness in occupational cancer studies will become more evident in the future. 


\section{ACKNOWLEDGMENTS}

The authors wish to thank the Central Archives and Occupational Health Services of DSM for participating in the study and the IKL Comprehensive Cancer Centre Limburg for providing the cancer data.

\section{REFERENCES}

Ames RG, Gamble JF (1983): Lung cancer, stomach cancer and smoking status among coal miners. A preliminary test of a hypothesis. Scand J Work Environ Health 9: 443-448.

Brandt van den P, Schouten LJ, Goldbohm RA, Dorant E, Hunen PMH (1990): Development of a record linkage protocol for use in the Dutch cancer registry for epidemiological research. Int J Epidemiol 19: 553-558.

Breslow NE, Day NE (1987): "Statistical Methods in Cancer Research. Vol. II. The Design and Analysis of Cohort Studies". Lyon: IARC, Sci Publ no. 82.

Coggon D, Parker DJP, Cole RB (1990): Stomach cancer and work in dusty industries. Br J Ind Med 47: 298-301.

Falk HL, Jurgelski W (1979): Health effects of coal mining and combustion: Carcinogens and cofactors. Environ Health Persp 33: 203-226.

Jacobsen $M$ (1976): Dust exposures, lung diseases and coal miners' mortality. PhD Thesis, Scotland: University of Edinburgh.

Meijers IMM, Swaen GMH, Slangen JJM, Vliet van C (1988): Lung cancer among Dutch coal miners: A case-control study. Am J Ind Med 14: 597-604.

Meijers JMM, Swaen GMH, Slangen JJM, Vliet van C, Sturmans F (1990): Long-term mortality in miners with coal workers' pneumoconiosis in the Netherlands: A pilot study. Am J Ind Med: in press.

Miller BG, Jacobsen M (1985): Dust exposure, pneumoconiosis and mortality of coal miners. Br J Ind Med 42: 723-733.

Monson RR (1980): "Occupational epidemiology". Florida, CRC Press.

Swaen GMH, Aerdts CWHM, Slangen JJM (1987): Gastric cancer in coal miners: Final report. $\mathrm{Br}$ J Ind Med 44: 777-779.

Whong WZ, Long R, Ames RG, Ong TM (1983): Role of nitrosation of the mutagenic activity of coal dust: A postulation for gastric carcinogenesis in coal miners. Environ Res 32: 298-304.

World Health Organization (1986): "Recommended health-based limits in occupational exposure to selected mineral dusts (silica, coal)". Report of a WHO-study Group. Geneva: Technical Report. Series 734. 


\title{
CHAPTER 8
}

\section{Epidemiological studies of inorganic dust-related lung diseases in the Netherlands}

\author{
J.M.M. Meijers, G.M.H. Swaen, K. van Vliet, P.J.A. Borm
}

Department of Occupational and Environmental Health and Toxicology, University of Limburg, Maastricht, the Netherlands.

Published in Experimental Lung Research 1990; 16: 15-23.

\section{ABSTRACT}

The results of two epidemiological investigations on dust-related lung diseases are presented. The two studies had different aims and designs.

A cross-sectional study was done to investigate the silicosis prevalence in Dutch fine ceramic workers. In the small ceramic workshops in the Gouda region, simple pneumoconiosis is still commonly present $(13.3 \%)$, whereas the silicosis prevalence in the highly mechanized industries is very low $(1.7 \%)$. Furthermore, heavy smoking seems to enhance the risk for silicosis after longterm exposure to quartz.

A case-control study was performed to analyze the relation between dust exposure in the fine ceramic and coal mining industries and lung cancer. No relation between a work history in the dusty trades and lung cancer emerged, and a correlation with a specific histologic tumor cell type could not be demonstrated. Apparently, workers in the Dutch fine ceramic or coal mining industry have no increased risk of developing lung malignancies. 


\section{INTRODUCTION}

Currently, the Netherlands is a modern, postindustrialized country in which many people are working in the chemical and high-technological industries as well as the service, administrative and educational sectors. At the beginning of this century, however, tens of thousands workers were employed in industries in which the occupational exposure to respirable dust was a major industrial hy gienic problem. Especially in the foundry and blast furnace trades, the fine ceramic and coal mining industries, many workers contracted airborne dust-related diseases.

Because of the presence of secondary clay deposits along the main Dutch rivers the country has a long history relating to the ceramic industry, which is concentrated in the Gouda and Maastricht districts. The prevalence of silicosis in the ceramic industry resulting from exposure to dust containing crystalline silica (quartz) was investigated in the 1950 s by Gerritsen [1955]. Among workers who had worked for 10 years or more in divisions with high respirable silica dust concentrations, silicosis was seen in $36.3 \%$ on radiological examination. Occupational hygienic measures and technical innovations of production processes in the 1960 s led to a strong decrease in the airborne quartz concentrations. Because information was lacking about the prevalence of silicosis in the modern Dutch ceramic industries, the Labour Inspectorate conducted a nationwide health survey among ceramic workers in the 1970 s to determine whether or not a pneumoconiosis risk still exists for the workers. The results of this study are presented here.

The International Agency for Research on Cancer (IARC) has classified crystalline silica (e.g. quartz) as a probably carcinogenic substance [IARC, 1987]. Animal experimental data have suggested an increased tumor incidence in several rat strains exposed to quartz [Johnson et al, 1987]. In a recent study an increase in lung cancer emerged after chronical exposure of F-344 rats to 1.0 $\mathrm{mg} / \mathrm{m}^{3} \alpha$-quartz [Muhle et al, 1989]. Elevated rates of lung cancer have been observed in a wide range of workers exposed to quartz, such as ore miners, foundry workers, stone cutters, and granite workers [Goldsmith et al, 1982]. Most occupational studies in the ceramic and pottery industry have shown an approximately twofold increase in the lung cancer risk among these workers [IARC, 1987]. This uniformity is striking because crystalline silica dust is usually considered to be the only serious exposure component in these industries; concomitant exposures to various known carcinogens are minimal or nonexistent [Forastiere et al, 1986]. 
Epidemiological investigations involving coal miners have mainly shown appreciable lower than expected rates of lung cancer [Meijers et al, 1988], although coal mine dust contains both quartz and various potentially carcinogenic organic compounds such as benzo(a)pyrene, chrysene and benzo(a)anthracene derivates and some inorganic carcinogens (mostly trace metals such as cadmium, chromium and nickel in various concentrations) [Falk and Jurgelski, 1979].

From 1902 until 1974 a coal mining industry existed in the southern part of the Netherlands, which employed almost 20,000 underground miners in eleven mines in the late 1950s [Messing, 1988]. In a cross-sectional study, 27\% of all underground workers showed anthracosilicotic lesions on $\mathrm{X}$-ray examinations, partly as a result of the high concentration of quartz in the coal dust [Hendriks, 1961. ]. After occupational hygiene measures were instituted in successive years, the coal workers' pneumoconiosis (CWP) prevalence dropped rapidly.

To address the relation between the dust exposure in the Dutch fine ceramic and coal mining industries and the relative risk for workers to develop lung cancer, we decided to conduct a case-control study. Because of the geographical concentration of both fine ceramic industries and former coal mines in the Maastricht region in the southern part of the Netherlands, this region was regarded as suitable for a hospital based study.

\section{METHODS}

The purpose of the Dutch Labour Inspectorate study was to determine the prevalence of silicosis in quartz-exposed workers in the ceramic industries. For this reason the study had a cross-sectional design [Valk, 1981]. The first phase of the survey was restricted to ceramic companies in the geographic area of Gouda, in which small, unmechanized ceramic shops prevail. In this area 520 ceramic workers from 76 companies were medically examined. In the second phase the study was expanded to two large, mechanized fine ceramic companies in Maastricht, where 1,975 workers were surveyed, and other small ceramic industries scattered over the country. In Maastricht there is a complex division of labor, which is necessary for the production of earthenware, tiles and sanitary ware.

The medical examinations consisted of an $8 \times 8 \mathrm{~cm}$ roentgenogram and a questionnaire to collect information about job history, pulmonary symptoms, and current smoking habits. The roentgenograms were interpreted by a specially formed panel of experts, according to the International Labour Office 
(LO) International Classification of Radiographs of Pneumoconioses (1971). If a suspected case of silicosis was found by the panel, a larger radiograph was made and evaluated according to the ILO classification.

The question of the relationship between dust exposure and lung cancer deals not with the description of the amount of a certain health risk but with the possible origin of that risk. Therefore an analytical, longitudinal and hospitalbased case-control design was chosen. From the registers of the pathology department of the only general hospital in the town, all men with histologically confirmed primary lung cancer between 1972 and 1988 were selected. This resulted in 381 lung cancer cases. For each case one control person was selected from the same registers, matched by gender, year of birth, and year of diagnosis plus or minus 1 year. Controls were chosen regardless of their diagnosis except for having primary lung malignancies. Information about employment in the ceramic industry was obtained by checking the files of the personnel and salary administration of the two companies for all 762 patients enrolled in the study in a standard, blind manner. Detailled information was abstracted from the records about job titles and employment period. A panel of occupational hygienists labeled each detected ceramic worker blindly, on the basis of the job title with a qualitative quartz- exposure qualification (high, moderate or low exposure). In the same way information about past employment in the coal mines was obtained from the General Mining Fund, a collaborative pension fund for all coal miners. This fund keeps accurate records with a complete occupational history for each person who ever worked in the Dutch coal mines.

In the analyses of the collected data, odds ratios and 95\% two-sided confidence limits were calculated according to the Mantel-Haenszel method for matched pairs [Schlesselman, 1982]. The odds ratio approximates the risk ratio for a disease in the exposed population.

\section{RESULTS}

Table I presents the silicosis prevalence in the 2,495 workers from Gouda and Maastricht. In total 102 workers were diagnosed as cases of silicosis [Swaen et al, 1988]. Of the workers in Gouda, $13.3 \%$ had silicosis; $1.7 \%$ of the workers in the Maastricht industries had silicosis. No cases of progressive massive fibrosis were observed. The prevalence of silicosis was strongly associated with the duration of exposure to quartz-containing airborne dust. After workers in the two areas who had been exposed less than 10 years were combined, the prevallence was $0.2 \%$. On the other hand, the prevalence was as high as $19.9 \%$ in those workers who had been exposed for 30 years or more (Table I). It is 
Table I. Prevalence of Silicosis in 520 Workers in Small Fine-Ceramic Workshops in Gouda. and 1,975 Workers in Two Large Mechanized Companies in Mastricht; by Duration of Exposure to Quartz-Containing Dust.*

\begin{tabular}{|c|c|c|c|c|c|c|}
\hline \multirow{2}{*}{$\begin{array}{l}\text { Duration } \\
\text { exposure } \\
\text { (years) }\end{array}$} & \multicolumn{3}{|c|}{ Gouda } & \multicolumn{3}{|c|}{ Maastricht } \\
\hline & $\begin{array}{l}\text { Number of } \\
\text { workers }\end{array}$ & $\begin{array}{l}\text { Number of } \\
\text { silicotics }\end{array}$ & $\begin{array}{c}\text { Prevalence } \\
(\%)\end{array}$ & $\begin{array}{l}\text { Number of } \\
\text { workers }\end{array}$ & $\begin{array}{l}\text { Number of } \\
\text { silicotics }\end{array}$ & $\begin{array}{c}\text { Prevalence } \\
\qquad(\%)\end{array}$ \\
\hline$\leq 3$ & 103 & $\mathbb{1}$ & 1.0 & 552 & 0 & 0.0 \\
\hline $4-9$ & 118 & 2 & 1.7 & 484 & 0 & 0.0 \\
\hline $10-19$ & 82 & $\mathbb{1 1}$ & 13.4 & 426 & 2 & 0.5 \\
\hline $20-24$ & 58 & 9 & 15.5 & 197 & 4 & 2.0 \\
\hline $25-29$ & 66 & 18 & 27.3 & 178 & 9 & 5.1 \\
\hline$\geq 30$ & 93 & 28 & 30.1 & 138 & 18 & 13.0 \\
\hline Total & 520 & 69 & 13.3 & 1,975 & 33 & 1.7 \\
\hline
\end{tabular}

* With permission from Int Arch Occup Environ Health.

evident that silicosis is still commonly present in the smaller fine ceramic workshops located in the area of Gouda and is comparatively rare in the two large companies in Maastricht. The difference cannot be attributed to a higher proportion of nonproduction workers in the large companies or to a longer average duration of exposure in Gouda, because the prevalence rates remain different in the various duration of exposure categories (Table I).

One of the effects of smoking on the respiratory system is the gradual replacement of ciliated epithelium by squamous epithelium in the bronchial tree, which reduces the pulmonary clearance mechanism and may enhance the risk of silicosis after long-term exposure to respirable quartz. If smoking increases the risk of silicosis after exposure to quartz-containing dust; the workers with silicosis should be heavier smokers than without silicosis. For all 3,258 workers enrolled in the survey (Gouda, Maastricht and other industries), data were collected on their smoking habits. The differences were small. $68.9 \%$ were smokers compared to $64.5 \%$ of those without silicosis. The prevalence of silicosis was calculated for different categories of smoking habits and exposure durations (Table II). The differences in sillicosis prevalence among non-smokers, light smokers and heavy smokers exposed for less then 20 years were marginal. In the long-exposure group, however, the prevalence of silicosis increased with increasing smoking habits. The p-value of the difference in 
Table I. Prevalence of Silicosig in 3,258 Workers in the Dutch Fine-Ceramic Industry, by Duration of Exposure to Quartz-Containing Dust and Smoking Habits.*

Smoking habits

Duration of exposure

\begin{tabular}{llllll}
$0-9$ & $\begin{array}{l}10-19 \\
\text { years }\end{array}$ & $\frac{19}{\text { years }}$ & year & $\begin{array}{l}\text { Total number } \\
\text { of workers }\end{array}$ \\
\hline
\end{tabular}

Non-smokers

$\begin{array}{llllll}3 & 0.5 & 9 & 3.2 & 38 & 10.1\end{array}$

1,247

Light smokers

(fewer than 20 cigarettes per day)

20.3

$7 \quad 3.0$

$38 \quad 11.0$

1,295

Heavy smokers

(20 or more cigarettes per day)

10.3

21.3

$35 \quad 15.0$

716

Total number of workers

1,644

622

952

3,258

* With permission from Int Arch Occup Environ Health.

prevalence of silicosis between non-smokers and heavy smokers was of borderline statistical significance $(p=0.06)$ and became statistically significant if the heavy smokers were compared to the non-smokers and light smokers combined.

As for the hospital-based case-control study, $152(20 \%)$ of the total study group of 762 men had worked for some time in the fine ceramic industry. As can be seen from Table III, an odds ratio of 1.11 was calculated for the risk of lung cancer among workers ever employed in the ceramic industry regardless of the duration of employment or the relative silica exposure. Persons who only worked for a short period (less than 1 year) were overrepresented in the control group (non-lung cancer patients) (37.5\% compared to $22.1 \%$ ). The average employment period for lung cancer cases amounted to 117 months compared with 76 months for controls. More cases than controls were ever exposed to high airborne silica concentrations (respectively $46.9 \%$ compared to $34.3 \%$ ). Odds ratios based on differences in duration of employment and exposure level did not reach statistical significance, however (Table III). After an extensive 
Table II. Odds Ratios for Lung Cancer among Workers in the Fine-Ceramic and Coal Mining Industries Based on Matched Pairs for Selected Exposure Differences.

Exposure situation

Number exposed Odds Confidence controls ratios* limits $(95 \%)$

\section{Fine Ceramic Industry}

Ever employed compared to never employed

Long ( $>3 \mathrm{yr}$ ) compared to short $(<3 \mathrm{yr}$ ) employment

High compared to low exposure level

High and long exposure compared to all others

22

1.62

$0.94-2.29$

\section{Coal Mining Industry}

Ever employed compared to never employed

*The odds ratio approximates the risk for lung cancer in the former group compared with the latter.

silica exposure classification based on moderate or high quartz exposure during at least 3 years was constructed, the odds ratios for lung cancer amounted to 1.62 (not statistically significant) (Table III).

There were 155 ex-coal miners $(20.4 \%)$ in the total study group. The calculated odds ratio for the risk of lung cancer was not increased for all mine employees regardless of specific occupations (Table III). When the analyses were restricted to the men with a history of underground mining and thus a considerable level of coal dust exposure, the odds ratio was 0.96 (Table III). The duration of underground mining did not differ substantially between cases and controls: The average employement period for cases was 117 months, compared with 108 months for controls.

Investigators have pointed to an increased occurence of specific lung tumors in certain occupational exposure groups [Wegman and Peters, 1978]. To investigate this possibility, odds ratios for selected lung tumor cell types were calculated for the fine ceramic and coal mining industry (Table IV). As can be seen, no convincing relation between a certain tumor cell type and a work history in the fine ceramic industry or coal mining could be demonstrated. 
Table IV. Lung Cancer among Workers in the Fine-Ceramic and Coal Mining Industries. Odds Ratios per Lung Tumor Cell Type.

Tumor cell type

Odds ratios:

Confidence limits

Fine Ceramic Industry (ceramic workers compared to all other occupations)

Squamous cell carcinoma

1.13

$0.70-1.82$

Adenocarcinoma

1.13

$0.43-2.92$

Small cell carcinoma

1.25

$0.49-3.17$

Coal Mining Industry (underground miners compared to all other occupations)
Squamous cell carcinoma
1.06
$0.55-2.06$
Adenocarcinoma
1.66
$0.40-6.95$
Small cell carcinoma
0.67
$0.11-4.0$

\section{DISCUSSION}

Results were presented concerning the prevalence of silicosis in the modern Dutch fine ceramic industries. In conclusion, evidence was found that silicosis is still commonly present in the smaller fine ceramic workshops in the Gouda region, whereas it is much less prevalent in the two industries in Maastricht. Although the silicosis manifestation is restricted to simple pneumoconiotic lesions, the occupational physician should be aware of the still existing risk for workers in the fine ceramic workshops. It is not at all clear how these differences can be explained. Perhaps protective measures and expert medical surveillance are less well established in the small-scale workshops in Gouda.

Another interesting result of the analyses was that heavy smoking seems to favor the clinical manifestation of silicosis after 20 years' exposure to quartzcontaining dust or more.

From the described case-control study, no elevated risk of lung cancer emerged in workers occupationally exposed to respirable silica or coal mine dust in the Netherlands. Also, no clear dose-response relation or correlation with a specific histologic tumor cell type could be demonstrated. The group of fine ceramic workers with the highest and longest exposure, however, experienced an increased but non-significant lung cancer risk. Nevertheless, there are a few methodological flaws. Selection bias may have occurred because both cases and controls were collected from the register of a pathologic institute. To account for this bias we investigated whether there were differences in home 
address between cases and controls and whether there appeared to be differences in disease classifications between controls with and without a work history in dusty trades. This proved not to be the case. Therefore serious selection bias seemed not to have influenced the outcomes. No exact measurements of respirable dust concentrations were available, however it is likely that the exposure estimates by the occupational hygienist panels provide a sound qualitative basis for the dust levels especially in the ceramic industry. Only if ceramic workers and coal miners in general smoke appreciably less than other persons would standardisation for smoking lead to positive results. At the moment there is no evidence for a different smoking pattern in these trades compared with the general population.

The outcomes for the coal miners are in line with the results of many other investigations, in which no elevated lung cancer risk emerged. The results for the ceramic industry differ strongly from earlier results, however. It is difficult to interpret the various contradictory outcomes. It is possible that dust levels were too low in the Maastricht fine ceramic industries to detect an increased lung cancer risk. Nevertheless, we know that many workers in the period prior to the occupational hygienic changes contracted pneumoconiosis. There may be other confounding factors in the work environment that enhance the lung cancer risk but were not then present in the Dutch fine ceramic industries. Investigators mentioned the influence of polycyclic aromatic hydrocarbons and talc, which contains asbestos, in this regard but these substances did not contaminate the workplaces in this study. It is important to know whether respirable silica is directly related to lung malignancies. It is possible that it is an initiating agent or a promotor that only exerts its malignant effect when combined with other toxic substances. These questions cannot be easily answered with an epidemiological design.

The relation between the chemical and surface characteristics of airborne particles and lung disorders is an important field of study. It is also of vital importance to pay attention to the pathophysiological mechanism of dust-induced lung fibrosis and its relation to lung cancer. Some investigators have suggested that silicosis is an essential step in the development of lung cancer due to silica. This hypothesis could not be tested in this case-control study. New investigations in the Dutch industries will concentrate on the possible relation between pneumoconiosis and lung cancer. At the moment a historical cohort study of the mortality characteristics for workers with and without silicosis in the Dutch fine ceramic industry is being carried out. Smoking differences and exposure variations will be taken into account. Another retrospective cohort study will draw attention to the mortality outcomes of several thousand coal miners with and without CWP who were diagnosed in the late $1950 \mathrm{~s}$, of whom 
more than $50 \%$ have already died. With these studies we hope to contribute to the ongoing discussion of whether or not crystalline silica and coal mine dust are carcinogenic substances.

\section{ACKNOWLEDGMENTS}

The authors thank the staff of the pathology department of the Academical Hospital in Maastricht, the Dutch Labour Inspectorate, the staff of the AZL Heerlen and the managers and salary administration staffs of the two ceramic industries in Maastricht for their collaboration during the studies.

\section{REFERENCES}

Falk HL, Jurgelski W (1979): Health effects of coal mining and combustion: Carcinogens and cofactors. Env H Persp 33: 203-226.

Forastiere F, Lagorio S, Michelozzi P, Cavariani F, Arca M, Borgia P, Penucci C, Axelson O (1986): Silica, silicosis and lung cancer among ceramic workers: A case-referent study. Am $\mathrm{J}$ Ind Med 10: 363-370.

Gerritsen WB (1955): Silicose in de aardewerk- en porcelein industrie. De veiligheid: 245-250.

Goldsmith DF, Guidotti TL, Johnston DR (1982): Does occupational exposure to silica cause lung cancer? Am J Ind Med 3: 423-440.

Hendriks CAM (1961): "Silicose en long-TBC bij de arbeiders in de Nederlandse steenkolenmijnen". PhD thesis, University of Utrecht, the Netherlands.

IARC Working Group on the Evaluation of the Carcinogenic Risk of Chemicals to Humans (1987): Silica and some silicates. In: "IARC Monographs on the Evaluation of the Carcinogenic Risk of Chemicals to Humans", Vol. 42, pp 39-143.

Johnson NF, Smith DM, Sebring R, Holland LM (1987): Silica-induced alveolar cell tumors in rats. Am II Ind Med 11: 93-107.

Meijers JMM, Swaen GMH, Slangen JJM, Vliet C van (1988): Lung cancer among Dutch coal miners: A case-control study. Am J Ind Med 14: 597-604.

Messing FAM (1988): "Geschiedenis van de mijnsluiting in Limburg". Leiden: Martinus Nijhoff, pp 53-96.

Muhle H, Takenaka S, Mohr U, Dasenbrock C, Mermelstein R (1989): Lung tumor induction upon long-term low-level inhalation of crystalline silica. Am J Ind Med 15: 343-346.

Schlesselman JJ (1982): "Case-control studies. Design, conduct, analysis". New York: Oxford University Press.

Swaen GMH, Passier PECA. Attekum AMNG van (1988): Prevalence of silicosis in the Dutch Fine-ceramic industry. Int Arch Occup Environ Health 60: 71-74.

Valk JHCM (1981): Het silicose onderzoek in de fijnkeramische industrie. T Soc Geneesk: 790-794.

Wegman DH, Peters JM (1978): Oat cell lung cancer in selected occupations. J Occup Med 20: 793-796. 


\section{CHAPTER 9}

\section{Trends and geographical patterns of pleural mesotheliomas in the Netherlands, 1970-1987}

J.M.M. Meijers ${ }^{1}$, H.T. Planteydt ${ }^{3}$, J.J.M. Slangen ${ }^{1}$, G.M.H. Swaen ${ }^{1}$, C. van Vliet $^{1}$, F. Sturmans ${ }^{2}$

${ }^{1}$ Dpt of Occupational and Environmental Health and Toxicology, ${ }^{2}$ Dpt of Epidemiology, University of Limburg, Maastricht, the Netherlands. ${ }^{3}$ Regional Pathological Laboratory Zeeland, Middelburg, the Netherlands.

Published in The British Journal of Industrial Medicine 1990; 47: 775-781.

\section{ABSTRACT}

The sex and age related trends and geographical distribution of asbestos-related mortality from pleural mesothelioma in the Nederlands between 1970 and 1987 are investigated. Deaths from pleural malignancies recorded by the Dutch Central Bureau of Statistiscs (CBS) were used and death rates were age adjusted per year by the indirect method. Standardised mortality ratios (SMR) were computed for 43 regions over the period 1979-1986. For men total mortality increased from 10.8 per million in the period $1970-1978$ to 20.9 per million during $1979-1987$. The highest mortality occurred in the group aged between 65 and 74 with 147.7 per million in 1987. The death rate for the group aged between 55 and 64 was 96.5 per million in 1987. For women, total pleural mesothelioma death rates showed a moderate increase from 2.5 per million in the period 1970- 1978 to 3.6 per million during 1979-1987. The highest mortality occurred in the group aged over 65 , fluctuating around $10-1.5$ per million. For men and women under 45 years mortality was very low and presented no upward trend. 
The geographical distribution over the country showed a pattern with a clear concentration of deaths from mesothelioma deaths for the period 1979-1986 in men, in conurbations with many harbours, shipyards and heavy industry near the rivermouths and along the North Sea coast.

\section{INTRODUCTION}

Since the first report of an association between exposure to asbestos and diffuse pleural mesothelioma [Wagner et al, 1960], there has been a growing interest in the cause and manifestations of malignant mesothelioma (hereafter referred to as mesothelioma). It is now widely accepted that about $80 \%$ of all mesotheliomas are due to asbestos exposure [McDonald, 1985]. The amphibole crocidolite is the main type of asbestos fibre responsible for this tumor. Mesotheliomas appear principally in the pleura, peritoneum and occasionally in the pericardium. The prevalence of mesothelioma of the pleura is about 10 times higher than peritoneal mesothelioma [Churg, 1985]. Mesothelioma appears to have a 30 to 40 year mean latency period and eventually is fatal [Scataridge and Stitik, 1988]. The diagnosis of mesothelioma is often made by evaluating the cytological material from a pleural effusion of the tissue from an open or blind biopsy and most patients survive less than one year after diagnosis.

Although mesothelioma is still a rare tumor, the incidence of the disease has increased dramatically in many industrialized countries. This is because of the increased annual production of asbestos from about 1 million to 5 million tons between 1970 and 1975 [Selikoff and Lee, 1978]. In countries such as the United Kingdom, South-Africa and Australlia a register of mesothelioma was set up to monitor the incidence and distribution of the disease [Jones et al, 1989; Zwi et al, 1989; Ferguson et al, 1987]. In other developed countries national cancer registries and the analyses of death certificates provided information about the variations in incidence of mesothelioma [Andersson and Olsen, 1985; Minder and Vader, 1988, Enterline and Henderson, 1987]. The outcomes of the population based studies from various countries all indicate that the incidence of mesothelioma is still increasing in the western world; mesothelioma is diagnosed much more often in men than in women and a geographical concentration within areas with a higher exposure to asbestos has been observed [Newhouse, 1981].

It was not until the introduction of the 7 th revision of the International Classification of Diseases (ICD) in 1958, that a separate category for pleural malignancies incorporating mesothelioma was introduced. The code 162.2 was reserved for this, but it was also possible to label a pleural mesothelioma in the 
category 163 in this classification ("malignant neoplasms of the lung and pleura, unspecific as to whether primary or secundary"). Starting with the 8 th ICD revision in 1968, all pleural malignant mesotheliomas were to be included under 163.0 and $163(\mathrm{ICD}, 9$ th revision). This category comprised mallignant neoplasms of the pleura, mediastinum and unspecified sites. An analysis of a sample of deaths from this category has shown that about $90 \%$ of deaths in men and $70 \%$ of deaths in women from malignant neoplasms are probably due to pleural mesotheliomas [Gardner et al, 1982]. The other primary pleural tumor is a localized type of mesothelioma which rarely metastasises and is usually curable. As pleural mesotheliomas are fatal, mortality directly reflects incidence and is expected to reflect exposures to aetiological agents after the latency period [Archer and Rom, 1983]. Hence the anallysis of mortality from pleural malignancies has been succesfully used to describe the incidence of mesotheliomas as a consequence of exposure to asbestos in populations [Zwi et al, 1989].

In the Netherlands cause-specific deaths rates are accumulated through the Central Bureau of Statistics (CBS), according to the latest ICD-classification. Trends and geographical patterns of pleural malignancies deaths in the Netherlands, referred to as deaths due to pleural mesothelioma, are presented in this report for the period between 1970-1987. A statutory mesothelioma surveillance program does not exist in the Netherlands. Since 1969, however, an expert mesothelioma panel has invited all pathologists to send it sections of suspected diffuse malignant mesotheliomas on a voluntary basis to the panel in order to register all histologically verified cases of mesothelioma [Planteydt, 1979]. The results of the mesothelioma register are compared with the outcomes of the official national death classifications.

\section{METHODS}

From the Dutch Central Bureau of Statistics (CBS) the absolute numbers of death due to pleural malignancies (ICD-7, 162.2; ICD-8, 163.0; ICD-9, 163) were obtained. The Netherlands are divided in 12 provinces and 43 smaller regions within these provinces. For the period 1970-1978 absolute numbers of deaths were given by sex, age group and province. For the period 1979-1986, numbers of deaths were obtained for each region. For the same years total numbers of inhabitants for each region, sex and age group were obtained. After computerization of the data, death rates for each year, sex and age group were produced. 
To analyze the geographical distribution of the deaths from mesothelioma over the 43 regions in the period 1979-1986, death rates were age adjusted separately for each year for men and women by the indirect method of standardisation. Firstly the Dutch age specific death rates from pleural mesothelioma were applied to the populations of each region for every year to calculate the expected number of mesothelioma deaths. Secondly a standardised mortality ratio (SMR) was calculated and multiplied by the Dutch crude sex specific annual death rates for the 8 year period. Confidence limits were calculated according to the method described by Breslow and Day [1987].

\section{RESULTS}

\section{Mortality by year and age}

Between 1958 and 1987 the crude death rate due to pleural mesotheliomas in the Netherlands has increased from 1.9 per million $(\mathrm{N}=21)$ to 15.8 per million $(\mathrm{N}=232)$. Table I presents the absolute number of deaths due to pleural mesothelioma for men and women in the Netherlands since 1970. The total number of mesotheliomas shows an almost fourfold increase for men from 7.9 per million in 1970 to 28.1 per million in 1987 . For women mortality increased from 2.1 per million to 3.8 per million over the same period. Thus men experienced a much stronger upward trend than women, with a man to woman ratio varying from 3.7: 1 in 1970 to $7.3: 1$ in 1987.

Table II shows the mortality from mesothelioma for the aggregated years $1970-1978$ and 1979-1987. The overall death rates per million for men doubled between the periods. The largest increase occured in the group aged from 65 to 74 , followed by the group aged from 55 to 64 , and the group older than 75 . Mortality in the group aged between 45 and 54 was higher than the average mortality in the two periods, whereas the death rate from mesothelioma for men under 45 years was very low and almost constant over time.

For women overall death rates were much lower than for men and increased only slightly between 1970-1978 and 1979-1987. In agreement with the figures for men, highest mortality occured in the group aged between 65 and 74 , followed by the women older than 75 . In the group under 45 mortality due to mesotheliomas was very rare and reflected the normal background mortality.

Figure I presents trends in mortality for both sexes in the selected groups aged between 1970 and 1987 . The mortality for men aged between 65 and 74 showed a pattern of gradual increase from 50.6 to 147.7 per million. For the other age 
Table I. Number of Deaths From Pleural Mesothelioma in The Netherlands by Year of Death and the Sex of the Decedents.

\begin{tabular}{lccc}
\hline Year of death & Number of men & Number of women & Total \\
\hline 1970 & 52 & 14 & 66 \\
1971 & 64 & 17 & 81 \\
1972 & 66 & 14 & 80 \\
1973 & 67 & 19 & 86 \\
1974 & 78 & 18 & 96 \\
1975 & 67 & 9 & 76 \\
1976 & 81 & 15 & 96 \\
1977 & 96 & 24 & 120 \\
1978 & 118 & 19 & 137 \\
1979 & 110 & 27 & 137 \\
1980 & 145 & 41 & 186 \\
1981 & 127 & 30 & 157 \\
1982 & 147 & 19 & 166 \\
1983 & 158 & 22 & 180 \\
1984 & 180 & 29 & 209 \\
1985 & 157 & 21 & 178 \\
1986 & 166 & 27 & 193 \\
1987 & 204 & 28 & 232 \\
\hline
\end{tabular}

groups mesothellioma mortality was lower and showed a less pronounced growth. Mortality trends for the men aged 55 and 64 increased from 33.6 per million in 1970 to 96.5 per million in 1987. For the group aged between 45 and 54 mortality over the period rarely exceeded 30 per million, and mortality for men younger than 45 was consistently low, varying between 0.22 and 1.19 per million in respectively 1970 and 1987 . In Figure I the mortality experience for the different age groups in women is also shown. Compared with the same age groups in men, death rates for mesothelioma in women were much lower and only sporadically exceeded 20 per million. The highest mortality from mesothelioma occurred in those aged over 65 . The mortality for the two oldest age groups was of the same order of magnitude with only a moderate increase over time from 9-11 per million in 1970 to $14-17$ per million in 1989. In the age groups younger than 65 mortality from mesothelioma did not show an upward 
Table II. Number of Deaths From and Annual Average Death Rates per Million per Pleural Mesothelioma by Age and Sex During 1970 - 1978 and 1979 - 1987 in The Netherlands.

\begin{tabular}{|c|c|c|c|c|c|c|c|c|}
\hline \multirow[b]{3}{*}{ Age } & \multicolumn{4}{|c|}{ Deaths $1970-1978$} & \multicolumn{4}{|c|}{ Deaths $1979-1987$} \\
\hline & \multicolumn{2}{|l|}{ Men } & \multicolumn{2}{|c|}{ Women } & \multicolumn{2}{|l|}{ Men } & \multicolumn{2}{|c|}{ Women } \\
\hline & $\begin{array}{l}\text { No. of } \\
\text { deaths }\end{array}$ & $\begin{array}{l}\text { Rate per } \\
\text { million }\end{array}$ & $\begin{array}{l}\text { No. of } \\
\text { deaths }\end{array}$ & $\begin{array}{l}\text { Rate per } \\
\text { million }\end{array}$ & $\begin{array}{l}\text { No. of } \\
\text { deaths }\end{array}$ & $\begin{array}{l}\text { Rate per } \\
\text { million }\end{array}$ & $\begin{array}{l}\text { No. of } \\
\text { deaths }\end{array}$ & $\begin{array}{l}\text { Rate per } \\
\text { million }\end{array}$ \\
\hline All ages & 680 & 10.75 & 158 & 2.50 & 1394 & 20.90 & 244 & 3.60 \\
\hline$<45$ & 25 & 0.58 & 5 & 0.12 & 36 & 0.80 & 7 & 0.16 \\
\hline $45-54$ & 87 & 13.53 & 18 & 2.70 & 191 & 30.36 & 18 & 2.63 \\
\hline $55-64$ & 205 & 39.40 & 40 & 6.93 & 375 & 64.82 & 54 & 8.51 \\
\hline $65-74$ & 235 & 65.75 & 46 & 10.14 & 469 & 118.93 & 76 & 4.92 \\
\hline$>75$ & 128 & 26.34 & 49 & 9.09 & 323 & 57.01 & 89 & 13.58 \\
\hline
\end{tabular}

trend with time. Mortality for those aged between 55 and 64 varied around 6 per million, for women aged between 45 and 54 from one to 5 per million; and for women aged under 45 years it was below 0.5 per million.

\section{Mortality by region}

Expected numbers of death and standardised mortality ratios (SMRs) were calculated over the aggregated years between 1979 and 1986 for 43 smaller regions scattered over the country. For men, the SMRs for several regions were significantly increased as shown in Table III. The highest SMRs were observed in the midwestern regions. These regions resemble each other in many aspects. The population density is high and the regions are located near river estuaries or along the coast. Several large harbours are located in these regions. A shipbuilding and restoring industry has developed and many other heavy industries, including petrochemical processing, refineries and the production of steel are situated in the midwestern areas. In Rijnmond, where the harbour of Rotterdam is located, an almost threefold increase in mortality from mesothelioma is observed. In IJmond and North Sealand regions along the North Sea coast the SMRs showed a more than twofold excess. Mortality due to pleural mesothelioma was also significantly increased in the capital city of Amsterdam 

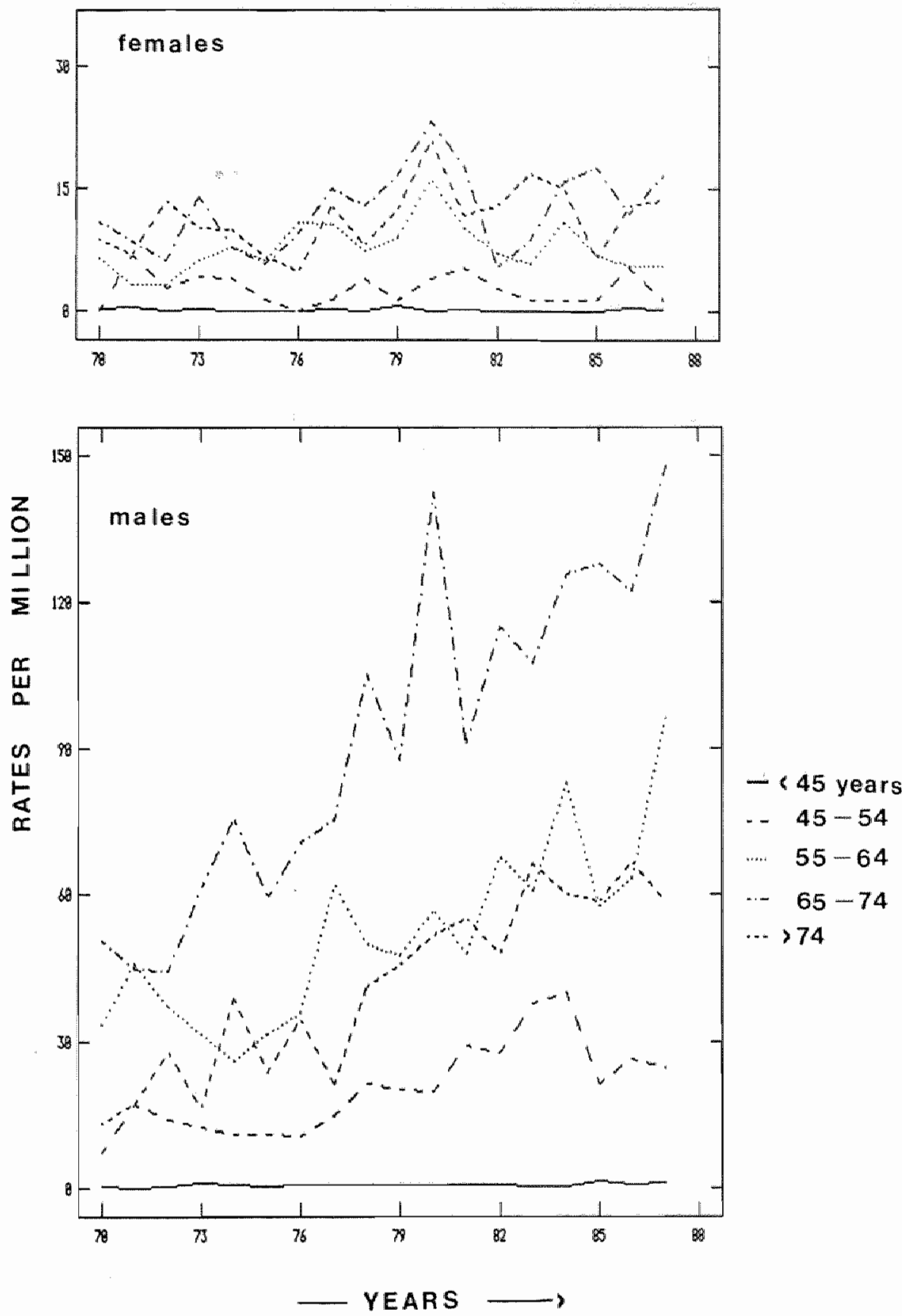

Figure I. Mortality per Million for Pleural Mesothelioma by Age and Sex in the Netherlands, $1970-1987$. 
Table III. Observed (O) and Expected (E) Deaths and SMRs for Mesothelioma of the Pleura for Selected Regions in The Netherlands 1979 - 1986.

\begin{tabular}{lccc}
\hline $\begin{array}{l}\text { Region } \\
\text { number }\end{array}$ & $\begin{array}{l}\text { No. of } \\
\text { deaths }\end{array}$ & SMR & $\begin{array}{c}95 \% \\
\text { Confidence } \\
\text { limits }\end{array}$ \\
\cline { 2 - 3 } & Obs. Exp. & \\
\hline
\end{tabular}

\begin{tabular}{clrrrr} 
Men & & & & \\
1 & Groningen & 12 & 15.1 & 79.7 & $41-139$ \\
2 & Imond & 32 & 13.9 & 229.9 & $157-325$ \\
3 & Zaanstreek & 21 & 11.6 & 180.9 & $112-277$ \\
4 & Amsterdam City & 124 & 67.2 & 184.4 & $153-220$ \\
5 & Rest of Amsterdam & 38 & 25.8 & 147.5 & $104-202$ \\
6 & Gooi and Vecht & 35 & 22 & 113.7 & $111-221$ \\
7 & Rijnmond & 274 & 97.9 & 280.0 & $248-315$ \\
8 & South-east South Holland & 48 & 30.7 & 156.6 & $115-208$ \\
9 & North Sealand & 61 & 23.7 & 257.4 & $197-330$ \\
10 & Flevoland & 13 & 5.1 & 253.0 & $135-433$ \\
& & & & & \\
Women & & & & & \\
1 & West Groningen & 14 & 5.7 & 244.3 & $134-410$ \\
2 & IJmond & 6 & 2.4 & 249.3 & $91-543$ \\
3 & Zaanstreek & 5 & 2.0 & 249.6 & $81-583$ \\
4 & Amsterdam City & 29 & 14.2 & 203.9 & $137-293$ \\
5 & Rest of Amsterdam & 4 & 4.3 & 92.8 & $25-238$ \\
6 & Gooi and Vecht & 6 & 4.5 & 134.4 & $49-293$ \\
7 & Rijnmond & 26 & 18.6 & 140.0 & $91-205$ \\
8 & South-east Souih Holland & 5 & 5.3 & 94.6 & $31-221$ \\
9 & North Sealand & 4 & 4.1 & 96.7 & $26-248$ \\
10 & Flevoland & 1 & 0.6 & 165.0 & $2-918$ \\
\hline & & & & &
\end{tabular}

and its surroundings Zaanstreek, Gooi and Flevoland. Clearly the clusters of mortality from mesothelioma in these harbour and coastal areas are due to high occupational exposure to asbestos in the past. It is well known that workers employed by shipyards and other heavy industries used asbestos for insulation 
and other technical purposes [Stumphius, 1971]. In the other 34 Dutch areas no significant excess in pleural mortality from mesothelioma for men was experienced during the period of observation.

We investigated whether or not the distribution of SMRs over the regions showed a similar pattern for women. This did not seem to be the case. The only two Dutch regions where the pleural mortality from mesothelioma was significantly increased for women were the city of Amsterdam and the Western Groningen region. In all the other areas SMRs did not reach statistical significance. Traditionally most Dutch wives are housewives and do not work in heavy and insulation industry. It is likely that the geographical patterns of pleural mesotheliomas for men and women visualise the differences in the occupational exposure of the sexes to asbestos. A high occupational exposure of men in the areas earlier mentioned did not necessary imply an increased incidence of mesothelioma for women living in the same area. An explanation for the significant increase in mesotheliomas in women in Western Groningen compared with other areas is not available.

Figures II and III show the death rates for pleural mesotheliomas over the period 1979-1986 by quartile for respectively men and women. Mortality in men varies greatly. The clustering in the western areas of the Netherlands with shipbuilding and other heavy industries is obvious. Mortality for men in the Rotterdam area was 59 per million, in North Sealand 54 per million, in IJmond 48 per million and in Amsterdam 39 per million. In the southern and north eastern part of the country there was also some clustering up to 21 per million. For women regional mortality was much lower and did not exceed 10 per million. The highest rates of pleural mesothelioma were found in the province of Groningen in the north eastern part of the country, in small clusters in the middle of the country and the Rotterdam area, and also in the region of Twente in the middle east. In Twente a concentration of factories with much asbestos pollution and a factory producing asbestos cement products existed. Possibly the high exposure levels in these industries led to the increased risk of mesotheliomas for men and women.

The mesothelioma panel registered 100 new cases with a proven or probable pleural mesothelioma diagnosis during 1986. An additional questionnaire to all Dutch pathological laboratories resulted in another 88 cases of mesothelioma of which 17 showed a peritoneal origin. Thus the total number of histologically verified pleural mesotheliomas (morbidity) amounted to 171 in 1986, which is in reasonable agreement with the national mortality figure of 193 cases. 


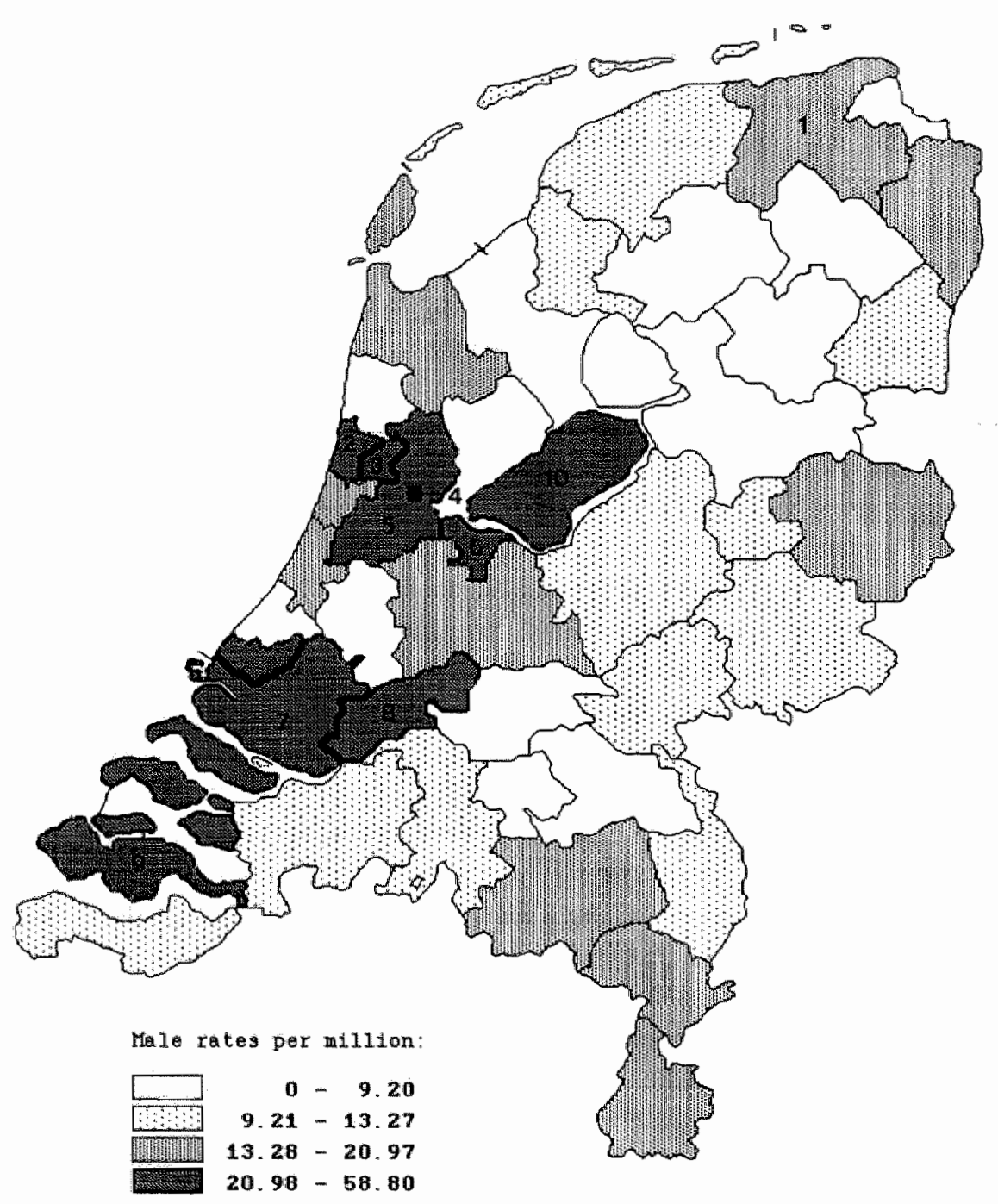

Figure II. Geographic Pattern of Death from Pleural Mesothelioma in Men for 43 Regions in the Netherlands, by Quartile 1979 - 1986.

Numbers refer to selected regions shown in Table III. 


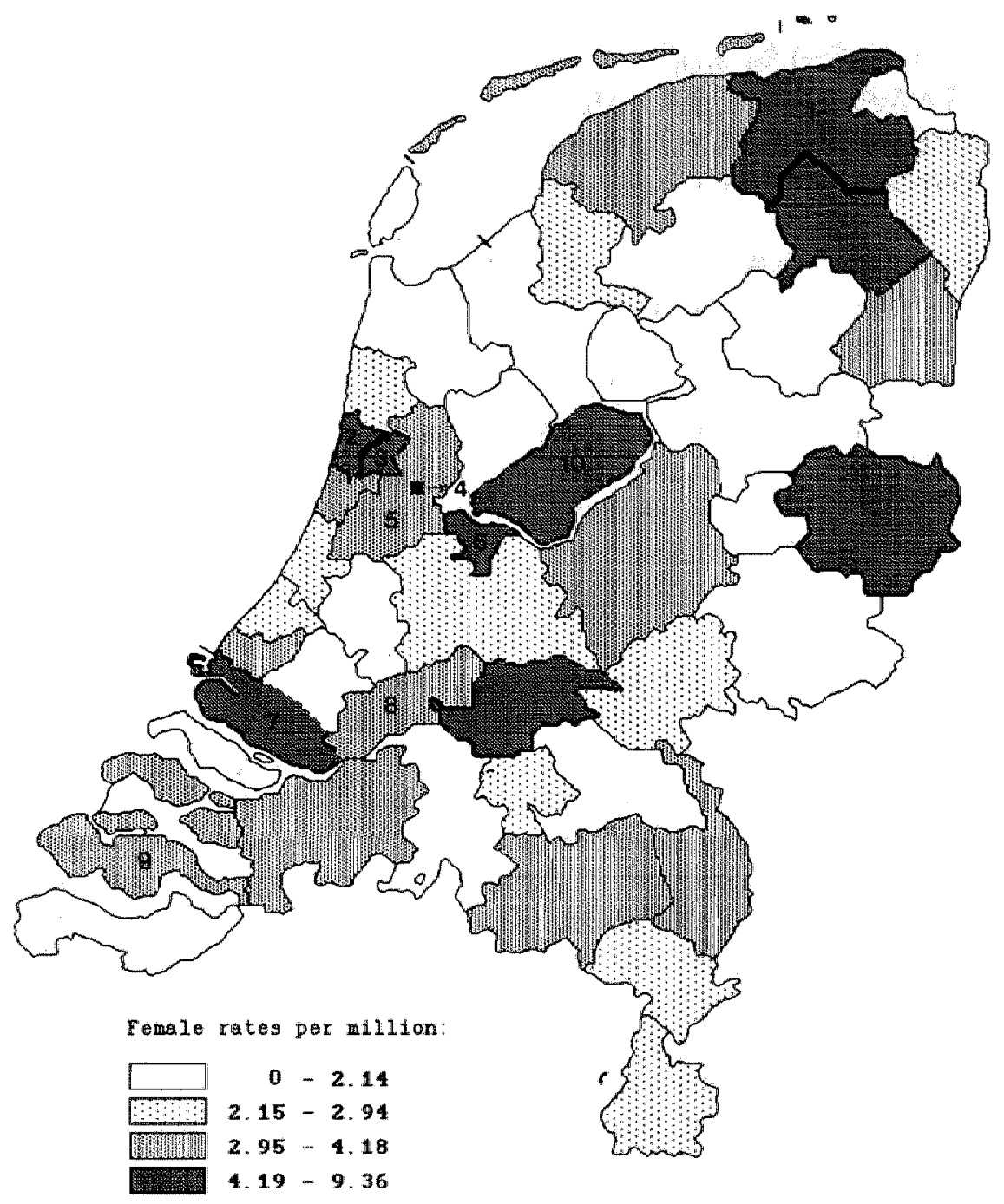

Figure III. Geographic Pattem of Death from Pleural Mesothelioma in Women for 43 Regions in The Netherlands, by Quartile 1979 - 1986.

Numbers refer to selected regions shown in Table III. 


\section{DISCUSSION}

Our study presents trends and geographical patterns in deaths from pleural mesothelioma in the Netherlands based on the ICD-classification of pleural malignancies. This can lead to under- or overestimations of the real number of pleural mesotheliomas. The pathological characterisation of mesotheliomas can be difficult and differences between a lower awareness in the sixties and the recently increased focus upon asbestos related diseases could lead to classification bias. Nevertheless, the comparison between numbers derived from the ICD and the results from the mesothelioma register, together with the expected age and sex related trends and geographical patterns demonstrate that misclassification of pleural mesotheliomas has not seriously influenced the outcomes. Pleural mesothelioma is particularly a disease of middle and old age resulting from exposure to asbestos early in the subjects' working history. The risk of mortality for women is low compared with men, and the mortality for men has shown a marked increase over the past 20 years.

Jones et al [1988] reported a crude death rate from mesothelioma in the United Kingdom of 17.5 per million for men and 3.2 per million for women in 1983. In the United States the incidence of pleural mesothelioma for men and women amounted to 10.6 and 1.9 per million for the years 1973 to 1984 [Connelly et al, 1987]. In Denmark the incidence of mesothelioma in the period 1978-1980 reached 14.7 cases per million men and 7.0 cases per million for women [Andersson and Olsen, 1985]. In Western Australia, where crocidolite was mined and milled between 1943 and 1966, the age standardised incidence of mesotheliomas in 1980-1982 was 66 per million for men and 7 per million for women aged over 35 [Armstrong et al, 1984]. In South Africa, Zwi et al [1989] reported an incidence of mesothelioma of 32.9 and 8.9 per million for men and women for the years 1976-1984. Compared with these outcomes for selected industrialized countries, the average Dutch death rates per million for pleural mesothelioma during 1979-1987 are considerably lower than the figures for men and women from the countries producing and exporting asbestos

namely, South-Africa and Western-Australia, but twofold higher than the reference figures of the United States and the outcomes for men in Denmark, They resemble the results from the United Kingdom. Just as in the United Kingdom, the Netherlands have never had any asbestos mining and milling corporations, but importation rose to 49400 tonnes of raw asbestos and 15300 tonnes of asbestos in finished products in 1976 [CBS, 1986]. Asbestos cement products and floor coverings containing asbestos were produced in the Netherlands, along with the application of asbestos insulation in construction, shipbuilding, and other heavy industry. The widespread and increased occupational 
exposure to asbestos has clearly led to the relatively high incidence of pleural mesotheliomas. This is especially demonstrated by the sharp increase in mortality for men aged 65 to 74 , which is much higher than the rates in the United States, Denmark and the United Kingdom. Numbers of deaths from pleural mesothelioma over time for women older than 54 are somewhat higher than in the United Kingdom and their moderate upward trend is comparable with the outcomes from other countries.

Concerning the geographical distribution of deaths from mesothelioma, Enterline and Henderson [1987] compared sex related pleural mesotheliomas between 1968 and 1981 for the 51 American states. Clusters of mesothelioma on a state level did not exceed 3.38 per million for men and 1.67 per million for women. The quartile with the highest death rates in the Netherlands demonstrates regional clusters of between 21 and 59 per million for men. This can be partly explained by the fact that the American states are many times larger than the Dutch regions and as a result possible excisting clusters are diluted in the United States. It is also possible that the strong clustering for men in some Dutch regions is due to the the high occupational exposure in the industrialized areas with many harbours and shipyards. For women the American studies showed clusters up to 1.77 per million on a state level compared to a highest quartile in the Netherlands of between 4.2 and 9.4 per million. The reason for these differences in mortality for women between the Netherlands and the United States is less clear. It is again possible that because of the large geographical regions in the United States local clusters of increased mortality cannot be detected; but perhaps the differences reflect variations in environmental exposure to asbestos for women. On a county level in the United Kingdom, crude death rates for all mesotheliomas amounted to 30.5 per million for men in regions with shipbuilding and repair industries and 11.0 for women in Lancashire [Jones et al, 1988]. The clustering of pleural mesotheliomas for men in certain Dutch regions seems to be more pronounced than in the United Kingdom. The levels of mortality in women are comparable between the Netherlands and the United Kingdom.

Because of legislation in 1977 (the Asbestos decrees) which led to a prohibition of the use of crocidolite and a threshold limit value for the other types of asbestos and a higher general awareness of the risks to health associated with asbestos, the import of raw asbestos declined from 49400 tonnes in 1976 to 5600 tonnes in 1985 [CBS, 1986]. It is difficult to predict the future trend of mortality from pleural mesothelioma in the Netherlands. Assuming that the mean latency time for mesotheliomas after exposure to asbestos is about 35 years, we expect that the increased use combined with the increased exposure to asbestos up to 1976 will not result in a decline in the asbestos related 
mesotheliomas until 2010. By applying techniques of linear regression to the overall sex rellated mortality rates shown in Figure I, mortality rates to the year 2010 were projected. This resulted in an extrapolated overall mortality from mesothelioma of about 50 per million for men and 5.8 per million for women. Combined with the prognosis about the growth of the total population provided by the Central Bureau of Statistics, this produced a crude number of 397 deaths from mesothelioma in men and 48 deaths in women in 2010. These projections are highly speculative, because exact information about the variations in exposure with time is lacking. We can, however, expect the mortality from mesothelioma to increase, especially in men, as their exposure to asbestos during the 1950s and 1960s in the insulation industry has increased and occupational hygiene standards were relatively poor. Altogether the data presented show that asbestos related mortality from mesothelioma imposes a serious health problem to the Dutch society, and it is feasible that the mortality from pleural mesothelioma will increase in the near future. It will be another 20 years before a significant decrease in mortality from pleural mesothelioma in the Netherlands can be expected.

\section{ACKNOWLEDGMENTS}

We thank the Central Bureau of Statistics and the Medical Information Centre (MEMIC) of the University of Limburg for providing the mortality figures on which this paper is based.

\section{REFERENCES}

Andersson M, Olsen JH (1985): Trend and distribution of mesothelioma in Denmark. Br J Cancen 51: 699-705.

Archer VE, Rom WN (1983): Trends in mortality of diffuse malignant mesothelioma of pleura, Lancet July 9: 112-113.

Armstrong BK, Musk AW, Baker JE, Hunt JM, Newall CC, Henzell HR, Blunsdon BS, Clarke-Hundley MD, Woodward SD, Hobbs MST (1984): Epidemiology of malignant mesothelioma in Western Australia. Med IJ Aust 141: 86-88.

Breslow NE, Day NE (1987): "Statistical Methods in Cancer Research Vol. II. The Design and Analysis of Cohort Studies". Lyon: IARC, Sci Publ No. 82.

Centraal Bureau voor de Statistiek (1986): Personal and scriptural communications.

Churg A (1985): Malignant mesothelioma in British Columbia in 1982. Cancer 55: 672-674.

Connelly RR, Spirtas R, Myers MH, Percy CL, Fraumeni JF (1987): Demographic patterns for mesothelioma in the United States. JNCI 78: 1053-1060. 
Enterline PE. Henderson VL (1987): Geographic patterns for pleural mesotheliona deaths in the United States, 1968-81. JNCI 79:31-37.

Ferguson DA, Berry $G$, Jelihovsky $T$, Andreas SB, Rogers AJ, Fung C, Grimwood A, Thompson R (1987): The Australian mesothelioma surveillance program 1979-1985. Med J Aust 147: 166-172

Gardner MJ, Acheson ED, Winter PD (1982): Mortality from mesotheliona of the pleura during 1968-78 in England and Wales. Br JCancer 46: 81- 88 .

Jones RD, Smith DM, Thomas PG (1988): Mesothelioma in Great Britain in 1968-1983. Scand J Work Environ Health 14: 1:45-152.

McDonald JC (1985): Health implications of environmental exposure to asbestos. Environ Health Persp 62: 319-328.

Minder CE, Vader JP (1988): Malignant pleural mesothelioma among Swiss furniture workers. Scand J Work Environ Health 14: 252-256.

Newhouse M (1981): Epidemiology of asbestos-related tumors. Seminars in Oncology 8 : $250-257$.

Planteydt HT (1979): Netherlands Mesothelioma Register. Ann NY Acad Sci 330: 467-471.

Scataridge JC. Stitik FP (1988): Induction of thoracic malignancy in inorganic dust pneumoconiosis. J Thorac Imag 3: 67-79.

Selikoff IF, Lee DHK (1978): Asbestos and disease. New York: Academic Press.

Stumphius J (1971): Epidemiology of mesothelioma on Walcheren Island. $\mathrm{Br} J$ Ind Med 28 : 59-66.

Wagner JC, Sleggs CA, Marchand P (1960): Diffuse pleural mesothelioma and asbestos exposure in the North Western Cape province. Brit JInd Med 17: 260-271.

Zwi AB, Reid G, Landau SP, Kielkowski D, Sitas F, Becklake MR (1989): Mesothelioma in South Africa, 1976-84: Incidence and case characteristics. Int J Epidemiology 18: 320-329. 


\title{
Chronical exposure to man-made vitreous fibres (MMVF) and respiratory diseases
}

\author{
J.M.M. Meijers, C. Cuypers, C. van Vliet, G.M.H. Swaen
}

Department of Occupational and Environmental Health and Toxicology, University of Limburg, Maastricht, the Netherlands.

Adapted version from the paper published in the "Tijdschrift voor Sociale Gezondheidszorg" 1988; 66: 113-119.

\section{ABSTRACT}

In this article a review is presented of the scientific data, concerning the long term respiratory health risks after chronical exposure to man-made vitreous fibres. The results of in vitro studies, animal experimental studies and transversal and longitudinal epidemiological investigations are discussed.

In short term tests no mutagenicity has been demonstrated for MMVF, although concentrated and local application of MMVF in body cavities and lungs of experimental animals yielded an increase in malignancies. Among workers in the glass, rock and slagwool industry no unambiguous relation could be demonstrated between exposure to MMVF and nonmalignant respiratory diseases or lung cancer. However, some studies pointed to the increased lung cancer prevalence after a latency period of more than 30 years in workers employed in the early production phase of rock and slagwool.

Based on the experimental and observational data, an adverse effects of MMVF on the respiratory tract after chronical and substantial occupational exposure cannot be entirely excluded. 


\section{INTRODUCTION}

Man-made mineral fibres (MMMF) form a heterogenous group of artificial fibre products, which are industrially manufactured from materials of natural origin [Hill, 1983]. This in contrary with naturally occurring mineral fibres, like asbestos. Within the group of man-made fibres a distinction is made between types of fibres with a vitreous or glassy structure, like glass fibres, glasswool, slagwool and rockwool, and fibres without a vitreous structure (including carbon- and aluminium oxide fibres). The so-called man-made vitreous fibres (MMVF) are very effective as substitution for asbestos and find a broad application in sound- and thermal insulation (rock- and glasswool), in the textile industry and as reinforcement of plastics and paper (glass fibres) [Kolk, 1982]. Thanks to their solidity, their resistancy to chemicals and their insulating characteristics they have more than 35,000 applications by now [Bernard and Gee, 1984]. At the end of the 1970s the number of employees in the West European fibre synthetising industry was estimated at 30,000. A larger group of workers is involved in the applications of the fibres in among others the construction industry [Saracci, 1985]. In 1973 the world-wide production of artificial fibres was approximately 4.6 million tons [WHO, 1983].

The commercial production of MMVF started a hundred years ago. Through the years numerous publications have focussed the attention to acute exposure effects among MMVF production workers, especially mechanic irritation of the skin, the respiratory mucosae of nose and throat and the conjunctivae [Gross, 1986]. These effects only occur when exposed to high levels and are generally a passing thing [Milby and Wolf, 1969]. Nowadays, there is extensive scientific knowledge on the lung pathology occurring with asbestos exposure, particularly asbestosis, lung cancer and mesotheliomas, but the mechanism on the basis of which asbestos causes malignancies is not yet clarified. Because MMVF have a mineral origin and possess a fibrous structure, the question arose whether exposure to these fibres could possibly lead to similar health risks in the long term. In 1972 Stanton and Wrench published the results of a study, from which appeared that mesotheliomas occurred after intrapleural implantation of small balls of long, thin glass fibres in rats [Stanton and Wrench, 1972]. This aroused the scientific interest and from that moment on much experimental and observational studies were undertaken with regard to the chronical biological effects of MMVF. In this article a survey will be given of the study results concerning the relation between MMVF-exposure and chronic respiratory diseases and cancer of trachea, bronchus and lung. 


\section{IN VITRO STUDIES}

Many researchers apply short-term in vitro tests, in which cells are treated with mineral particles, in order to judge the relative pathogenicity of separate minerals and to trace the mechanisms causing cell damage. In bacterial mutation tests with phyla of Salmonella typhimurium and. Escherichia Coli no mutagenicity was observed after treatment with glass fibres [Chamberlain and Tarmy, 1977]. The same applied for asbestos fibres. In vitro glass fibres appeared to cause haemolysis and were damaging to lung- and peritoneal macrophages [Szentei, 1969; Beck et al, 1972; Beck, 1976; Chamberlain and Brown, 1978; Davies, 1980]. In addition, glass fibres appeared to decrease the colonizing ability of lung fibroblasts of Chinese hamsters while the median cell diameter of humane alveolar type-II cells was increased [Chamberlain and Brown, 1978]. In 1982 Sincock et al reported chromosomal damages after treatment of Chinese hamster cells with various glass fibres [Sincock et al, 1982]. Finally, Hesterberg and Barrett used an in vitro test in which morphological changes can be determined in Syrian hamster embryo cells [Hesterberg and Barrett, 1984]. Glass fibres appeared very active in causing these morphological transformations. Oshimura et al concluded that the morphological changes are accompanied by chromosomal deformations [Oshimura et al, 1984]. The mechanism by which vitreous fibres cause this cellular and chromosomal damage in vitro, is by no means known. In a number of experimentil studies the attention was focussed on the good solubility of the fibres in artificial fysiological liquids [[Förster, 1984; Klingholz and Steinkopf, 1984; Leineweber, 1984]. On the contrary to asbestos, most MMVF soften in fysiological solutions, during which a gel is formed on the surface of the fibres. This gel disappears, after which the diluted fibre surface is exposed to the next attack of the solution. In this way MMVF are gradually transformed and disappear completely in the end. Glass- and slagwool and glass fibres appear to have a relatively better solubility than rockwool [Klingholz and Steinkopf, 1984]. In vivo study results show that similar reactions occur in lung tissue of rats [Bernstein et al, 1984; Morgan and Holmes, 1986]. After intratracheal instillation of glass fibres complete dissolution of the fibres with a diameter of less than a micrometer occurred within one year. In this regard, long fibres $(60 \mu \mathrm{m})$ softened faster than short fibres $(5$ and $10 \mu \mathrm{m})$. Morgan and Holmes attributed this change to variations in the acidity between the external environment to which long fibres are exposed, and the intracellular phagosomes of the alveolar macrophages causing short fibres to be phagocyted completely [Morgan and Holmes, 1986]. In addition, long rockwool fibres appeared to dissolve more slowly in vivo than glass fibres comparable in length. 
The numerous animal experimental studies which have been undertaken during the years are, in relation to the biological effects of MMVF, globally to be classified into two groups: injection studies in which the fibres are administered concentrated and locally, and inhalation studies in which experimental animals inhale the fibres from the ambient air.

Most injection studies concern the intrapleural or intraperitoneal administration of glass fibres and other types of MMVF. In this regard, Stanton and his colleagues in the United States published a series of study results. Carefully defined glass fibres with fixed lengths and diameters were intrapleurally implanted in small rodents, after which pleura mesotheliomas appeared to occur in many exposed animals [Stanton and Wrench, 1972; Stanton et al, 1977; Stanton et $a l, 1981]$. Initially, Stanton et al concluded that the most damaging glass fibres had a length of more than $8 \mu \mathrm{m}$ and a diameter of less than $1.5 \mu \mathrm{m}$ (the so-called"Stanton"fibres) [Stanton et al, 1977]. On the basis of refinements of research methods it appeared later that the carcinogenicity of the implanted fibres increased with the decrease of the fibre diameter to $0.25 \mu \mathrm{m}$. Also Pott et $a l$, Davis and Wagner concluded that glass fibres injected in the peritoneal- and pleura cavities in animals were able to induce malignancies [Pott and Friedrichs, 1972; Pott et al, 1984; Davis, 1976; Wagner et al, 1984]. Other experiments reported that rock- and slagwool, administred according to the same route, caused mesotheliomas as well, slagwool however less than glass fibres [Pott et al, 1984; Wagner et al, 1984; Pott et al, 1987]. Especially the work of Pott et al confirmed the conclusions of Stanton, that long and thin fibres show the strongest tumor induction [Pott et al, 1984]. Intraperitoneal injections with special glass fibres (micro fibres with a diameter of less than $0.5 \mu \mathrm{m}$ ) in Spraque Dawley and Wistar rats yielded that after single administration of doses up to $10 \mathrm{mg}$ tumors occur in a maximum of $45 \%$ of the rats [Pott et al, 1987].

After intratracheal injections of solutions with glass fibres in groups of rats and guinea pigs, apart from accumulations of macrophages no pathological alterations in the lung tissue could be observed. A series of experiments with guinea pigs, in which longer fibres ( $92 \%$ longer than $10 \mu \mathrm{m}$ ) were administred intratracheally, resulted in an obvious fibrose reaction, whille administration of short fibres ( $93 \%$ shorter than $10 \mu \mathrm{m}$ ), apart from macrophage aggregations in the alveoli, showed no pathological changes [Wright and Kuschner, 1977].

In all the memorized studies the fibres were only administered in single doses. On the contrary, Pott et al injected eight separate doses of glasswool fibres intratracheally in hamsters. Lung carcinomas as well as pleura mesotheliomas were seen in the animals [Pott et al, 1987]. 
Inhalation studies, in which animals were exposed to airborne concentrations during a long period, form a more realistic approach as opposed to injection studies in order to determine the carcinogenic potentions of the fibres. The results of years of inhalation studies with rats, guinea pigs, rabbits and monkeys were summarized by Schepers in 1976 [Schepers; 1976]. Exposure to glasswool and special glass fibres in concentrations varying from 0.1 to $5 \mathrm{mg} / \mathrm{m}^{3}$ did not induce pulmonary tumors in animals. Macrophage aggregations containing fibres were seen along the alveolar walls of all the animals. Schepers concluded that the fibres are not fibrogenous. In this regard it should be noted that the median fibre diameter was $5 \mu \mathrm{m}$ and only $20 \%$ of the fibres had a diameter of less than $2 \mu \mathrm{m}$. In addition, after exposure of rats and hamsters for two years to high concentrations of glass fibres $\left(100 \mathrm{mg} / \mathrm{m}^{3}\right)$ with a median diameter and length of respectively 0.5 and $10 \mu \mathrm{m}$, Gross found only histological changes that are seen when exposed to inert particles [Gross, 1976].

Lee et al exposed rats and hamsters during 90 days to a glass fibre preparation with a median diameter of $1.2 \mu \mathrm{m}$ and a length shorter than $5 \mu \mathrm{m}$ and had a follow-up of the animals for the rest of their lives [Lee et al, 1979]. The dust exposure levels were very high $\left(400 \mathrm{mg} / \mathrm{m}^{3}\right)$, but only $15 \%$ of the particles had a fibreous structure. The researchers did not find lung tumors. The most important pathological deformations were alveolar lipoproteinosis in both types and very light interstitial fibrosis in some of the older animals.

During a symposium on the biological effects of MMVF in 1982, Le Bouffant $e t$ al presented the results of their study in which rats were exposed during 12 or 24 months to glass- and rockwool fibres and microfibres with a large variety of lengths and diameters in concentrations of $5 \mathrm{mg} / \mathrm{m}^{3}$ [Le Bouffant $e t$ $a l, 1984]$. The three fibre types caused minor local interstitial fibrosis in older animals. After exposure to rockwool this reaction was the less striking. One animal, treated with glasswool, developed a squamous-cell carcinoma. The authors considered this to be a coincidental reaction. Also the study of Smith et $a l$ in rats, during 24 months exposed to fine glass fibres (median diameter 0.45 $\mu \mathrm{m}$, length over $5 \mu \mathrm{m}$ ) in concentrations of 800 and 80 fibres $/ \mathrm{ml}$, did not show any pulmonary tumors [Smith et al, 1984]. Minor lung fibrosis and bronchoalveollar hyperplasia were seen in the exposed groups as well as the control groups. The results of other experiments in rats with glasswool, glass microfibres and rock- and slagwool were similar: no obvious relation was determined between exposure to fibres and lung fibrosis or tumors [Wagner et al, 1984; Smith et al, 1987; Muhle et al, 1987; McConnell et al, 1984]. 
Most researchers limited themselves in their observations to small rodents. Goldstein et al, however, exposed baboons up to 35 months to respirable glass micro fibres in a concentration of 1,100 fibres/ml (lenght more than $5 \mu \mathrm{m}$ ) [Goldstein et al, 1984]. A minor lung fibrosis was observed, increasing in seriousness with the post-exposure period. Solid tumors were not found.

After an exhaustive analysis mostly based on results of injection studies, the International Agency of Research on Cancer (IARC) concluded that there is sufficient evidence for the carcinogenicity of glasswool in experimental animals, limited evidence for rockwool and inadequate evidence for slagwool [IARC, 1988].

\section{EPIDEMIOLOGICAL RESEARCH}

Only epidemiological research methods are able to provide a reliable answer to the question to what extent the various MMVF with their different chemical and geometrical characteristics in a human model actually lead to respiratory diseases. The majority of the (numerous) epidemiological studies with regard to MMVF took place under employees in the fibre production industry.

Thirteen studies, in six different countries, had a transversal character. In these studies it was examined whether nonmalignant, chronic respiratory diseases (a multicoloured image of clinical and pathological phenomena, like bronchitis, asthma and pneumoconiosis) occur excessively among MMVF production-workers [Saracci, 1986]. Workers in the glass- and rockwool production and control persons were submitted to radiographical thorax examinations, physical examination and lung function measurements. In 1985 Saracci published a survey of the final results of the transversal studies: Only one study resulted in a strong correlation between working in the MMVF-industry and chronic respiratory diseases, two studies showed a weak correlation and from ten studies no correlation could be deducted [Saracci, 1985]. A causal association between MMVF and chronic respiratory diseases could not be definitely determined in any study, although in three studies a similar correlation was called probable. The results from an necropsy study under 20 deceased employees of a MMVF-factory and 40 control persons of other factories in the United States did not show any lead for an increased prevalence of fibrosis among MMVF-workers [Gross, 1986].

A historical cohort study of the mortality among 1,448 employees of a glass wool factory in the United States did not result in an increased mortality due to malignancies. However, an increased mortality as a result of nonmalignant respiratory diseases was concluded (19 observed versus 10 expected, SMR: 
189) [Gross, 1986]. The last result was criticized when it appeared that a number of the deceased had worked in a dusty environment earlier. Morgan et al described the mortality in a cohort of 6,586 employees of a number of glass fibre factories [Morgan et al, 1981]. From the 389 deaths no significant excess mortality could be observed for respiratory diseases. The follow-up of a cohort consisting of 2,576 employees of a Canadian glass fibre factory between 1955 and 1977 showed 88 deaths. The mortality as a result of nonmalignant respiratory diseases was according to the expected numbers, the standardised mortality ratio (SMR) for lung cancer was 166 (7 observed, 4.2 expected) which was not statistically significantly increased [Shannon et al, 1984].

The two most extensive and most recent reported studies are cohort studies in 17 factories in the United States and in 13 factories in Europe [Enterline and Marsh, 1984; Simonato et al, 1986]. In these studies more emphasis was put on the geometric characteristics of the fibres and their ambient air concentrations than in the other investigations. Therefore these studies wil be discussed more thoroughly. In the U.S. 1.1 glasswool- and 6 mineral (rock- or slag)wool factories were included in the study and the cohort consisted of 16,730 employees who had been exposed to MMVF in the past. The concentration of respirable fibres (longer than $5 \mu \mathrm{m}$, diameter smaller than $3 \mu \mathrm{m}$ ) was at the time of the study generally low: less than 0.5 fibres $/ \mathrm{cm}^{3}$. A total of 3,761 deaths were registered in the follow-up period until 1978. Table I gives a survey of findings in relation with the mortality resulting from diseases of the respiratory system. The mortality due to nonmalignant diseases of the respiratory system appeared to have increased for both types of fibres. However, only in the glass fibre industry this increase was statistically significant. A clearly stronger effect after a long latency period (more than 30 years) could not be observed by the authors. The standardised mortality ratio (SMR) for malignancies of the respiratory system was only in the mineral wool industry statistically significantly increased. In addition, in the glasswool industry as well as the mineral wool industry a small increase in SMR could be observed after a latency period of 30 years or longer. On the basis of these results the American researchers concluded that their study did not consistently prove the existence of a possible causal relation between diseases of the respiratory system and exposure to MMVF in branches of this industry [Enterline and Marsh, 1984]. In this research no correction was made for smoking habits of the employees and a national reference population was used, which could imply a misinterpretation of the results. In a prolonged follow-up until 1982 the researchers compared the mortality rates in the cohort to the regional mortality rates and performed a nested case-reference study with regard to smoking [Enterline et al, 1987]. There appeared to be a statistically significant excess mortality to lung cancer 


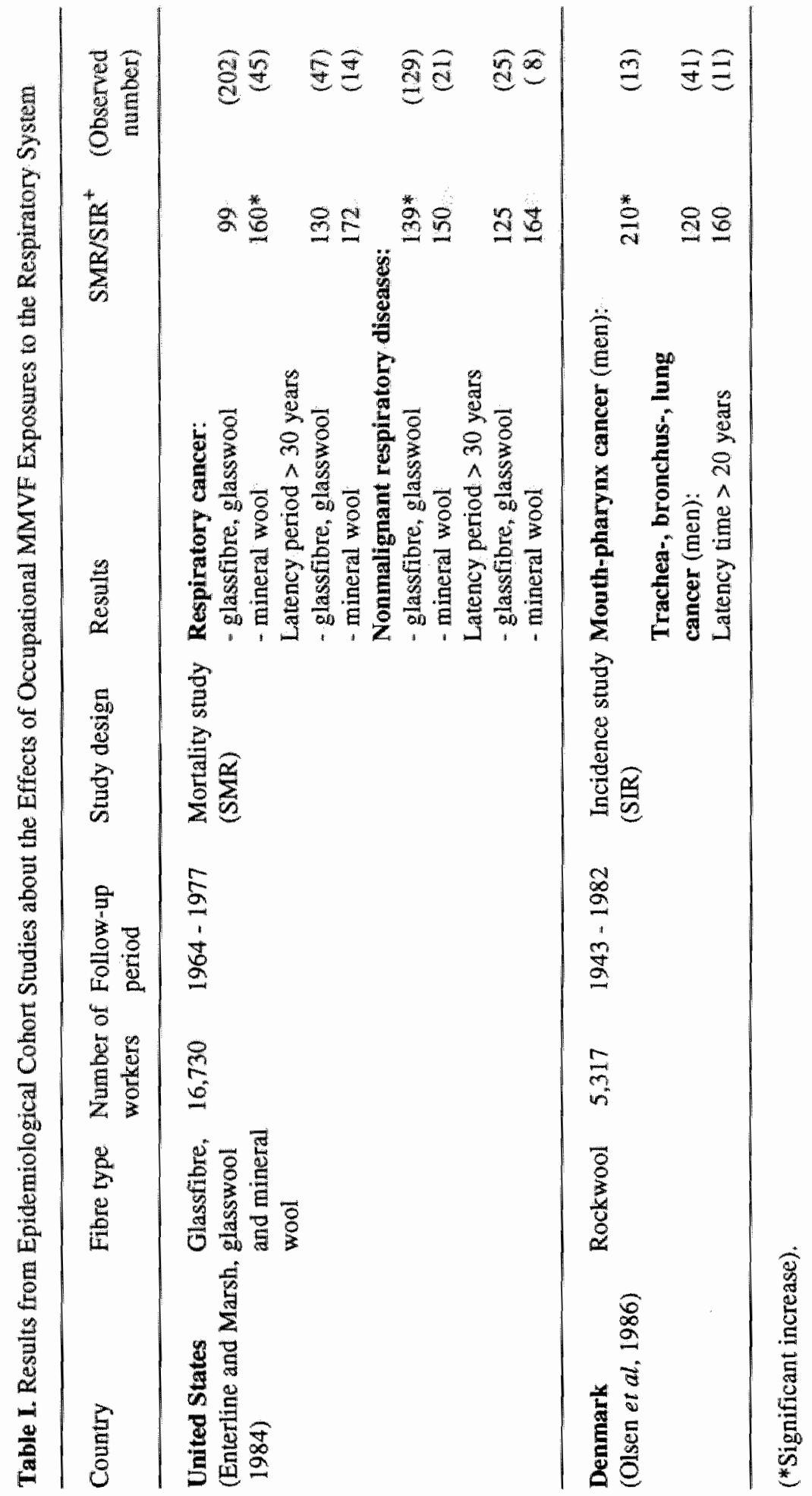




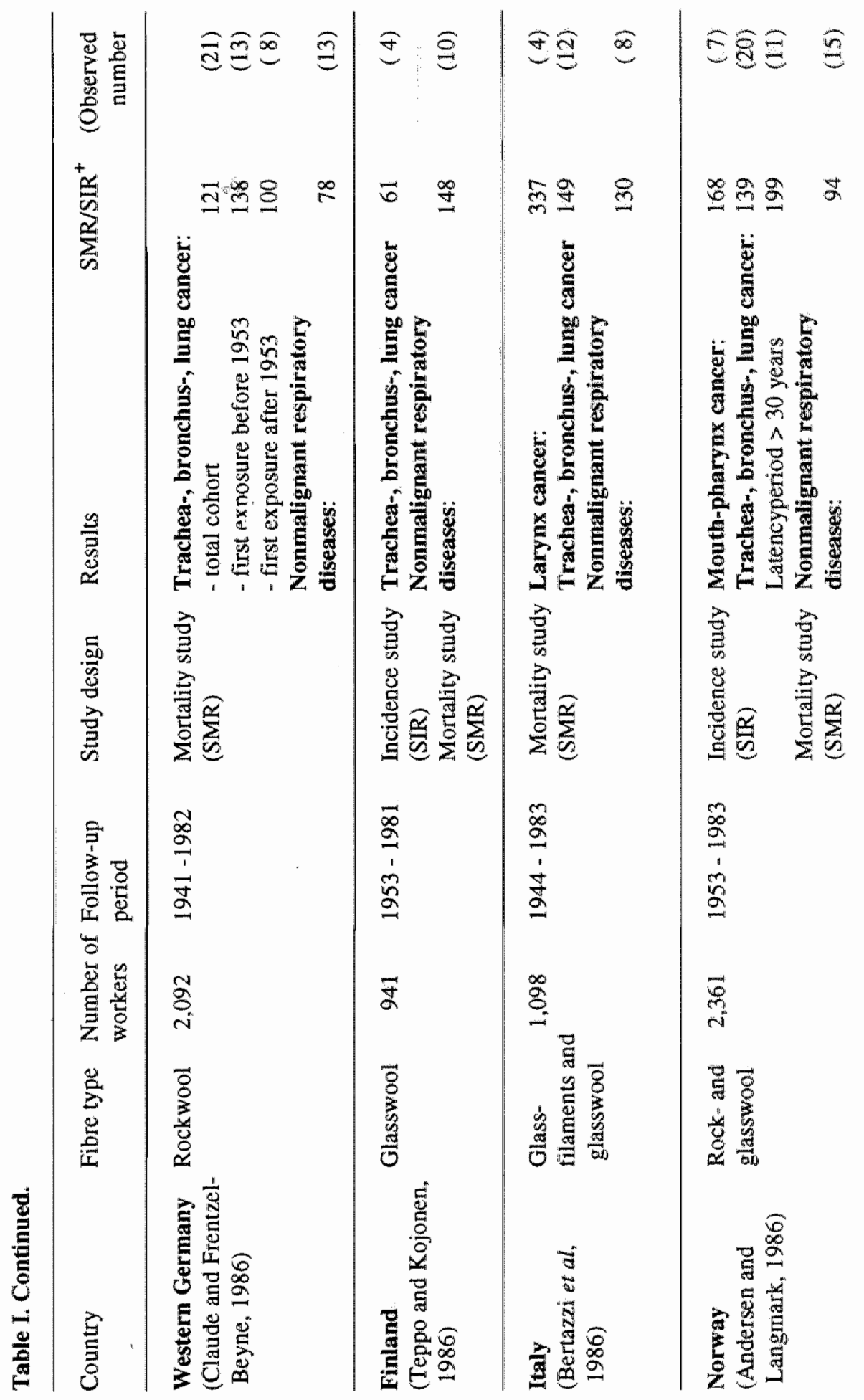




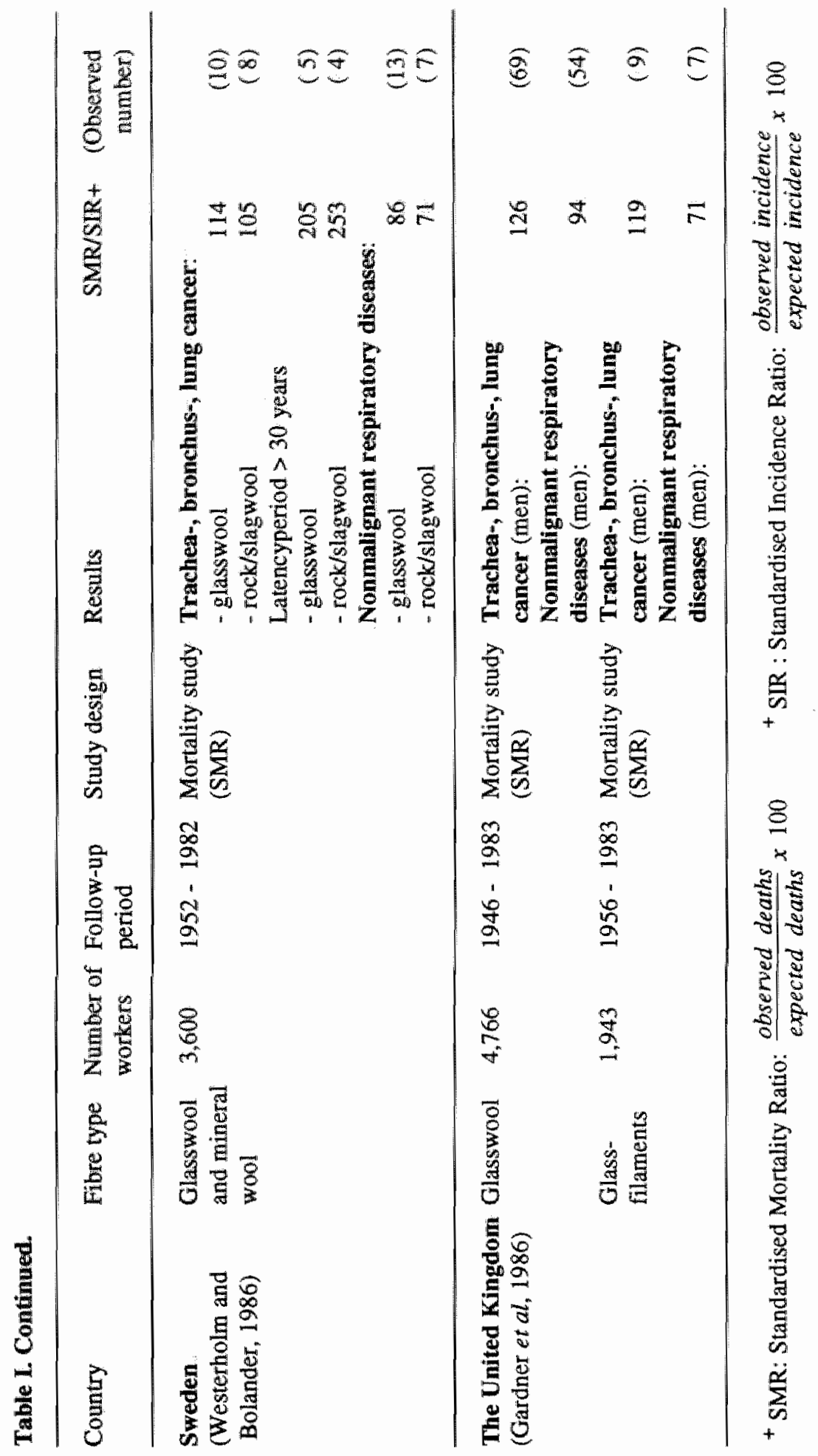


after 20 years since the first exposure (SMR: 112.7). This mortality was a little higher among mineralwool workers than among glasswool workers, however none of both groups showed a significant increase. There appeared to be no clear correlation between the respiratory cancer SMRs and exposure-duration, latency period and level of exposure [Enterline et al, 1987].

In the European study thirteen factories were involved spread over seven countries (see Table I) [Saracci, 1985]. The research was coordinated by the department for analytical epidemiology of the "International Agency for Research on Cancer"(IARC) in Lyon. It included four glasswool, seven rock/slagwool and two glass fibre plants. These two last companies produced very long, so-called glass filaments (continuous filaments). The total exposed cohort consisted of more than 20,000 workers and during the follow-up period the mortality and/or cancer incidence of these workers was listed. Measured recent mean exposure levels were relatively low, respectively $0.02,0.04$ and 0.004 fibres per $\mathrm{cm}^{3}$ for the glasswool-, mineral wool- and glass fibre companies [Cherrie et al, 1986]. Knowledge about previous levels of exposure in the MMVF-industry is inadequate. Since 1950 the production process has been changed fundamentally and so-called"binders"are used. The fibres are glued together by means of these binders, causing the fibre concentration in the ambient air to diminish considerably [Cherrie and Dodgson, 1986]. In addition, other adjustments in the fibre production, like a transition from batch processes to closed continuous processes and the increasing automation of the finishing, have led to a decrease of the fibre concentrations on the production sites. In the European study the production process was, wherever possible, historically divided into three phases:

1) Before 1940: "Early technologic phase". No use of binders, bad ventilation and often labour-intensive manual work.

2) Around 1940: "Intermediate technologic phase". Transitional phase, with regard to hygiene as well as the method of production, sometimes with and sometimes without the use of binders.

3) After 1952: "Late technologic phase". Use of oil and resin binders and mechanized production methods, implying lower exposure levels.

In general it is presumed that the respirable fibre concentrations on the shop floor during phase 1 were high, although quantitative data from this period are lacking [Cherrie and Dodgson, 1986].

The occurrence of nonmalignant diseases of the respiratory system appeared only to be increased in Italy (SMR: 130) and Finland (SIR:148) (Table I). For mouth- and pharynx cancer a statistically significant increase was observed in Denmark (SIR: 210) and in Norway (SIR: 168). Because in Norway 6 of the 7 cases occurred in one factory, the researchers were of the opinion that these 
cancer cases were related to other factors than exposure to mineral wool [Andersen and Langmark, 1986]. Remarkable is the increased, although nonstatistically significant, standardised mortality ratio for larynx cancer in Italy. It concerned here a single finding with a relatively small number of cases.

The incidence of trachea-, bronchus- and lung cancer was slightly (not significantly) increased in Denmark (SIR in men: 120) and Norway (SIR: 139). With an increased latency period the concerned cancer incidence in both countries appeared to increase slightly [Olsen et al, 1986; Andersen and Langmark, 1986]. In Germany, Italy, Sweden and the United Kingdom the total standardised mortality ratios (SMR) for lung and respiratory tract cancer under MMVF-workers was a little higher than expected. In none of these countries the reported excess mortality reached a statistically significant level. In Germany the increased total SMR appeared to be caused by the increased lung cancer mortality in the group of workers who were exposed for the first time before the general introduction of binders [Claude and Frentzel-Beyme, 1986]. In Sweden the lung cancer mortality was increased among employees in the glass- and mineral wool production with a latency period of more than thirty years. Also this group consisted of employees who had been involved in fibre production before the late technologic phase [Westerholm and Bolander, 1986]. The increased mortality in Italy disappeared completely after application of a local reference population [Bertazzi et al, 1986].

During an analysis of the mortality pattern of the total European cohort (2,719 mortality cases) no increased mortality due to nonmalignant respiratory diseases could be determined in the mineral- and glasswool industry as well as in the glass fibre industry [Simonato et al, 1986]. The lung cancer mortality appeared to be statistical significantly increased for the complete cohort (SMR: $125 ; 189$ observed versus 151 expected). The risk increased with the latency period, however not with duration of exposure [Simonato et al, 1986]. The excess lung cancer mortality occurred only in employees in the rock- and slagwool industry and was concentrated in the group of employees who had been involved in the production process during the early technologic phase. In this early period there was no use of binders and the airborne fibre concentrations in the workplaces were considerably higher than after the introduction of binders. According to Simonato $e t$ al this implies that the exposure to rock- and slagwool may have contributed to the increased lung cancer risk alone or in combination with other, still unknown factors. They consider earlier occupational exposures or smoking unlikely to clarify this increase [Simonato et al, 1986]. For workers in the glasswool industry no increased cancer mortality in relation to the local reference population could be determined in the group with a latency period of more than thirty years. Excess mortality in workers exposed 
to glass filaments did not occur. Because of the short follow-up period of the glass filaments subcohort (two companies), no definite statement could be made about the health effects in the long term. The results did not give a single lead to the occurrence of pleura mesotheliomas as a result of working in the MMVFindustry: Only one person with an exposure time of less than one year and a latency period of 13 years developed a pleura mesothelioma, while on the basis of the general mortality characteristics $\mathbb{1}$ to 3 cases were expected [Simonato et al, 1986].

A few studies paid attention to diseases of the respiratory system in workers who have been exposed to respiratory MMVF in the application and consumer sector. Lung function values in 23 sheet metal workers, periodically exposed to glass fibres, did not show obvious defects [Sixt et al, 1983]. In Sweden a very extensive study took place among approximately 135,000 construction workers. In a prevalence study as well as in a patient control approach a correlation was seen between professional MMVF-exposure and chronic bronchitis and lung cancer. The exposure estimations for MMVF and other relevant factors (like asbestos) were however not adequate, implying that these results have to be interpreted with the necessary care [Saracci, 1986].

The IARC concluded that there is inadequate evidence for the carcinogenicity of glasswool and of glass filaments in humans, and limited evidence for the carcinogenicity of rock/slagwool in humans [IARC, 1988].

\section{CONCLUSIONS AND DISCUSSION}

During application of short term tests no mutagenicity could be determined for any of the separate man-made vitreous fibres. However, particularly glass fibres appeared to be able to cause cellular and chromosomal damage in vitro. The knowledge about the causes of this damage on a molecular level is as yet inadequate. A number of experiments with experimental animals show that intraperitoneal and intrapleural administration of MMVF may cause malignancies. The carcinogenicity correlates with the geometric and chemical characteristics of the fibres; long fibres with a small diameter induce more tumors than short, thick fibres, and micro glass fibres are more carcinogenic than mineral wool fibres (rock- slagwool). Only one, not replicated study in which glass fibres are repeatedly intratracheally instilled, reported an increase of malignant tumors. The results of a great number of researches with single intratracheal application of glass fibres varied from local minor macrophage accumulations to a clear fibrosis. Here appeared as well the importance of the fibre geometry. Finally, long term inhalation studies with MMVF in various types of animals 
showed no proof whatsever for an increase of the cancer risk. At present, it is not clear what causes the considerable discrepancy between the experimental studies. Perhaps a solution can be derived from the fact that the most respirable MMVF-fibres are well soluble in the peripheral lung tissue, while in the body cavities they remain present long enough to induce malignancies [Davies, 1986]. Departing from this hypothesis one would however expect that rockwool, considering the larger durability at equal length and diameter, causes more damage than glass fibres. The opposite appears to be true.

Transversal epidemiological studies did not offer any convincing leads for an increase of chronic obstructive pulmonary diseases, fibrosis or lung cancer among workers in the production sector exposed to MMVF. The results of retrospective cohort studies in the United States and Europe are little consistent. The mortality as a result of nonmalignant respiratory tract diseases appeared to be statistically significantly increased in the American glasswool industry and there was a light excess mortality after a latency period of 20 years or more. However, a dose-response relation between MMVF-exposure and lung cancer was not present. On the contrary, in an aggregated analysis of seven separate European studies no increase of nonmalignant lung diseases was observed. The lung cancer risk was only increased for employees in the rock- and slagwool industry with a long latency period and a probably higher fibre concentration in the ambient air at first exposure than is the case nowadays.

The question whether employees who are exposed to MMVF in the fibre producing industry experience a higher risk for respiratory diseases, cannot be answered univocally at present. On the one hand no cause-effect relation between the various MMVF exposures and lung fibrosis or lung cancer can be determined on the basis of the numerous epidemiological data; on the other hand there is no convincing proof for the proposition that MMVF do not cause any damage at all to the respiratory tracts. Some data support the conclusion that MMVF in the earlier phase of rock- and slagwool production could have played a role in the development of lung cancer. The contribution of additional, confounding occupational exposures in this regard like asbestos, polycyclic aromatic hydrocarbons and arsenic remains unclear. An increased risk for lung diseases appears not to be present for workers in the modern MMVF-production sector. However, a reservation should be made in this regard. The latency period for the occurrence of lung cancer after exposure to carcinogenic particles is in most cases 30 years or more. For the majority of the employees who were exposed to MMVF for the first time after the introduction of binders, the period since the first exposure is considerably shorter, causing an effect on the respiratory tract to show itself only in the future. A further analysis of the incidenceand mortality rates after a long follow-up is therefore desired for the American 
as well as the European studies. Furthermore fundamental research on the molecular mechanism of the cytotoxicity of MMVF offers interesting perspectives for future research. Also the effects of repeated intratracheal instillation and chronic inhalation of glass-, rock and slagwool could be examined more thoroughly in new experimental models. It is remarkable that in epidemiological research little attention is paid up to now to the health of the workers who are exposed to respirable MMVF in the application area. From occupational hygienic studies it appeared that during insulation activities relatively high airborne fibre concentrations can occur $\left(0.56 \mathrm{fibres} / \mathrm{cm}^{3} 5.3 \mathrm{fibres} / \mathrm{cm}^{3}\right.$ [Esmen et al, 1982]). From the point of view of industrial health further study of the health of these workers appears desirable.

\section{REFERENCES}

Andersen A, Langmark F (1986): Incidence of cancer in the mineral-wool producing industry in Norway. Scand J Work Environ Health 12 suppl 1: 72-77.

Bayliss DL, Dement JM, Wagoner JK, Blejer HP (1976): Mortality patterns among fibrous glass production workers. Ann NY Acad Sci 271: 324-335.

Beck EG, Holl PF, Manojlovic N (1972): Comparison of the effects on macrophages in culture of glass-fibre, glass powder and chrysotile asbestos. Br J Ind Med 29: 280-2986.

Beck EG (1976): Biologische Wirkungen von faserigen Stäuben. Heft Unfallheidk 126: 584-588.

Bernard J, Gee L (1984): Occupational Lung Disease. New York: Churchili Livingstone, pp 91.

Bernstein DM, Drew RT, Schidlowsky G, Juschner M (1984): Pathogenicity of MMMF and the contrasts with natural fibres. In Guthe $\mathrm{T}$ (ed): "Biological effects of man-made mineral fibres: Proceedings of a WHO/IARC conference in association with JEMRB and TIMA, Copenhagen 20-22 April 1982". Vol. 2. World Health Organisation, Regional Office for Europe, Copenhagen, pp 169-195.

Bertazzi PA, Zocchetti C, Riboldi L, Pesatori A, Radice L, Larocca R (1986): Cancer mortality of an Italian cohort of workers in man-made glass-fibre production. Scand J Work Environ Health 12, suppl 1: 65-71.

Le Bouffant L, Henin JP, Martin JC, Normand C, Tichoux G, Trolard F (1984): Distribution of inhaled MMMF in rat lung long term effects. In Guthe $T$ (ed): "Biological effects of man-made mineral fibres: Proceedings of a WHO/LARC conference in association with JEMRB and TIMA, Copenhagen 20-22 April 1982". Vol. 2. World Health Organisation, Regional Office for Europe, Copenhagen, pp 143169.

Chamberlain M, Tarmy EM (1977): Asbestos and glass fibres in bacterial mutation tests. Mutat Res 43: 159-164.

Chamberlain M, Brown RC (1978): The cytotoxic effects of asbestos and other mineral dust in tissue culture cell lines. Br J Exp Pathol 59: 183-189. 
Cherrie J, Dodgen 1 , Groat $S_{4}$ MacLaren W (1986): Envirommental surveys in the European man-made mineral fiber prodaction industry. Scand J of Work Environ Health 12, suppl 1: $18-25$.

Cherrie J, Dodgson J (1986): Past exposures to airborne fibres and other potential risk factors in the European man-made mirieral fibre production industry. Scand J Work Environ Health 12 , suppl 1:26-33.

Claude J, Frentzel-Beyme R (1986): Mortality of workers in a German rockwool factory a second Look with extended follow-up. Scand J Work Environ Health 12, suppl 1: 53-60.

Davies R (1980): The effect of mineral fibres on macrophages. In Wagner JC, (ed): "Biological effects of mineral fibres". IARC Scientific publication no. 30. IARC, Lyon, pp 419-425.

Davis JMG (1976): Pathological aspects of the injection of glass fiber into the pleural and peritoneal cavities of rats and mice. In Le Vee WN, Schulte PA (eds): "Occupational exposure to fibrous glass". DHEW Publ. No. (NIOSH) 76-151. Cincinnati: NIOSH, pp $141-149$.

Davis JMG (1986): A review of experimental evidence of the carcinogenity of man-made vitreous fibres. Scand J Work Environ Health 12, suppl 1: 12-17.

Enterline PE, Marsh GM (1984): The health of workers in the MMMF industry. In Guthe T (ed): "Biological effects of man-made mineral fibres: Proceedings of a WHO/LARC conference in association with JEMRB and TIMA, Copenhagen 20-22 April 1982". Vol. 2. World. Health Organisation, Regional Office for Europe, Copenhagen, pp 311-339.

Enterline PE, Marsh GM, Henderson V, Callahan C (1987): Mortality update of a cohort of US man-made mineral fibre workers. Ann Occup Hyg 31: 625-656.

Esmen NA, Sheehan MJ, Corn M, Angel M, Kotsko N (1982): Exposure of employees to man-made vitreous fibres: Installation of insulation materiall. Environ Res 28: 386-398.

Forster H (1984): The behaviour of mineral fibres in physiological solutions. In Guthe $T$ (ed): "Biological effects of man-made mineral fibres: Proceedings of a WHO/LARC conference in association with JEMRB and TIMA, Copenhagen 20-22 April 1982". Vol. 2. World Health Organisation, Regional Office for Europe, Copenhagen, pp 27-60.

Gardner MJ, Winter PD, Pannett B, Simpson MJC, Hamilton C, Acheson ED (1986): Mortality study of workers in the man-made mineral fibre production industry in the United Kingdom. Scand J Work Environ Health 12, suppl 1: 85-93.

Goldstein B, Webster I, Rendall REC (1984): Changes produced by inhalation of glass fibre in non-human primates. In Guthe T (ed): "Biological effects of man-made mineral fibres: Proceedings of a WHO/LARC conference in association with JEMRB and TIMA, Copenhagen 20-22 April 1982". Vol. 2. World Health Organisation, Regional Office for Europe, Copenhagen, pp 273-286.

Gross $P$ (1976): The effects of fibrous glass dust on the lungs of animals. In Le Vee WN, Schulte PA (eds): "Occupational exposure to fibrous glass". DHWE publ. nol (NIOSH) 76-151, Cincinatti: NTOSH, pp 169-179.

Gross P (1986): Man-made vitreous fibres; An overview of studies on their biologic effects. Am Ind Hyg Assoc J 47: 717-723.

Hesterberg TW, Barrett JC (1984): Dependence of asbestos an mineral dust induced transformation on mammalian cells in culture on fiber dimension. Cancer Research $44: 2170-2180$.

Hill GW (1983): Fibres, man-made glass and mineral. In Parmeggiani L (ed): "Encyclopaedia of occupational health and safety". Vol. 1. International Labour Office, Geneva, pp 852-855. 
IARC Working Group on the Evaluation of the Carcinogenic Risk of Chemeials to Humans (1988): Man-made mineral fibres and radon. In: "IARC Monographs on the Evualation of the Carcinogenic Risk of Chemicals to Humans". Vol. 43, pp 39-171.

Klingholz R, Steinkopf B (1984): The reactions of MMMF in a physiological model fluid and in water. In Guthe $T$ (ed): "Biological effects of man-made mineral fibres: Proceedings of a WHO/ARC conference in association with JEMRB and TIMA, Copenhagen 20-22 Apri] 1982". Vol. 2. World Health Organisation, Regional Office for Europe, Copenhagen, pp 102-105.

Kolk JJ (1982): Biologische effekten van man-made mineral fibres. T Soc Geneesk 60: 770-773.

Lee KP, Baras CE, Griffith FD, Waritz RS (1979): Pulmonary response to glass fibre by inhalation exposure. Lab Invest 40: 123-133.

Leineweber JP (1984): The solubility of fibres in vitro and in vivo. In Guthe T (ed): "Biological effects of man-made mineral fibres: Proceedings of a WHO/LARC conference in association with JEMRB and TIMA, Copenhagen 20-22 April 1982" . Vol. 2. World Health Orgarisation, Regional Office for Europe, Copenhagen, pp 87-101.

McConnell EE, Wagner JC, Skidmore JW, Moore JA (1984): Two inthalation studies: A comparative study of the fibrogenic and carcinogenic effects of UICC Canadian chrysotile $B$ asbestos and glass microfibre (JM 100). In Guthe T (ed): "Biological effects of man-made mineral fibres: Proceedings of a WHO/LARC conference in association with JEMRB and TIMA, Copenhagen 20-22 April 1982". Vol. 2. World Health Organisation, Regional Office for Europe, Copenhagen, pp 234-250.

Milby TH, Wolf CR (1969): Respiratory irritation from fibrous glass inhalation. J Occup Med 11: $409-410$.

Morgan A, Holmes A (1986): Solubility of of asbestos and man-made mineral fibres in vitro and in vivo: Its significance in lung disease. Environ Res 39: 475-484.

Morgan RW, Kaplan SD, Bratsberg JA (1981): Mortality study of fibrous glass production workers. Arch Environ Health 36: 179-183.

Muhle H, Pott F, Bellmann B, Takendra S, Zjem U (1987): Inhalation and injection experiments in rats to test the carcinogenicity of MMMF. Ann Occup Hyg 31: 755-764.

Olsen JH, Jensen OM, Kampstrup O (1986): Influence of smoking habits and place of residence on the risk of lung cancer among workers in one rock-wool producing plant in Denmark. Scand J Work Environ Health 12 , suppl 1: 48-52.

Oshimura M, Hesterberg TW, Tsutsui T, Barrett CJ (1984): Correlation of asbestos-induced cytogene tic effects with cell transformation of Syrian hamster embryo cells in culture. Cancer Research 44: 5017-5022.

Pott F, Friedrichs KH (1972): Tumoren der Ratte nach i.p. Injection faserformige Staube. Naturwissenschafterer 59:318.

Pott F, Schlipköter HW, Ziem U, Spurny K, Huth F (1984): New results from implantation experiments with mineral fibres. In Guthe $T$ (ed): "Biological effects of man-made mineral fibres: Proceedings of a WHO/IARC conference in association with JEMRB and TIMA, Copenhagen 20-22 April 1982". Vol. 2. World Health Organisation, Regional Office for Europe, Copenhagen, pp 286-302.

Pott F, Ziem U, Mohr U (1984): Lung carcinomas and mesotheliomas following intratracheal instillation of glass and asbestos. In"Bergbau-Berufsgenossenschaft, VI International Pneumoconiosis Conference". Bochum, pp 746-757. 
Pou $F$; Ziem U, Reiffer FJ, Huth F Ernst H, Mohr U (1987); Carcinogenicity studies on fibres, metal compounds and some other dusts in rats. Exp Pathol 32: 129-152.

Saracci (1985): Man-made mineral libers and health. Scand J Work Environ Health 11 : 215-222.

Saracci R (1986): Ten years of epidemiologic investigations on man-made mineral fibers and health. Scand I Work Environ Health $12,5-11$.

Schepers GHW (1976): The comparative pathogenicity of inhaled fibrous glass dust. In Le Vee WN, Schulte PA (eds): "Occupational exposure to fibrous glass". DHWE publ. nol (NIOSH) 76-151, Cincinati: NIOSH, pp 265-341.

Shannon HS, Hayes M, Julian JA, Minr DLF (1984): Mortality Experience of Glass Fibre Workers. In Guthe $\mathrm{T}$ (ed): "Biologicall effects of man-made mineral fibres: Proceedings of a WHO/LARC conference in association with JEMRB and TIMA, Copenhagen 20-22 April 1982". Vol. 2. World Health Organisation, Regional Office for Europe, Copenhagen, pp $347-349$.

Simonato L, Fletcher $\mathrm{AC}_{\text {, }}$ Cherrie J, Andersen A, Bertazzi RA et al (1986): The man-made mineral fiber. European historical cohort study: Extension of the follow-up. Scand J Work Environ Health 12, suppl 1: 34-47.

Sincock AM, Delhanty JDA, Casey GA (1982): A comparison of the cytogenic response to asbestos and glasfibre in Chinese hamster and human cell lines. Mutat Res 101: 257-268.

Sixt $R_{*}$ Bake B, Abrahamasson G (1983): Lung function of sheet metal workers exposed to fiber glass. Scand J Work Environ Health 9:9-14.

Smith DM, Ortiz LW, Archuleta RF (1984): Long term exposure of Syrian Hamsters and Osborne-Mendel rats to aerosolized $0.45 \mathrm{~m}$ mean diameter fibrous glass. In Guthe $T$ (ed): "Biological effects of man-made mineral fibres: Proceedings of a WHO/LARC conference in association with JEMRB and TIMA, Copenhagen 20-22 April 1982". Vol. 2. World Health Organisation, Regional Office for Europe, Copenhagen, pp 253-273.

Smith DM, Ortiz LW, Archuleta RF, Johnson NF (1987): Long-term health effects in hamsters and rats exposed chronically to Man-made vitreous fibers. Ann Occup Hyg 31: 731-754.

Stanton MF, Wrench C (1972): Mechanisms of mesothelioma induction with asbestos and fibrous glass. J Natl Cancer Inst 48: 797-821.

Stanton MF, Layard M, Tegeris A, Miller E, May M, Kent E (1977): Carcinogenicity of fibrous glass: Pleural response in the rat in relation to fiber dimension. J Natl Cancer Inst 58: 587-603.

Stanton MF, Layard M, Tegeris A, Miller E, May M, Morgan E, Smith A (1981): Relation of particle dimension to carcinogenicity in amphibole asbestos and other fibrous minerals. I Natl Cancer Inst 67: 965-975.

Szentei E (1969): Hamolyseversuche mit Asbest. Medizinisches Institut fir Lufthygiene und Silikoseforschung, Dusseldarf.

Teppo L, Kojonen E (1986): Mortality and cancer risk among workers exposed to man-made mineral fibres in Finland. Scand J Work Environ Health 12, suppl 1:61-64.

Wagner JC, Berry GB, Hill RJ, Munday DE, Skidmore JW (1984): Animal experiments with MMM(V)F

Effects of inhalation and intrapleural noculation in rats. In Guthe $T$ (ed): "Biological effects of man-made mineral fibres: Proceedings of a WHO/LARC conference in association with JEMRB and TIMA, Copenhagen 20-22 April 1982". Vol. 2. World Health Organisation, Regional Office for Europe, Copenhagen, pp 209-234. 
Westerholm P, Bolander AM (1986): Mortality and cancer incidence in the man-made mineral fibre industry in Sweden. Scand J Work Environ Health 12, suppl 1: 78-84.

World Health Organisation (1983): Biological effects of man-made mineral fibres. Euro reports and studies 81. Regional Office for Europe, Copenhagen.

Wright GW, Kuschner M (1977): The influence of varying lengths of glass and asbestos fibre on tissue response in Guinea pigs. In Walton WH (ed): "Inhaled particles IV". Oxford: Pergamon Press, pp 455-477. 


\section{Final discussion}

In the preceeding 10 chapters the use of human study results in risk assessment concerning chemicals in the occupational environment is addressed. The identification of occupational hazards is important in this process, followed by dose-effect calculations on which exposure standards can be based. If chemicals are used at the workplace, it is necessary to know whether they can have acute or chronic toxic effects and at what exposure levels, in order to decide if preventive and protective measures are required. Experimental studies with cell cultures and laboratory animals can provide useful information in this respect. However, the estimation of the potency of substances in humans should preferentially be based on human data.

In occupational epidemiology a variety of methods has been developed which creates the opportunity to study adverse health effects of chemicals in exposed workers. In this thesis the possibilities and application of occupational epidemiology in risk assessment concerning potential carcinogenic inorganic dust and fibres are evaluated. First of all it is analyzed what the specific contribution of epidemiological outcomes in the cancer risk assessment is. The International Agency of Research on Cancer (IARC) uses epidemiological data and animal results for the classification of the carcinogenicity of substances. An analysis of 597 agents in the latest overall evaluation of carcinogenicity by IARC shows, that epidemiological studies only play a minor part in the cancer risk evaluation. For the majority of animal carcinogens no human data are available. This is partly due to the fact that it is difficult, time consuming and expensive to conduct human exposure studies concerning possible carcinogens. For the substances with animal and human data the correlation between these outcomes is poor. Differences in study design characteristics between experimental and empirical studies certainly affect the inconsistencies. This makes it difficult to extrapolate animal outcomes directly to humans and emphasizes the need for more well conducted epidemiological studies in the process of cancer risk assessment. High quality exposure data and detailed information about the duration of exposure are absolutely necessary in this respect, in order to base quantitative dose-response computations on epidemiological outcomes. 
A frequently applied study design which is well suited for epidemiological studies concerning the long-term effects of chemical hazards in the occapational environment is the retrospective cohort design. In several studies reported in this thesis the retrospective cohort design was used. A meta-analysis of a number of retrospective cohort studies leads to the conclusion that it is not only the cumulative exposure to specific agents that determines the chronic effects.

Other factors such as the country in which the study is carried out or the background of the investigator, for instance industrial or governmental, and methodological variables as the latency period and the percentage lost to follow-up also influence the study outcomes. Besides, occupational cohort studies suffer from a healthy worker effect (HWE), which is defined as the manifestation of a deficit in mortality when an employed population is compared with a general population. The evaluation of a cross-sectional analysis of 270 occupational cohort studies shows that most of them suffer from a considerable healthy worker effect, which seriously distorts the outcomes.

The healthy worker effect seems not to be a static quantity, but is influenced by many design characteristics, for example the study size, follow-up period and the type of exposure. The results underline that because of the empirical character of occupational epidemiological studies their outcomes are influenced by many more variables than exclusively the type and level of exposure. This makes the interpretation of epidemiological results a difficult task in the process of occupational risk assessment.

In the second part of the thesis the long-term health effects of occupational exposure to inorganic dust and fibres in the Netherlands are studied. Several epidemiological techniques are used. Studies are reported using descriptive methods, cross-sectional designs, a proportionate morbidity and a retrospective cohort approach, case-control and meta-analyses. The knowledge about exposure characteristics and health effect parameters (morbidity, mortality) was gathered using routine information available at institutions such as pathology departments, pension funds, personnel and salary administration departments, occupational health services, the Labour Inspectorate, cancer registries and the Central Bureau of Statistics. The outcomes of the individual studies show that many institutions collect and retain information suited for the conduct of occupational epidemiological studies directed towards practical problems in occupational health.

One study is dedicated to the analyses of trends and distribution of asbestosrelated pleural mesothelioma mortality in the Netherlands. Although a growing public awareness exists concerning the health risks due to asbestos exposure in the Netherlands, very little information about the exact extent of the problem is 
is available at the moment. This information is necessary in order to evaluate the effectiveness of preventive measures in the future. The interpretation of trends and distribution of asbestos- related pleural mesothelioma mortality in the Netherlands show that occupational exposure to asbestos imposes a serious health problem to the Dutch society. The mesothelioma mortality in men almost doubled during the last twenty years, with a strong concentration in the mid western regions near the rivermouths and along the north sea coast were many harbours and heavy industry are located. Compared to other countries without asbestos mining and milling the prevalence of pleural mesotheliomas in the Netherlands is rather high and is not expected to decline in the next decade. Preventive regulations introduced in the 1970 s will only lead to a significant decrease in mortality from pleural mesothelioma after 20 or more years.

Man-made vitreous fibres have been succesfully introduced as asbestos substitutes and insulation materials. They are now used in a broad range of products and applications. It is extremely important to know whether they can impose a health risk upon man. Although man-made vitreous fibres (MMVF) have a fibrous and mineral nature just like asbestos fibres, there are many differences between these fibre types. Man made vitreous fibres have an amorphous character, usually a greater diameter than asbestos fibres and they easily dissolve in fysiological fluids. Asbestos related diseases such as pleural plaques and mesotheliomas have not been observed in workers historically exposed to MMVF. No unambiguous relation could be demonstrated between exposure to MMVF and fibrosis or lung cancer. A review of the scientific data concerning MMVF provides little or no evidence for health risks comparable to the asbestos issue. Provided that the airborne concentrations of MMVF are low, adverse effects on the repiratory system of workers are not to be expected.

Traditionally workers in the Dutch fine ceramic industry were exposed to substantial amounts of crystalline silica in the respirable dust, which initially led to a high prevalence of silicosis. Technical innovations and occupational hygiene measures taken in the 1960 s resulted in a decrease in airborne quartz concentrations. Analyses of the silicosis prevalence in a cross-sectional study of 2,495 ceramic workers in the Netherlands during the 1970s lead to the conclusion that silicosis still commonly occurs in smaller fine ceramic workshops, whereas it is much less prevalent in the large mechanized companies. The silicosis manifestation is restricted to simple pneumoconiotic lesions and seems to be more prevalent in heavy smokers.

The International Agency for Research on Cancer (IARC) defined crystalline silica as an agent which is probably carcinogenic in humans. In a case-control study the possible relation between silica exposure and lung cancer in the Dutch fine ceramic industry was investigated. No overall increased risk of lung cancer 
emerged in workers occupationally exposed to respirable silica dust in the Netherlands. No consistent cause-effect relation or correlation between a specific histologic tumor cell type and silica exposure could be demonstrated. Nevertheless, an increased lung cancer risk for the high exposure group in the past could not be totally excluded. Interpreting these results it is not possible to demonstrate nor to vitiate that crystalline silica is carcinogenic. A modulating rolle of lung fibrosis in this process is even less clear.

Coal mine dust is a complex mixture of coal with various potentially carcinogenic compounds. In order to investigate the cancer risk for former Dutch miners exposed to coal mine dust a case-control investigation, a retrospective cohort study and a proportionate morbidity study are reported in this thesis. A significant increased lung cancer risk has not emerged in Dutch coal miners with and without coal workers pneumoconiosis. Many studies in the United Kingdom and the United States reported an elevated gastric cancer risk for coal miners. The mortality study among Dutch miners shows the same results. A fourfold, statistically significant, excess of stomach cancer emerges, which seems to be related to the coal mine dust exposure.

The outcomes of a cancer morbidity study, based on linkage with the regional cancer registry, did not support the relation between underground coal mining and an increased stomach cancer risk. Nevertheless, it must be kept in mind that the regional cancer registry is only recently established and it is possible that an increased stomach cancer incidence in coal miners had already disappeared at the moment of linkage with the cancer registry.

In conclusion, the overall impression remains that epidemiological studies provide valuable information in the process of occupational risk assessment of inorganic dust and fibres. Nevertheless, especially retrospective cohort- and case-control studies suffer from the fact that historical exposure data are difficult to obtain, usually rather qualitative and not very accurate. Combined with the above mentioned methodological issues originating from the empirical background of occupational epidemiological studies, it is sometimes difficult to draw unambiguous conclusions from the results. Specially when occupational exposures have been generally low and the outcomes are not or only borderline significant. The studies reported in this thesis could not absolutely demonstrate nor deny the carcinogenicity of crystalline silica and coal mine dust for exposed workers in the Netherlands. New, well conducted prospective studies in exposed workers in other countries, with high quality cumulative exposure data, are certainly welcomed in this respect. 


\section{Summary}

One of the goals of occupational medicine is to detect health hazards in the occupational environment. Risk prevention can only be undertaken effectively if these health hazards are sufficiently known. Researchers use different methods to study the harmful effects of chemical substances: Toxicological tests in cell systems and tissue cultures (in vitro-tests) can provide evidence of the possible risks of substances. Experimental studies in laboratory animals are also frequently used for this purpose. However, the ultimate evidence of the detrimental effect of substances for humans can only be given by studies in exposed humans themselves. Because of medical ethical reasons it is not feasible to establish experimental studies in humans if a substance is thought to have a carcinogenic potential. The proof of the carcinogenicity of substances for humans must come from studies in which workers are more than incidentally exposed. In occupational epidemiology a number of research techniques can be applied, which make the empirical study of effects in exposed workers possible. In this thesis several of these methods are discussed and applied in studies concerning the harmful effects of inorganic dust and fibres.

Historically, the region of South-Limburg in the Netherlands is an interesting area to conduct these studies: The exposure to dust in the Maastricht fine ceramic factories and the regional coal mines was a daily occupational risk for many workers in the first half of this century. A lot of information about their working-careers is still available. In combination with existing medical files this creates an excellent opportunity to establish occupational epidemiological investigations.

The first three chapters are dedicated to the contribution of occupational epidemiology to the overall evaluation of carcinogenic properties of substances and the way in which the epidemiological methods can influence the results.

In chapter 1 it is analyzed for 597 substances, which have been international evaluated, whether a good correlation exists between animal experimental and human study results. It becomes clear that the results of studies in animals and humans differ widely from each other. Human data only appear to contribute on 
a small scale to the overall evaluation of carcinogenicity. Most epidemiological studies are not suited for quantitative dose-effect calculations. These conclusions stress the need for more epidemiological data to be used in the evaluation of carcinogenicity of substances.

The chapters 2 and 3 discuss the retrospective cohort method, which is frequently applied in occupational epidemiology and is used in a number of studies in this thesis. In retrospective cohort studies groups of persons which have experienced a specific exposure in the past are followed-up and their patterns of disease and mortality are compared with a reference population. From the interpretation of the results of many retrospective cohort studies emerges that these are influenced by variations in the applied study design, irrespective of differences in exposure and nature of the harmful substances. It is furthermore evident that most of the studies suffer from the "healthy worker effect", which means that the relative mortality in the exposed population of workers is lower than in the reference group. Various selection procedures underlie this phenomenon. The influence of the design characteristics on the study outcomes hampers the interpretation of retrospective cohort studies seriously.

In the second part of the thesis - chapters 4 to 10 - various epidemiological techniques are used in studies concerning occupational exposure to dust and fibres and resulting diseases. Applied are the case-control study (chapter 4 and 6 ), the retrospective cohort study (chapter 5), the proportionate morbidity study (chapter 7), the descriptive, cross-sectional study (chapter 8 and 9) and the meta-analysis (chapter 10).

Chapters 4,5 and 7 study morbidity and mortality patterns among miners in the Dutch coal mines with and without anthracosilicosis. It is well known that coal mine dust causes lung fibrosis. Nevertheless, there is much speculation about the possible carcinogenic properties of mine dust and the role of fibrosis in this respect. An increased lung cancer risk among Dutch coal miners with and without anthracosilicosis is not demonstrated in two separate studies (chapter 4 and 5). However, from a retrospective cohort study among a small group Dutch miners with anthracosilicosis a significantly increased mortality rate from cancer of the stomach and small intestine emerges (chapter 5). This finding is not confirmed in a proportionate morbidity study in which the records of 3,798 Dutch miners have been linked to the regional cancer registry over a relative short period of five years. At the moment a possible relation between exposure to coal mine dust and the occurrence of gastric cancer cannot be excluded. A more extensive follow-up of the group Dutch miners is necessary in order to get a definite answer to this question. 
Many international studies draw attention to the fact that crystalline silica is capable of inducing lung cancer in exposed workers. In this thesis a case-control study is included, which investigates the lung cancer risk in workers exposed to quartz in the Maastricht fine ceramic factories (chapter 6). The study does not demonstrate a consisient cause-effect relation between quartz exposure and lung cancer. Nonetheless an increased risk for the high exposure group in the past cannot be totally excluded.

In chapter 9 trends and geographical patterns in the occurrence of pleural mesotheliomas, malignant diseases of the pleura, in the Netherlands are described. About $80 \%$ of all mesotheliomas are related to exposure to crocidolite. The mesothelioma mortality in Dutch males has significantly increased during the last 20 years. Compared with this the mortality among women remains low. Mesotheliomas occur especially in the older age groups, probably because of occupational exposure to crocidolite early in the work history. The mortality is concentrated in conurbations with many harbours, shipyards and heavy industry near the Dutch rivermouths and along the North Sea-coast.

The last chapter (chapter 10) contains a meta-analysis of studies about the long-term effects of man-made vitreous fibres (MMVF), which are increasingly used as asbestos replacement products. Based on animal experimental data and historical observational reports, an adverse effect of MMVF on the respiratory tract after chronical and substantial occupational exposure cannot be entirely excluded. In present occupational setting, in which generally low concentrations of fibres occur, an increased risk of lung diseases among workers seems unlikely.

The substantial industrial, occupational hygienic and social changes which have taken place in the Netherlands and certainly in Limburg during the last decades, resulted in the fact that the health effects of dust exposure are no longer a major problem in occupational medicine. In many industrialized and developing countries, however, the mining and exploration of minerals is still a major industrial activity and the health effects of dust exposure create an important medical problem. It is the aim of this thesis to contribute to the knowledge of the relation between exposure to inorganic dust and fibres and malignant disease. Furthermore, the reported studies show that it is very well possible in the Dutch situation to conduct relevant investigations concerning occupational exposures and resulting diseases, using relativelly simple available personnel files and medical records. This type of epidemiological research can be used in the interpretation of potential dangers at the worksite and provides the opportunity to develop and analyze preventive activities. 


\section{SAMENVATting}

Eên van de hoofddoelstellingen van de arbeidsgeneeskunde is het opsporen van gezondheidsschadelijke faktoren in het arbeidsmilieu. Preventieve maatregelen kunnen slechts ontwikkeld worden als deze faktoren voldoende bekend zijn.

Voor de studie naar de schadelijke effekten van chemische agentia staan de onderzoeker diverse methoden ter beschikking: Toxicologische tests in cel-en weefselkultures (in vitro-tests) kunnen ons attent maken op de mogelijke gevaren van een stof. Experimentele studies in proefdiermodellen worden voor dit doel ook gebruikt. Men gaat er echter van uit dat het uiteindelijke bewijs van de schadelijkheid van een stof voor de mens geleverd wordt door deze effekten aan te tonen in de mens zélf. Indien het onderzoek zich richt op vermeende kankerverwekkende stoffen is het vanzelfsprekend medisch-ethisch niet mogelijk experimenten met mensen uit te voeren. Het harde bewijs van de schadelijkheid voor de mens moet in dat geval komen van studies onder mensen die onafhankelijk van het onderzoek blootgesteld zijn aan die stoffen. In de arbeidssituatie komt het vaak voor dat mensen blootgesteld zijn aan allerlei stoffen. In de zogenaamde arbeidsepidemiologie zijn een aantal onderzoekstechnieken verenigd, die empirische studies naar de effekten in blootgestelde arbeiders mogelijk maken. In dit proefschrift worden enkele van deze methoden geanalyseerd en toegepast in onderzoek naar de schadelijke effekten van anorganisch stof en vezels.

Historisch gezien vormt de Zuid-Limburgse regio een interessant gebied voor dit type studie: In de Maastrichtse fijnkeramische industrie en het regionale mijnbouw-bekken betekende blootstelling aan stof in de eerste helft van deze eeuw een dagelijks terugkerende arbeidsbelasting. Veel informatie over de loopbaanontwikkeling van de werknemers is bewaard gebleven; hetgeen gekoppeld aan de beschikbare medische dossiers en archieven een interessante voedingsbodem biedt voor arbeidsepidemiologisch onderzoek.

De eerste drie hoofdstukken van dit proefschrift gaan in op de bijdrage van epidemiologische studies in de arbeidssituatie aan het beoordelen van kankerverwekkende eigenschappen van stoffen en op de wijze waarop de methode van 
empirisch onderzoek de resultaten kan beïnvloeden. In hoofdstuk 1 wordt voor 597 stoffen, die internationaal getoetst zijn op kankerverwekkende eigenschappen, nagegaan in welke mate overeenstemming bestaat tussen dierexperimentele en humane resultaten. Het blijkt dat de uitkomsten van studies in dier en mens aanzienlijk van elkaar verschillen. Daarnaast leveren humane studies momenteel slechts een bescheiden bijdrage aan de evaluatie van de kankerverwekkendheid van stoffen. Ook voor kwantitatieve dosis-effekt schattingen zijn de meeste humane studies nog niet geëigend. Deze konklusies accentueren de noodzaak meer gebruik te maken van epidemiologische gegevens in de evaluatie van kankerverwekkende eigenschappen van stoffen.

De hoofdstukken 2 en 3 behandelen de zogenaamde retrospektieve kohortmethode, die tot de meest toegepaste arbeidsepidemiologische technieken behoort en in een aantal praktijkstudies in dit proefschrift gebruikt is. In retrospektieve kohortstudies worden groepen mensen die in het verleden een specifieke blootstelling hadden opgevolgd en worden hun ziekte- en sterftepatronen onderzocht in vergelijking met een referentiegroep. Uit de interpretatie van de uitkomsten van een groot aantal retrospektieve kohortstudies blijkt dat deze sterk beinvloed worden door variaties in de studie-opzet en niet slechts door verschillen in de blootstelling aan en aard van schadelijke stoffen. Daarnaast blijken de meeste studies last te hebben van het zogenaamde "healthy worker effect". Hetgeen betekent dat de relatieve sterfte in de blootgestelde arbeidspopulatie lager is dan in de referentiegroep. Diverse selektiemechanismen liggen hieraan ten grondslag. Eén en ander bemoeilijkt de interpretatie van retrospektieve kohortstudies uiteraard aanzienlijk.

In het tweede deel van het proefschrift - de hoofdstukken 4 tot en met 10 worden verscheidene epidemiologische technieken gebruikt in praktijkstudies naar de arbeidsblootstelling aan stof en vezels en ziekten die daarvan het gevolg zijn. Toegepast worden de patiënt-kontrole studie (hoofdstuk 4 en 6), de retrospektieve kohortstudie (hoofdstuk 5), de geproportioneerde incidentie studie (hoofdstuk 7), de transversale studie (hoofdstuk 8 en 9) en de meta-analyse (hoofdstuk 10).

De hoofdstukken 4,5 en 7 bestuderen ziekte- en sterftepatronen bij mijnwerkers in de Nederlandse kolenmijnen met en zonder anthracosilicose. Het is genoegzaam bekend dat kolenmijnstof longfibrose kan veroorzaken. Er bestaat evenwel veel diskussie omtrent de mogelijke kankerverwekkende eigenschappen van mijnstof en de rol van de fibrose in dit geheel. Een verhoogd risiko op longkanker onder Nederlandse mijnwerkers met en zonder longfibrose kan in twee afzonderlijke studies niet worden aangetoond (hoofdstuk 4 en 5). Echter uit een retrospektieve kohortstudie onder een kleine groep Nederlandse mijn- 
werkers met anthracosilicose blijkt een belangrijk toegenomen sterfterisiko als gevolg van kanker van maag en darm (hoofdstuk 5). Dit wordt niet bevestigd in een geproportioneerde incidentie studie waarin de gegevens van $3.798 \mathrm{Neder}$ landse mijnwerkers over een relatief korte periode van vijf jaar gekoppeld werden aan de regionale kankerregistratie (hoofdstuk 7). Vooralsnog kan een positief verband tussen kolenmijnstofblootstelling en het optreden van maagkanker niet uitgesloten worden geacht. Een volledige follow-up van de groep Nederlandse mijnwerkers is noodzakelijk om in dit vraagstuk meer helderheid te verschaffen.

Talrijke internationale studies wijzen erop dat kristallijn silica longkanker kan veroorzaken onder blootgestelde werknemers. In het onderhavige proefschrift wordt volgens een patiënt-kontrole methode onderzocht of aan kwartszand blootgestelde arbeiders in de Maastrichtse fijnkeramische industrie een verhoogd longkankerrisiko hebben (hoofdstuk 6). De studie toont geen konsistent oorzaak-effekt verband tussen de kwartsblootstelling en longkanker aan. Echter voor de groep werknemers die in het verleden de hoogste blootstelling hadden kan een toegenomen risiko niet geheel uitgesloten worden.

In hoofdstuk 9 worden de trends en geografische patronen in het voorkomen van pleuramesotheliomen, kwaadaardige aandoeningen van het borstvlies, in Nederland geschetst. Ongeveer $80 \%$ van deze mesotheliomen worden veroorzaakt door de blootstelling aan crocidoliet (blauw asbest). De sterfte als gevolg van deze tumoren onder Nederlandse mannen is aanzienlijk gestegen gedurende de laatste 20 jaar. De sterfte onder vrouwen is in vergelijking hiermee laag. Mesotheliomen komen vooral in de oudere leeftijdsgroepen voor, waarschijnlijk als gevolg van een beroepsblootstelling vroeg in het arbeidsleven. De mesotheliomensterfte onder mannen koncentreert zich vooral in gebieden waar in het verleden veel blauw asbest toegepast is: De zware industrie regio's, rond de grote riviermondingen en de havengebieden langs de Noordzee-kust.

Het laatste hoofdstuk (hoofdstuk 10) betreft een meta-analyse van onderzoeken naar de chronische effekten van zogenaamde man-made vitreous fibres (MMVF), die als asbestvervangprodukten in toenemende mate worden gebruikt. Op basis van experimentele gegevens en historische epidemiologische studies onder produktiewerkers kan een negatief effekt van MMVF op longen en luchtwegen bij chronische en aanzienlijke blootstelling niet geheel uitgesloten worden geacht. In de moderne produktieprocessen waarbij overwegend lage omgevingskoncentraties aan MMVF optreden, lijkt een verhoogde kans op longziekten voor de werknemers onwaarschijnlijk.

De grootscheepse industriële, arbeidshygiënische en maatschappelijke veranderingen die zich de afgelopen decennia in Nederland en zeker in Limburg voltrokken hebben, leidden er toe dat de gevolgen van de blootstelling aan stof 
niet meer tot de belangrijkste arbeidsgeneeskundige problemen in Nederland gerekend worden. In veel geindustrialiseerde en zich ontwikkelende landen daarentegen betekent het winnen en bewerken van vaste delfstoffen een belangrijke bron van inkomsten en vormen de gevolgen van de stofblootstelling een ernstig medisch probleem. De resultaten uit dit proefschrift pogen een bescheiden bijdrage te leveren aan de inzichten in de relatie tussen blootstelling aan anorganisch stof en vezels en kwaadaardige aandoeningen. Daarnaast bewijzen de studies dat het ook in de Nederlandse situatie goed mogelijk is om met relatief eenvoudige middelen en aan de hand van routinematig verzamelde gegevens gericht onderzoek te doen naar het verband tussen arbeidsblootstelling enerzijds en ziekten en sterfte anderzijds. Dit type onderzoeken kan verdergaand inzicht verschaffen in de potentiële gevaren op de werkvloer en biedt de mogelijkheid preventieve aktiviteiten te ontwikkelen en het effekt ervan te evalueren. 
Een proefschrift gebaseerd op empirische gegevens is tegenwoordig ondenkbaar zonder de inzet en ondersteuning van een groot aantal mensen. Op het risiko af sommigen te vergeten, is een dankwoord aan de volgende personen zeker op zijn plaats.

De beide promotores, Prof. Dr. Sturmans en Prof. Dr. De Boorder, die mij de afgelopen jaren vertrouwen geschonken hebben en op voortvarende wijze de afronding van het proefschrift begeleid hebben.

Co-promotor Dr. Gerard Swaen en kollega Dr. Kees van Vliet, waarmee ik altijd zeer plezierig heb samengewerkt.

Marliese van Wissen en Jos Slangen, die onmisbare steunpilaren vormden en zonder wie dit proefschrift zeker niet zo voorspoedig tot stand gekomen zou zijn.

De student-assistenten die bij de gegevensverzameling en -verwerking de afgelopen jaren behulpzaam zijn geweest: Carin Cuypers, Ellen van Noort, Marianne Doornbos, Jolanda van Golde en Gerrit Schreiber.

Lex Volovics voor de statistische ondersteuning.

De vele medewerkers van de Maastrichtse fijnkeramische bedrijven Mosa en Sphinx, AZL-Heerlen, de Vakgroep Pathologie van de Rijksuniversiteit Limburg, het Centraal Bureau voor de Statistiek, DSM, IKL-Limburg, die de gegevens waarop het proefschrift gebaseerd is bereidwillig ter beschikking hebben gesteld.

Alle anderen die op enigerlei wijze bij het geheel betrokken zijn geweest ben ik erkentelijk.

En natuurlijk de vele familieleden en vrienden die ik bij tijd en wijle met mijn wetenschappelijke misère's heb lastig gevallen. 


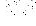




\section{URRICULUM VITAE}

Jan Meijers werd geboren op 26 juni 1957 te Stein. In 1975 behaalde hij het Gymnasium- $\beta$ diploma aan het Sint Michiel Lyceum te Geleen.

Tussen 1975 en 1980 studeerde hij Westerse Sociologie aan de Landbouwhogeschool te Wageningen. Deze studie sloot hij in 1982 af met het Ingenieursdiploma.

In 1980 begon hij met de studie Geneeskunde aan de Rijksuniversiteit Limburg, die na het doctoraaldiploma (1985) in 1986 resulteerde in het verkrijgen van het artsexamen.

Tussen 1983 en 1985 was hij als part-time docent verbonden aan de Katholieke Leergangen te Tilburg/Sittard.

In 1986 trad hij als Universitair Docent in dienst van de Rijksuniversiteit Limburg bij de Vakgroep Arbeidsgeneeskunde, later Arbeidsgeneeskunde, Milieugezondheidkunde en Toxicologie. Een onderdeel van zijn werkzaamheden vormde het wetenschappelijk onderzoek, waarop dit proefschrift gebaseerd is. Tevens was hij betrokken bij beleidsondersteunend onderzoek binnen de bedrijfsgezondheidszorg en milieugezondheidkundige studies. Daarnaast gaf hij ondermeer vorm aan het onderwijs in de Sociale Geneeskunde aan de Fakulteit der Geneeskunde en de Fakulteit der Gezondheidswetenschappen. Na zijn registratie als Sociaal Geneeskundige, tak Arbeids- en Bedrijfsgeneeskunde in 1990 werd hij benoemd tot Distriktshoofd bij de Rijksbedrijfsgezondheids- en Bedrijfsveiligheidsdienst in het distrikt Heerlen. 



\section{Publikaties}

\section{FULL PAPERS}

Meijers J, Pedroli O, Putten van M (1979): Het dagboek als registratie-instrument in gezondheidsonderzoek. Een methodologische studie. Verslag Gezondheidsleer. Wageningen: Landbouwhogeschool: 72.

Knibbe RA, Meijers JM (1983): Enkele aspecten van hulpverlening aan probleemdrinkers. T Alc Drugs 9: 68-74.

Swaen GMH, Meijers JMM (1987): Lung cancer risk among workers with silicosis: Potential confounding by smoking habits. Am Ind Med 12: 223-225.

Knibbe RA, Meijers JM (1988): Comparison of problem drinkers known to agencies with problem drinkers in the general population. Med Law 7: 87-94.

Meijers JMM. Swaen GMH (1988): Passief roken en longkanker. Ned Tijdschr Geneeskd 132: 60-64.

Offermans XJMW, Meijers JMM, Nijhuis FJN, Rijssen-Moll van M, Boorder de Tj (1988): Bedrijfsgezondheidszorg voor het vervoerswezen in Nederland. Gezondheidsrisico's, structuur en inhoud. Directoraat Generaal van de Arbeid, Ministerie van Sociale Zaken en Werkgelegenheid: $\mathbf{S} 38$.

Rijssen-Moll van M, Nijhuis FJN, Meijers JMM, Bome van de P, Boorder de Tj (1988): Bedrijfsgezondheidszorg voor de intramurale gezondheidszorg in Nederland. Gezondheidsrisico's, structuur en inhoud. Directoraat Generaal van de Arbeid, Ministerie van Sociale Zaken en Werkgelegenheid: S 39.

Meijers JMM, Nijhuis FJN, Rijsen-Moll van M, Bome van de P, Boorder de Tj (1988): Bedrijfsgezondheidszorg voor de bouwnijverheid in Nederland. Gezondheidsrisico"s, structuur en inhoud. Directoraat Generaal van de Arbeid, Ministerie van Sociale Zaken en Werkgelegenheid: S 40 .

Swaen GMH, Meijers JMM (1988): Influence of design characteristics on the outcome of retrospective cohort studies. Br J Ind Med 45: 624-629.

Meijers JMM, Swaen GMH, Slangen JJM, Vliet van C (1988): Lung cancer among Dutch coal miners: A case-control study. Am J Ind Med 14: 597-604.

Meijers JMM, Cuypers C, Vliet van C. Swaen GMH (1988): Respiratoire aandoeningen bij langdurige blootstelling aan Man-Made Vitreous Fibres (MMVF). T Soc Gezondheidsz 66: 284-290.

Rijssen-Moll van M, Nijhuis F, Meijers J (1988): Gezondheidsrisico's in het Vervoerswezen, de Intramurale Gezondheidszorg en de Bouwnijverheid. Arbovisie 4: 4-7. 
Cuypers CEJ, Mertens PLJM, Mejers JMM (1988): Een onderzoek naar luch wegklachten in Melick, Herkenbosch, Asenray en Echt. Publikatie BAGD/Midden-Limburg, Rijksuniversiteit Limburg, Roermond.

Vliet van C, Swaen GMH, Meijers JMM, Slangen J, Boorder de Tj, Sturmans F (1989): Prenarcotic and neurasthenic symptoms among Dutch workers exposed to organic solvents. Br J Ind Med 46: 586-590.

Swaen GMH, Meijers JMM (1989): Risk assessment of leukaemia and occupational exposure to benzene. Br J Ind Med 46:826-830.

Meijers JMM, Kant 1J (1989); Arbeidsomstandigheden in het Car Hospital van de Lakstraat Volvo Car BV. Bedrijfsgeneeskundig survey. Vakgroep Arbeidsgeneeskunde, Milieugezondheidkunde en Toxicologie, Rijksuniversiteit Limburg, Maastricht.

Borm PJA, Meijers JMM (1989): Risiko's van stof: Oude koeien uit de sloot. Arbovisie 5: 6-7. Vliet van C, Swaen GMH, Volowics A, Slangen JIM, Meijers JMM, Boorder de Tj, Sturmans F (1989): Exposure-outcome relationship between organic solvent exposure and neuropsychiatric disorders: Results from a Dutch case-control study. Am J Ind Med 16: 707-718.

Meijers JMM, Swaen GMH, Volovics A, Lucas LJ, Vliet van C (1989): Occupational cohort studies: The influence of design characteristics on the Healthy Worker Effect. Int J Epidemiol 18: $970-975$.

Meijers JMM, Swaen GMH, Vliet van C (1990): Lung cancer among Dutch fine ceramic workers and coal miners. A case-control study. INSERM symposia, Paris.

Meijers JMM, Swaen GMH, Vliet van C (1990): Epidemiological studies of inorganic dust-related diseases in The Netherlands. Exp Lung Res 16: 15-23.

Borm PJA, Meijers JMM, Swaen GMH (1990): Molecular epidemiology of Coal Workers" Pneumoconiosis: Application to risk assessment of oxidant and monokine generation by mineral dusts. Exp Lung Res 16: 57-71.

Vliet van $C_{*}$ Swaen $\mathrm{GMH}$, Volovics $\mathrm{A}$, Tweehuysen $\mathrm{M}$, Meijers $J \mathrm{MM}$, Boorder de Tj, Sturmans $\mathbb{F}$ (1990): Neuropsychiatric disorders among solvent-exposed workers. First results from a Dutch case-control study. Int Arch Occup Environ Health 62: 127-132.

Meijers JMM, Swaen GMH, Volovics A, Slangen JJM, Vliet van C (1990): Sillica exposure and lung cancer in ceramic workers: A case-control study. Int J Epidemiol 19: 19-25.

Schreiber GH, Meijers JMM, Vhiet van C, Swaen GMH (1990): Biologische effekten van laagfrekwente elektromagnetische golfvelden. T Soc Gezondheidsz 68: 21 5-224.

Vliet van C, Swaen GMH, Volovics A, Slangen JJM, Meijers JMM, Boorder de Tj, Sturmans F (1990): Neuropsychiatric disorders among painters. In Sakurai $\mathrm{H}$, Okazaki I, Omae $\mathbb{K}$ (eds): "Occupational Epidemiology", Excerpta Medica Int Congress Series 889, Elseviers Science Publishers, pp 213-216.

Meijers JMM (1990): Comparing biological effects of mineral fibres. Letter to the editor. Br J Ind Med 47: 286-287.

Swaen G, Meijers J, Vliet van C (1990): Het belang van de epidemiologie voor het schatten van gezondheidsrisiko's. Giftig 3: 18-21.

Meijers JMM, Planteydt HT, Slangen JJM, Swaen GMH, Vliet van C, Swrmans F (1990): Trends and geographical patterns of pleural mesotheliomas in The Netherlands, 1970-1987. Br J Ind Med 47: 775-781.

Swaen GMH, Meijers JMM, Vliet van C, Sturnans F (1990): De haalbaarheid van retrospektief kohortonderzoek in de arbeidssituatie in Nederland. T Soc Gezondheidsz 68: 457-465. 
Meijers JMM, Swaen GMH, Slangen JM, Vliet van C, Sturmans F (1991): Long-term mortality in miners with Coal Workers' Pneumoconiosis in The Netherlands. A pilot study. Am J Ind Med 19: 43-50.

Meijers JMM, Planteydt HT, Vliet van C, Sturmans $\mathbb{E}$ (1991): Trends en spreiding van sterfte aan pleura mesotheliomen in Nederland 1970-1987. Ned Tijdschr Geneeskd 135: 93-98.

\section{ABSTRACTS}

Meijers JMM, Swaen GMH (1988): Lung cancer among Dutch coal miners: A case-referent study. 7th International Congress on Pneumoconiosis, Pittsburgh, USA.

Engelen JJM, Meijers JMM, Borm PJA (1988): Blood anti-oxidant parameters in Coal Workers' Pneumoconiosis. 7th International Congress on Pneumoconiosis, Pittsburgh, USA.

Meijers JMM, Swaen GMH (1989): Lung cancer among Dutch fine ceramic workers and coal miners. 2-eme Conference GERP sur les Pneumopathies Professionnelles, Paris, France.

Meijers JMM, Swaen GMH (1989): Epidemiological studies concerning silica and coal mine dust exposure and lung cancer. 30th Dutch Federa Meeting, Maastricht, The Netherlands.

Meijers JMM, Cuypers CEJ, Mertens PLJM, Swaen GMH (1989): Respiratory symptoms among primary schoolchildren living in areas with more and less air pollution in The Netherlands. First Annual Meeting of the International Society for Environmental Epidemiology, Long Island, New York, USA.

Schreiber GH, Meijers JMM, Swaen GMH (1989): Sterftepatronen van bewoners nabij hoogspanningslijnen. Symposium Milieu Epidemieën, Utrecht, The Netherlands.

Vliet van C, Swaen GMH, Volovics A, Slangen JJM, Meijers IMM, Boorder de Tj, Sturmans F (1989): Neuropsychiatric disorders among painters. 7th International Symposium Epidemiology in Occupational Medicine, Tokyo, Japan.

Swaen GMH, Schreiber G, Meijers JMM, Schouten L (1989): Electromagnetic fields (ELF) and incidence: A feasibility study. Annual Meeting International Association of Cancer Registries, Maastricht, The Netherlands.

Swaen GMH, Meijers JMM (1990): Influence of design characteristics on the outcome of retrospective cohort studies. 23rd Annual Meeting Society for Epidemiological Research, Utah, USA.

Swaen GMH, Meijers JMM, Schreiber GH (1990): The relewance of quality for risk assessment. Industrial Epidemiology Forum Conference, Salt Lake City, USA.

Meijers JMM, Swaen GMH (1990): Cancer mortality in miners with Coal Workers' Pneumoconiosis in The Netherlands. XIIth Scientific Meeting of the International Epidemiological Association, Los Angeles, USA.

Meijers JMM, Schreiber GH, Swaen GMH (1990): Mortality patterns in a Dutch district near electrical power lines. Second Annual Meeting of the International Society for Environmental Epidemiology, Berkeley, USA.

Meijers JMM, Planteydt HT, Swaen GMH (1990): Asbestos exposure and pleural mesotheliomas in The Netherlands. 23rd International Congress on Occupational Health of the International Commission on Occupational Health, Montreal, Canada. 